Old Dominion University

ODU Digital Commons

Theses and Dissertations in Biomedical Sciences

College of Sciences

Fall 1991

\title{
Transplantation of the Mammalian Pineal Gland: Studies of Survival, Revascularization, Reinnervation and Recovery of Function
}

Wutian $\mathrm{Wu}$

Old Dominion University

Follow this and additional works at: https://digitalcommons.odu.edu/biomedicalsciences_etds

Part of the Neurology Commons

\section{Recommended Citation}

Wu, Wutian. "Transplantation of the Mammalian Pineal Gland: Studies of Survival, Revascularization, Reinnervation and Recovery of Function" (1991). Doctor of Philosophy (PhD), dissertation, Biological Sciences, Old Dominion University, DOI: 10.25777/99qpsf73

https://digitalcommons.odu.edu/biomedicalsciences_etds/143

This Dissertation is brought to you for free and open access by the College of Sciences at ODU Digital Commons. It has been accepted for inclusion in Theses and Dissertations in Biomedical Sciences by an authorized administrator of ODU Digital Commons. For more information, please contact digitalcommons@odu.edu. 


\section{TRANBPLANTATION OF THE MLARLALIAN PINEAL GLAND:}

STUDIEB OF BURVIVAL, REVABCULARIZATION, REINAERVATION AND RECOVERY OP FUNCTION

by

WUTIAN WU

M.D., February 1976, Zhongshan Medical College, Guangzhou The People's Republic of China

M.S., February 1982, Zhongshan Medical College, Guangzhou The People's Republic of China

A Dissertation Submitted to the Faculties of the Eastern Virginia Medical School and old Dominion

University in Partial Fulfillment of the

Requirements for the Degree

of

DOC TOR OF PHILOSOPH Y

BIOMEDICAL SCIENCES

NEUROSCIENCE

EASTERN VIRGINIA MEDICAL SCHOOL

and

OLD DOMINION UNIVERSITY

DECEMBER， 1991

David E. Scott, Ph.D.

Eeorge E/foode, Ph.D.

Francis f. Liuzzi, Pr.\&.

Keith A. Carsón, Ph.D. 


\author{
AB8TRACT \\ TRANSPIANTATION OF THE MAMMALIAN PINEAL GLAND: \\ STUDIES OF SURVIVAL, REVASCULARIZATION, \\ REINNERVATION AND RECOVERY OF FUNCTION \\ Wutian Wu \\ Eastern Virginia Medical School \\ and \\ old Dominion University, 1991 \\ Director: David E. Scott, Ph.D.
}

The survival, revascularization, reinnervation, and recovery of function of transplanted newborn rat pineal glands were studied following grafting into four different locations in pinealectomized rats. These locations were the third cerebral ventricle, in situ (where the pineal gland is normally located), the renal capsule, and the anterior chamber of the eye.

Pinealocytes in the grafts maintained high metabolic activity as evidenced by the presence of euchromatic nuclei, prominent nucleoli, infolded nuclear envelopes, numerous mitochondria and Golgi apparati, and relatively abundant endoplasmic reticulum and ribosomes. In addition, morphological correlates of two putative secretory processes were observed in the grafts. The first type was neurosecretorylike (Golgi apparatus--dense-core vesicles) and the second was ependymal-like (rough endoplasmic reticulum--vacuoles containing flocculent material).

Pineal grafts were well vascularized by fenestrated capillaries surrounded by consistently wide perivascular spaces. Moreover, nerve fibers and terminals were seen in 
the grafts within the anterior chamber of the eye, the third cerebral ventricle, and the pineal region (in situ transplantation). By contrast, no fibers or terminals were found in grafts placed beneath the renal capsule. Reinnervating neurites in the grafts within the anterior eye chamber were found throughout the graft while those in the ventricular grafts and the in situ grafts were more abundant in some regions than in others.

Nighttime serum melatonin levels increased significantly in pinealectomized rats with transplants into either the third cerebral ventricle or the anterior eye chamber. This increase might reflect graft reinnervation. Yet day-night differences in serum melatonin were observed only in host rats receiving transplants to the anterior eye chamber. These differences were eliminated by bilateral removal of the superior cervical gangiion.

In conclusion, pinealocytes survived transplantation and exhibited ultrastructural features indicative of active secretory processes. Moreover, pineal grafts were well vascularized by fenestrated capillaries. Synthesis and release of melatonin is restored following transplantation into the third cerebral ventricle or the anterior chamber of the eye. However, day-night differences in serum melatonin is only restored following transplants into the anterior eye chamber. Finally, reinnervation of the grafts by the host superior cervical ganglion is necessary for this restoration. 
To the People I Love.

ii

Reproduced with permission of the copyright owner. Further reproduction prohibited without permission. 


\section{ACROHOWLDGEXENTS}

I am greatly indebted to my mentor, Dr. David E. Scott. Without his guidance and support, this dissertation would have been impossible. I am very grateful for his friendship and encouragement of these past years.

I would like to acknowledge the contribution of the other members of my coursework and Dissertation Guidance Committees: Dr. Keith Carson, Dr. George Goode, and Dr. Frank Liuzzi. They displayed a genuine interest in my progress and constant willingness to help with any problem that arose.

I would also like to acknowledge Dr. Russell J. Reiter, Department of Cellular and structural Biology, the UTHSC at San Antonio, for his valuable assistance in measuring serum melatonin concentration and for his many helpful suggestions for my dissertation research.

Finally, I would like to thank Ms. Eleanor Miller, Ms. Anna Shore, and Mr. James slusser for their excellent technical assistance. Particularly, I would like to thank Ms. Diane Carroll for her assistance in the preparation of this manuscript. 
LIST OF FIGURES $\quad$ PAGE

INTRODUCTION 1

A BRIEF OVERVIEW IN NEUROTRANSPLANTATION 1

REASON FOR THE USE OF THE PINEAL GLAND AS A MODEL FOR NEURAL TRANSPLANTATION 3

GENERAL RESEARCH TOPICS HAVE BEEN INVESTIGATED

IN THIS PROJECT 5

1) SURVIVAL AND FUNCTIONAL ACTIVITY OF
PINEAIOCYTES FOIIOWING TRANSPLANTATION

2) PATTERNS OF MEIATONIN SYNTHESIS AND
RELEASE IN THE PINEAL GRAFT

3) EFFECTS OF DIFFERENT IMPLANTATION SITES ON FUNCTIONAL RECOVERY OF THE PINEAL GLAND FOLLOWING TRANSPLANTATION

4) NEURAL REINNERVATION OF THE PINEAL GRAFT AND ITS SIGNIFICANCE IN THE RESTORATION OF THE PINEAL FUNCTION

METHODS

$\begin{array}{ll}\text { EXPERIMENTAL DESIGN } & 16\end{array}$

TRANSPLANTATION 21

COLLECTION OF BIOOD SAMPLES AND MEASURE OF
SERUM MELATONIN

STATISTICAL ANALYSIS $\quad 24$

TISSUE PROCESSING FOR ICC AND TEM 25

$\begin{array}{ll}\text { MICROFIL INFUSION } & 26\end{array}$

$\begin{array}{ll}\text { RESULTS } & 27\end{array}$

TRANSPLANTATION OF PINEAL GLAND INTO THE THIRD CEREBRAI VENTRICLE: STRUCTURAI CORREIATED AND FUNCTIONAL PARAMETERS

DAY-NIGHT DIFFERENCE OF SERUM MELATONIN CONCENTRATION IN PINEALECTOMIZED RATS WITH PINEAL GRAFTING INTO THE THIRD CEREBRAL VENTRICLE

FUNCTIONAL PARAMETERS AND STRUCTURAL CORRELATES OF PINEAL GRAFTS FOLLOWING TRANSPLANTATION INTO SELECTED SITES

EFFECTS OF REINNERVATION FROM THE SUPERIOR CERVICAL GANGLION ON THE FUNCTIONAL RECOVERY OF PINEAL GRAFTS FOLIOWING TRANSPLANTATION INTO THE ANTERIOR CHAMBER OF THE EYE 
VASCULARIZATION OF THE PINEAL GRAFTS

ULTRASTRUCTURAL CHARACTERISTICS OF PINEALOCYTES

EFFECTS OF PINEAL GRAFTING SITES ON FUNCTIONAL RECOVERY

SIGNIFICANCE OF REINNERVATION OF THE PINEAL

CONCLUSIONS

BIBLIOGRAPHY

113 
1. Light micrographs showing pineal grafts

in the third cerebral ventricle

2. Electron micrographs showing pinealocytes

3. Nighttime serum melatonin concentration in pinealectomized rats following pineal transplantation into the third cerebral ventricle

4. Light micrographs showing locations of the pineal grafts in the third cerebral ventricle

5. Electron micrograph showing migration of a

6. Light micrographs showing vascularization of the pineal grafts in the third cerebral ventricle

7. Electron micrographs showing fenestrated capillaries in the pineal grafts

8. Electron micrographs showing fenestrated capillaries in the pineal grafts

9. Electron micrographs showing dark and light appearing pinealocytes in the grafts localized in the third cerebral ventricle

10. Electron micrographs showing pinealocytes in the grafts

11. Electron micrographs showing the disposition of pinealocytes in the grafts

12. Electron micrographs showing the nuclei of the pinealocytes in the grafts

13. Electron micrographs showing nuclei of pinealocytes in the grafts

14. Electron micrographs showing organelles of pineal- 45 ocytes following transplantation into the third cerebral ventricle

15. Electron micrographs of pinealocytes in the grafts 47

16. Electron micrographs of pinealocytes in the grafts 48

17. Electron micrographs of pinealocytes in the grafts 49 
18. Electron micrographs showing the polar terminals of pinealocytes in the grafts

19. Electron micrographs of polar terminals of pinealocytes in the grafts

20. Electron micrographs of polar terminals of pinealocytes in the grafts

21. Electron micrographs showing special organelles, the synaptic ribbon, in the pinealocytes following transplantation into the third cerebral ventricle

22. Electron micrographs of myeloid bodies in the pinealocytes

23. Electron micrograph of inclusion body in the pinealocyte

24. Light micrographs showing the innervation of the pineal grafts following transplantation into the third cerebral ventricle

25. Electron micrographs showing the innervation of the pineal grafts

26. Electron micrographs showing the innervation of the pineal grafts

27. Electron micrographs of adrenergic nerve terminals in the pineal grafts

28. Nighttime serum melatonin concentration after transplantation of pineal gland into the third cerebral ventricle

29. Day-night difference of serum melatonin concentration after transplanatation of pineal gland into the third cerebral ventricle

30. Light micrographs showing the pineal grafts within the selected sites

31. Nighttime serum melatonin concentration after transplantation of pineal gland into the selected sites

32. Day-night difference of serum melatonin concentration after transplantation of pineal glands into the selected sites 
33. Electron micrographs showing ultrastructure of pinealocytes following transplantation into the anterior chamber of the eye

34. Electron micrographs of pineal graft in the anterior chamber of the eye

35. Electron micrographs showing pinealocytes in the grafts following transplantation beneath the renal capsule

36. Electron micrographs showing pinealocytes in the grafts following transplantation beneath the renal capsule

37. Light micrographs showing the innervation of the pineal tissues after being grafted into the selected sites

38. Electron micrographs showing the innervation of the pineal graft following transplantation into the anterior chamber of the eye

39. Electron micrographs that demonstrate the innervaton of pineal grafts following transplantation into the anterior chamber of the eye

40. Electron micrographs showing the innervation of pineal grafts into the anterior chamber of the eye

41. Electron micrographs showing myelinated and unmyelinated axons in the pineal grafts of the anterior chamber of the eye

42. Day-night serum melatonin concentration in pinealectomized and pinealectomized plus ganglionectomized animals following transplantation of the pineal gland into the anterior chamber of the eye

43. Electron micrographs showing the distinctive organelles, synaptic ribbons, in the pinealocytes following transplantation into the anterior chamber of the eye of the pinealectomized plus ganglionectomized host rats.

44. Electron micrographs showing the ultrastructures of the pineal grafts following transplantation into the anterior chamber of the eye in the pinealectomized and ganglionectomized rats. 


\section{INTRODUCTION}

A BRIEF OVERVIEW OF NEURAL TRANSPLANTATION

The first attempt to graft cNS tissue into the vertebrate brain was performed by Thompson near the turn of the century (Thompson, 1890). Since then attempts have been made to investigate neuronal survival and regeneration, host-graft interaction, and functional recovery following neuronal transplantation in a variety of species (Forssman, 1898; Delconte, 1907; Ranson, 1909; Tello, 1911; Dunn, 1917; Shirai, 1921; Faldino, 1924 ; LeGros Clark, 1940; Flerkó and Szentágothai, 1957).

However, the ability of a neural graft to alter neurological dysfunction was not shown until the $1970^{\prime}$ ' following the rapid development of powerful analytical tools and new methods for studying the nervous system. Several laboratories were able to demonstrate the survival, growth, and functional integration of neural grafts after transplantation (Bjorklund et al., 1971; Björklund and Stenevi, 1971; Das and Altman, 1971, 1972; Olson and Malmfors, 1970; Olson and Seiger, 1972). These and other studies (Björklund and Stenevi, 1984; 01son et al., 1984; Simons and Lund, 1985; Klassen and Lund 1987; Ii et al., 1988) provided insights into not only the growth characteristics of neural grafts, but their ability to reverse motor, endocrine, cognitive, and other neurologic defects. 
Recently, neural transplantation has been used to treat human neurodegenerative diseases. A team at the Karolinska Institute in stockholm conducted the first human trials in the spring of 1983. This group tried to treat a patient with advanced Parkinson's disease by transplanting medullary tissue (chromaffin cells) from one of the patient's own adrenal glands. The effect of the implant was disappointing and only improved the disorder (decreased off time) for a few months. Three subsequent patients did little better (Seiger, 1986) Human experimentation moved ahead in other countries, such as Mexico, China, Cuba, and the United states. Most of those results indicate modest to moderate benefits in only a small proportion of patients (Sladek and Shoulson, 1988). A recent report on seven patients showed that adrenal autografts into the head of the caudate nucleus was of limited value to Parkinsonian patients (Kelly, 1989).

Although neural transplantation research has progressed to a point where it could be considered for clinical application, especially with respect to some diseases of the central nervous system (Sladek and Shoulson, 1988), ethical and technical questions remain unanswered. It is time to assess what has been learned from earlier investigations, and to chose a direction for the future. Some scientists believe more basic research is needed to elucidate details about the molecular biological basis of host-graft interaction (Gash 
and sladek, 1989). The biochemistry of interaction between graft and host, site(s) and quantity of implantation, reestablishment of neuronal interaction between graft and host, and recovery and regulation of function, should be well understood before neural transplantation can be applied for clinical therapy. This project has focussed on some of these questions.

REASONS FOR THE USE OF THE PINEAL GLAND AS A MODEL FOR NEURAL TRANSPLANTATION

One difficulty in neuronal transplantation is understanding the interaction and integration between the graft and the host. The cellular diversity and complexity of neuronal grafts create variables difficult to control when assessing neuronal survival, reinnervation, revascularization, functional recovery and the underlying cellular mechanisms of neural transduction.

In view of these challenges, this project has utilized the mammalian pineal gland as the donor tissue. The rationale is as follows:

1. The pineal gland, common to all vertebrate species, is a relatively simple circumventricular organ with respect to its histological organization, possessing essentially one predominant cell line, the pinealocyte (Wolfe, 1965). 
This makes it easier to assess the cellular features and functional parameters of the pineal gland following transplantation.

2. The basic function of the normal intact pineal gland is to synthesize and release the pineal hormone, melatonin (Reiter, 1980). It is easy to evaluate functional recovery in pinealectomized animals which receive pineal transplants by measuring serum melatonin concentration in those animals.

3. Neural regulation of the normal intact pineal gland has been well investigated. The primary control of the pineal gland is exerted by the prevailing light-dark environment photoperiod, acting through the suprachiasmatic nuclei (Reiter, 1986a). Environmental information perceived by the eyes is transferred to the pineal gland over a complex series of neuronal pathways, which include the suprachiasmatic nuclei and paraventricular nuclei of the hypothalamus, preganglionic sympathetic neurons in the upper thoracic spinal cord, and postganglionic sympathetic neurons in the superior cervical ganglia (SCG) (Klein et al., 1971, 1979; Moore and Klein, 1974; Moore, 1975, 1978, 1979; Reiter, 1981). The direct innervation of the pineal gland is from the SCG. 
The production of the pineal hormone, melatonin, is cyclic with high levels of synthesis at night (dark environment) and low levels during the day (light environment). This cyclic synthesis is controlled by the neuronal pathway mentioned above. Synthesis of melatonin at night is a consequence of norepinephrine (NE) released from postganglionic sympathetic nerve endings that terminate in the vicinity of pinealocyte processes (Reiter, 1982).

Based on earlier studies, we can more easily assess the variety of neuroanatomical and physiological correlates that are attendant on neuronal reinnervation, regeneration, plasticity, and functional recovery following pineal transplantation.

GENERAL RESEARCH TOPICS INVESTIGATED IN THIS PROJECT.

1. Survival and functional activity of pinealocytes following transplantation.

Transplantation of pineal tissue has been performed for over fifty years. Earlier studies of pineal transplantation were designed to test the effects of the pineal gland and its hormonal influence upon the reproductive system (Johnson and Lahr, 1932; Kozelka, 1933; Einhorn et al., 1939; Gittes and Chu, 1965; Reiter, 1967). These studies provided some his- 
tological evidence of survival, organization and structural change of the pineal grafts after transplantation. All of the morphological data provided by these investigators were at the light microscopic level. Autografts of pineal tissues to the iris showed persistence of healthy pinealocytes and large peripheral and small blood vessels in the grafts a few weeks after transplantation (Holmes, 1957). With grafting of the pineal under the renal capsule, the overall morphology of pineal grafts was good (Reiter, 1967). Intramuscular pineal transplantation demonstrated excellent histological survival and maintenance of characteristic morphology (Gittes and Chu, 1965). While earlier investigations paid little attention to morphological characteristics and integrity of the pineal grafts, a recent investigation with pineal transplantation into the 4 th cerebral ventricle demonstrated that pinealocytes in the grafts survived and were arrayed individually and in clusters. These pinealocytes were identified with electron microscopy that showed the presence of synaptic ribbons with associated rows of microvesicles (Brightman et al., 1985). Unfortunately, the authors did not provide micrographs of these findings. Thus, to date, a detailed description of the ultrastructure of pinealocytes within pineal grafts has not been documented.

Direct biochemical tests for pineal transplant survival and metabolic activity have been applied during the last two decades (Wragg et al., 1966, 1967; Quay, 1976; Pang, 1977; 
Gittes and Chu, 1965; Moore, 1975; Bäckström et al., 1976; Brightman et al., 1985; Lingappa et al., 1987). These earlier studies focussed chiefly upon pineal enzyme activity, especially N-acetyltransferase (NAT) activity which was often used to evaluate the functional status of the graft. In addition, the functional status of pineal grafts was investigated by examining whether circadian rhythm in pineal NAT activity was restored. Pineal grafts exhibited lower NAT enzyme activity than normal intact pineal glands but yielded a highly significant increase in NAT activity during the dark phase as compared to that during the light phase (Moore, 1975; Bäckstrom et al., 1976). Concentrations of urinary 6-hydroxymelatonin (the major metabolite of melatonin) were also used to indicate functional activity and viability of pineal grafts. Urinary 6-hydroxymelatonin was detectable in animals which received pineal transplants into the fourth cerebral ventricle and higher levels were detected in animals which received multiple grafts (Brightman, et al., 1985).

The morphological observations in animals with pineal grafts were chiefly at the light microscopic level. Little attention has been paid to the ultrastructural characteristics of pineal grafts or to the contributions of these to functional recovery. This investigation has focussed upon the fine structural characteristics of the pineal grafts and their contribution to functional recovery. 
Serum melatonin concentration is a precise index for evaluating the function of pineal glands. Melatonin is released into the circulation immediately following synthesis by pinealocytes (Kennaway et al., 1977; Rollage et al., 1977; Wilkinson et al., 1977; Reiter, 1986b). In this study, serum melatonin concentration was used as the physiological parameter to evaluate the recovery of function following pineal transplantation.

2. Patterns of melatonin synthesis and release in the pineal grafts.

one important characteristic of normal pineal function is the circadian rhythm in melatonin synthesis and release, which, in the mammal, is controlled by neural pathways from the retina $\rightarrow$ suprachiasmatic nucleus $\rightarrow$ paraventricular nucleus $\rightarrow$ spinal cord $\rightarrow$ SCG $\rightarrow$ pineal gland (Klein et al., 1970, 1971, 1979, 1983; Moore and Klein, 1974; Reiter, 1981). Most earlier investigations of pineal transplants focussed on nighttime NAT activity, although some examined day-night differences in NAT activity of pineal grafts (Moore and Klein, 1974; Bäckström et al., 1976; Lingappa and zigmond, 1987). However, day-night difference in serum melatonin concentrations has not been studied in pineal transplantation.

Serum melatonin concentration was chosen as a parameter for functional recovery in this study because it allows 
comparisons of day-night differences in the same host animal, while measuring NAT activity only allows comparisons between animals. This study investigated the levels of serum melatonin (e.g., day-night rhythm) following transplantation in pinealectomized host rats.

3. Effects of different implantation sites on functional recovery of the pineal gland following transplantation.

Since pineal transplantation has been performed for many years, numerous sites have been chosen for the implantation of pineal grafts. These sites include subcutaneous connective tissue, fascial planes, cartilage, bone, skeletal muscle, orbital glands, submandibular glands, pancreas, liver, stomach, omentum, thymus, spleen, testis, ovary, adrenal, thyroid, kidney, eye (anterior chamber), and the brain (see review by Quay, 1987). Of these sites, the anterior chamber of the eye, the renal capsule, and the brain were most frequently used.

The anterior chamber of the eye is one site in which rejection of genetically dissimilar grafts does not generally occur. Following transplantation of the pineal gland inside the anterior chamber of the eye, the pineal grafts demonstrated surviving pinealocytes which exhibited a normal microscopic appearance (Moore, 1975; Bãckstrom et al., 1976). Following 
transplantation into the anterior chamber of the eye, circadian rhythms of NAT activity were restored in the grafts (Moore, 1975; Băckstrom et al., 1976; Lingappa and Zigmond, 1987; Zimmerman and Menaker, 1975a, b).

The preservation of histological structure of pineal grafts beneath the renal capsule was verified 14 weeks after transplantation (Reiter, 1967). Morphological findings suggested that grafted pinealocytes undergo important modifications. During the first 40 days following grafting under the renal capsule, pinealocytes showed typical ultrastructural correlates of high protein secretory activity (Aguado et al., 1977).

To determine whether pineal grafts beneath the renal capsule are able to influence the neuroendocrine-reproductive system, Reiter (1967) measured the gonadal response of blinded, pinealectomized hamsters with grafts placed in that site. Two pineal glands were transplanted beneath the renal capsule in each animal. Blinded hamsters with intact fin situ) pineal glands or blinded, pinealectomized hamsters were used as controls. All animals were euthanized after 14 weeks of treatment, and the weights of testes and accessory sex organs (seminal vesicles and coagulating glands) were recorded. Blinded hamsters with intact pineal glands showed marked reduction in reproductive organ size and weight. This change was prevented if the animals were blinded and pinealec- 
tomized. Pineal grafts beneath the kidney capsule did not cause gonadal atrophy in otherwise blinded pinealectomized hamsters (Reiter, 1967).

Pineal glands have been transplanted into different areas of the brain, such as cerebral cortex (Nonaka et al., 1990; McNulty et al., 1991), the hypothalamus (Vries, 1972), the fourth cerebral ventricle (Brightman et al., 1985), and the third cerebral ventricle (Welsh and Rollage, 1986; Li et al., 1989). Nonaka et al. (1990) grafted pineal glands into the frontal cerebral cortex and found that the graft parenchyma demonstrated intense serotonin immunoreactivity, indicating normal development and differentiation of the pinealocytes within the grafts.

Studies by Vries (1972) indicate that pineal glands grafted into the rat hypothalamus can reverse the effect of pinealectomy on the neurosecretory activity of the hypothalamic magnocellular supraoptic nucleus (SON). Pieces of pineal gland or cerebellum from male littermate donors were transplanted into the hypothalamic area of young adult pinealectomized male rats $(200-300 \mathrm{~g}$ BW) for a period of 7-10 days. In pinealectomized rats with cerebellar grafts in the hypothalamus, the soN showed decreased thiamine diphosphatephosphohydrolase (TPP-ase, a Golgi apparatus-specific enzyme) activity, suggesting decreased neurosecretory activity. on the other hand, in the pinealectomized rats with unilateral 
pineal grafts in the hypothalamus, normal TPp-ase values were found on the ipsilateral side, while on the contralateral side the TPP-ase activity was decreased to a level comparable to that found in the cerebellar-implant group. These findings suggest that the pineal may directly act on the son to influence TPP-ase activity (Vries, 1972).

The CSF compartment, which sequesters a variety of solutes from the cerebral parenchyma, serves as an excellent site for the transplantation of neural tissue (Scott and Sherman, 1984). Despite a large number of investigations dealing with neural grafting within the cerebral ventricular system, little data exist with respect to the intraventricular transplantation of pineal tissue.

In a recent study by Brightman et al. (1985), superficial pineal glands and superior cervical ganglia taken from 4-weekold Sprague-Dawley rats were co-transplanted to the IVth cerebral ventricle of pinealectomized host rats. The primary cell type in the graft maintained the ultrastructural morphology indicative of typically functional pinealocytes. The axonal bundles from co-grafted SCG neurons grew very close to the fenestrated capillary endothelium and to certain pinealocytes. Urinary 6-hydroxymelatonin (6-HM), the major metabolite of melatonin, was measured as a means of monitoring the pineal grafts. Prior to grafting, no 6-FM was detectable. The levels of 6-HM were essentially undetectable when only one 
pineal was grafted, however, the majority of animals receiving 2 to 8 transplants had detectable 6-HM levels although these levels were lower than those in an intact rat (Brightman et al., 1985).

Although pineal glands have been grafted into diverse sites and some morphological and functional observations have been made, to date, no one has compared the effects of different implantation sites on functional recovery of transplanted pineal glands. Little is known about the day-night rhythm of melatonin synthesis following pineal grafting to these different sites. This investigation involved several implantation sites and compared the effects of those sites on functional recovery of the transplanted gland (e.g., the restoration of the day-night rhythm of melatonin synthesis). The mechanisms of functional recovery are discussed below.

4. Neural reinnervation of the pineal graft and its significance in the restoration of the pineal function.

Both the synthetic (Wurtman et al., 1965) and the endocrine capabilities (Reiter and Hester, 1966) of the intact normal pineal gland rely on an intact sympathetic innervation. Sympathetic denervation of a number of endocrine glands, e.g., the thyroid, is usually of little consequence to the produc- 
tion and release of secretory products. Conversely, the same procedure severely depresses the function of the pineal gland.

Sympathetic neurons that innervate the pineal gland are found in the superior cervical ganglia (SCG). The course of the postganglionic fibers from the SCG to the pineal is along blood vessels (the internal carotid plexus). As the fibers near the gland they enter the tentorium cerebelli and eventvally form one or two relatively discrete nerves, the nervi conarii, before entering the gland (Kappers, 1960). The nervi conarii usually penetrate the capsule near the distal end of the gland. The nerve fibers follow blood vessel ramifications within the gland and terminate in perivascular spaces and occasionally between pinealocytes (Matsushima and Reiter, 1977). Moxphologically identifiable synapses between sympathetic nerve endings and pinealocytes are extremely rare (Kappers, 1971). Rather, terminal boutons typically end between plasmalemmae of adjacent pinealocytes with no consistently obvious alterations of the postsynaptic membrane (Matsushima and Reiter, 1977).

Besides the sympathetic fibers that enter the pineal gland via the nervi conarii, other nerve fibers from the brain have been observed in the gland following retrograde horseradish-peroxidase tracing techniques in the guinea-pig (Korf and wagner, 1980), Mongolian gerbil (Moller and Korf, 1983 a, b), rat (Dafny, 1983; Guerillot et al., 1982), and golden 
hamster (Moller and Korf, 1987). This central innervation of the pineal gland was from the medial and lateral habenular nuclei, the dorsal nucleus of the lateral geniculate, the posterior commissural nucleus, and the paraventricular nucleus of the hypothalamus (Guerillot et al., 1982; Moller and Korf, 1983 a, b; Moller, 1985)

Obviously, pineal glands lose neural innervation when removed from donor animals. It was of interest to know whether pineal glands would become reinnervated by the host SCG or by other CNS sources, especially from those that normally innervate gland. It was also interesting to know whether transplanted pineal glands could resume theix synthetic and endocrine capabilities and whether the restoration relies on the reinnervation of the grafts by the host SCG or other reinnervating regions of the brain. Neural reinnervation of the pineal grafts have been investigated in the present study, and its significance in the restoration of pineal function is discussed. 


\section{METHOD8}

\section{Experimental Design:}

\section{Experiment \#1.}

This experiment was designed to investigate whether pinealocytes can survive and maintain functional activity following transplantation. What are the ultrastructural features of transplanted pinealocytes and the fine structural correlates of revascularization and reinnervation.

Pinealectomized Sprague-Dawley (SD) rats were used as hosts. Pinealectomy was performed by zibic Miller Co., 1-2 weeks before transplantation, at 4 weeks of age. Donor pineal tissue were harvested from neonatal SD rats (2-3 days old) and grafted into the third cerebral ventricle. The reasons we chose the third cerebral ventricle as the implanting site are based on: 1) In normal situations, there is an active exchange between the pineal gland and cerebrospinal fluid (CSF) (Quay, 1976; Reiter et al., 1975; Tilney and Warren, 1919) and the CSF compartment, which sequesters a variety of bioactive molecules from the cerebral parenchyma. This serves as an excellent site for the transplantation of neural tissue (Broadwell et al., 1987; Erlich et al., 1985; Rodriguez, 1976; Scott and Sherman, 1984; Scott, 1985; Scott et al., 1988). And, 2) As discussed above, the normal intact pineal gland is innervated by the neuronal pathway from the retina $\rightarrow$ 
hypothalamus $\rightarrow$ spinal cord $\rightarrow$ SCG $\rightarrow$ pineal gland. More direct pineal-brain connections have not been demonstrated. The hypothalamus is part of the pathway which innervates the normal intact pineal gland. Direct nerve connection between the paraventricular nucleus of the hypothalamus and the pineal gland has been observed with HRP tracing technique (Moller and Korf, 1983 a, b; Moller, 1985). Hence, by grafting pineal glands into the third cerebral ventricle, we confront the question as to whether pineal grafts can be reinnervated directly from the hypothalamus and if such reinnervation can re-establish functional activity. The question of alternative pathways for plasticity, reorganization and reinnervation are central to this fundamental question.

Twenty-five pinealectomized rats were divided into three groups. One group of animals remained untreated (no transplantation). Eight pinealectomized rats were used in this group. The second group of eight pinealectomized rats were used as sham controls and received occipital cortical transplants. The other nine pinealectomized rats in the third group received two donor pineal glands. Six normal intact rats were used as controls.

After transplantation, all animals were maintained under a light/dark cycle of 10/14 (light on at 8:00 am) and received food and water ad libitum. 
Eight weeks following transplantation, all animals were euthanized between 1:00 am and 2:00 am undex red light. Blood samples of each animal were collected by decapitation and serum melatonin concentration were measured by radioimmunoassay (RIA).

After collecting blood, host rats in group 3, which received pineal transplants, were perfused with $4 \%$ paraformaldehyde and 1 glutaraldehyde through the carotid artery followed by "microfil" infusion to demonstrate the revascularization. Tissues were then prepared for immunocytochemistry (ICC) with antiserum against tyrosine hydroxylase (TH) and then processed for transmission electron microscopy (TEM) .

2. Experiment \#2.

This experiment was designed to determine whether daynight rhythm of melatonin synthesis could be restored in the pineal grafts following transplantation into the third cerebral ventricle.

Pinealectomized rats were divided into two groups with 8 in each group. One group remained untreated (no transplantation). The other group was grafted with two pineal glands which were harvested from $2-3$ day old SD rats. Six normal rats were used as controls. 
Eight weeks following transplantation, two blood samples were collected from each rat. One blood sample was collected during the day (between 2-3 pm) from the jugular vein. Another blood sample, from the same rat, was collected at night (between 1-2 am) under red light by decapitation. Serum melatonin concentration was measured by RIA. Day-night difference in serum melatonin concentration were compared.

\section{Experiment \#3}

This experiment was designed to compare the effects of different implantation sites on functional recovery of the pineal gland (e.g., restoration of day-night rhythm of melatonin synthesis and release) and to determine which of the four sites for restorated of day-night rhythm of melatonin synthesis.

The host rats were pinealectomized as those in experiment \#1. Selected sites were 1) the third cerebral ventricle 2) in situ (where the pineal is normally located) 3) the anterior chamber of the eye (on the iris) 4) and the under renal capsule.

The rationale for the selection of these sites is based on the following considerations: 1) the third cerebral ventricle is close to the normal innervating pathway of the intact pineal gland. 2) Both in situ and the anterior eye chamber transplants are located in areas which normally 
receive innervation from the superior cervical ganglion (SCG). However, in the case of in situ transplantation, the graft location was previously damaged by the pinealectomy which undoubtedly damaged the axons of neurons in the SCG which had innervated the host pineal gland. 3) The renal capsule transplantation represents a site that is distant from the innervating pathway of the normal intact pineal gland.

Pinealectomized rats in this experiment were divided into five groups ( 8 in each group). One group of pinealectomized rats remained untreated (no transplantation), rats in the other groups received pineal transplants into the four selected sites respectively. Six normal intact rats were used as controls.

Eight weeks following transplantation, blood samples were collected twice from each rat following the same steps as in experiment \#2. Serum melatonin concentration were compared within and between groups.

After collecting blood, host tissues with the pineal grafts were blocked, fixed, and prepareci fิธี icc and TEM following the same steps as experiment \#1. 
4. Experiment \#4

This experiment is designed to determine the significance of reinnervation from the host SCG on the functional recovery of the graft.

Pinealectomized hosts in this experiment were divided into three groups ( 8 in each group). Again, one group of pinealectomized rats remained untreated (no transplantation). Pinealectomized rats in the other two groups received pineal transplants into anterior chamber of the eye. Rats in one group of transplanted hosts underwent bilateral removal of the superior cervical ganglion one week before pineal transplantation. six normal intact rats were used as controls. The following steps remained the same as in experiment \#3. Serum melatonin concentrations and their day-night difference were compared within and between groups. Innervation of grafts were compared morphologically between two transplanted groups.

\section{Transplantation}

All surgical procedures described in the Methods Section were performed using sterile conditions. The animals were anesthetized with Ketamine and xylazine (Ketamine $80 \mathrm{mg} / \mathrm{kg}$ xylazine $8 \mathrm{mg} / \mathrm{kg}$ I.M.). 
All host rats, pinealectomized rats and normal intact controls were male. The age of host rats was 6-7 weeks old at the time of transplantation.

All donor pineal glands were harvested from 2-3 day old SD rats under anesthesia minutes before transplantation and immersed in sterile Eagle's solution. Pineal glands were partially decapsulated and minced into small pieces before transplantation.

Owing to the damage of pinealocytes during the collection and preparation of the donor pineal glands, pinealocytes in a donor pineal gland after transplantation are usually fewer than that in an in sity intact gland. Based on earlier studies in pineal transplantation, it was estimated that the amount of recognizable pineal tissue of 2 implants approximated that of one in situ gland (Rejter, 1967). In this study, each host rat received two donor pineal glands.

1. Transplantation of pineal glands into the third cerebral ventricle.

Host rats were placed in a Kopf stereotaxic instrument. A dental drill was used to make a hole through the skull at the bregma. Donor pineal tissue fragments were drawn into the lumen of an 18 gauge spinal needle affixed to the kopf stereotaxic instrument. The spinal needle was stereotaxically 
lowered through the corpus callosum into the lumen of the third cerebral ventricle. Indwelling fragments of pineal glands were extruded from the spinal needle with a stylet and gently deposited into the lumen of the third cerebral ventricle.

2. Transplantation of pineal glands in situ.

A dental drill was used to make a hole through the lambda of the skull of host rats. A small opening was carefully made in the dura adjacent to the confluens sinuum. Donor pineal glands were picked up with forceps and placed into the location under the confluens sinuum.

3. Transplantation of pineal gland into the anterior chamber of the eye.

A scalpel and iridectomy scissors were used to discreetly incise the cornea of recipients. Donor pineal glands were picked up with forceps and placed upon the iris.

4. Transplantation of pineal gland under the kidney capsule.

The lumbar area of anesthetized host rats were cleanly shaved, the skin and muscle over the LI, I2, and L3 vertebrae was incised. The kidney was exposed and a small opening was 
made in the kidney capsule. The donor pineal gland was placed into the capsule.

After transplantation, all animals were maintained under a light/dark cycle of $10 / 14$ (light on at $8 \mathrm{am}$ ). Food and water was available ad libitum.

Collection of Blood samples and Measure of Serum Melatonin.

All blood samples were collected in $12 \times 75 \mathrm{~mm}$ glass tubes, allowed to clot, and centrifuged. Serum was transferred to another tube, frozen at $-70^{\circ} \mathrm{C}$ and stored until assay. Serum melatonin was measured in the laboratory of $\mathrm{Dr}$. R. J. Reiter, Department of Cellular and structural Biology, University of Texas, San Antonio.

Serum melatonin concentration was analyzed statistically with either one way ANOVA or student t-test. Values were expressed as means \pm standard errors.

\section{Statistic Analysis}

Statistical analysis of group means was done using student's t-test when two groups were compared. Analysis of variance (ANOVA) was used for comparison among three groups or more. Duncan's multiple comparison test was used following ANOVA. 
Tissue Processing for ICC and TEM

Following collection of blood, tissues of host rats with indwelling grafts were blocked and fixed with 48 paraformaldehyde, 18 glutaraldehyde, and $0.2 \%$ picric acid for 24-48 hours. Tissue was then routinely prepared for ICC and for TEM. Fifty $\mu \mathrm{m}$ - thick vibratome sections were collected in wells containing $0.05 \mathrm{~m}$ phosphate buffered saline (PBS) and washed four to six hours. Free-floating fixed sections were incubated in primary antisera against tyrosine hydroxylase (TH), diluted in 0.05 molar PBS containing $1 \%$ NGS and $0.1 \%$ Triton X100 for 48 hours at $4^{\circ} \mathrm{C}$. Dilution of primary antisera was 1 to 2000 . Antisera against $T H$ was purchased from Immunonuclear corporation. In order to characterize the specificity of the primary antisera, in some alternate sections antisera was omitted from ICC reactions and served as controls. Results of controls were appropriately negative. Following rinsing in PBS three times ten minutes each, sections were incubated in biotinylated goat anti-rabbit immunoglobulin G (using the Vectastain $A B C$ kit) for 40 minutes at room temperature. Sections were rinsed and incubated in $A B C$ reagents (Vectastain $A B C$ kit) for 60 minutes at room temperature. Sections were then rinsed completely and incubated in $0.05 \%$ $D A B$ and $0.03 \% \mathrm{H}_{2} \mathrm{O}_{2}$ for three to ten minutes until a brown reaction product was observed. Sections for light microscopy were counterstained with cresyl violet and mounted on glass 
slides, dried overnight and cover slipped. Alternate $50 \mu \mathrm{m}$ sections, prepared for electron microscopy, were treated with $1 \%$ osmium tetroxide for one hour, rapidly dehydrated in graded alcohol and propylene oxide and flat embedded in epon. Sections were then mounted on blank beam capsules and sectioned on a Reichert ultramicrotome. Ultrathin sections were stained with uranyl acetate and lead citrate and examined in a Philips model TEM 301 electron microscope.

\section{Microfil infusion}

Following blood sample collection, animals in Group 3 of the experiment which received pineal transplants were perfused with $4 \%$ paraformaldehyde and $1 \%$ glutaraldehyde in $0.05 \mathrm{M}$ phosphate buffer, $\mathrm{PH} 7.4$, through the carotid artery. Following complete flushing, the brains were infused with 9 $\mathrm{ml}$ of orange polymerizing silastic agent "microfil" (Canton Biomedical Products, Boulder, co) to delineate the vascular system within the brains and grafts. Tissues were then prepared following the process described above for ICC and TEM. Fifty $\mu \mathrm{m}$ sections were examined at the light microscopic level. 
REBULT8

\section{TRANBPLANTATION OF PINEAI GLAND INTO THE THIRD CEREBRAL VENTRICLE: BTRUCTURAL CORRELATEB AND PUNCTIONAL PARA- METERS.}

In this experiment, only those animals that met both of the following criteria were included in the study. The first criterion was that pineal graft(s) were located within the third cerebral ventricle. If after sectioning, no graft was found within the third cerebral ventricle, the animal was excluded from the study. The second criterion was that pinealocytes must survive in the graft(s). (Fig. 1A-C; Fig. 2A). If the graft contained mainly macrophages (Fig. 1B-D; Fig. 2B), the animal was excluded from the study.

In this experiment, group 1 was the normal control (6 rats). Group 2 consisted of pinealectomized rats without treatment (untransplanted, 8 rats). Group 3 is a sham control. Pinealectomized rats in this group received occipital cortex tissue transplants, 5 of 8 rats were found to have grafts within the third cerebral ventricle. In group 4 only 6 of 9 rats with the pineal transplants met the criteria and were used for analysis. 
Figure 1

Light micrographs showing pineal grafts (PG) in the third cerebral ventricle. (A): The graft is located within the third cerebral ventricle ( $V$ ) and contacts the host brain ( $H)$. (C): Higher magnification of light micrograph from (A) showing surviving pinealocytes in the graft. (B): This graft (PG) is filled mainly with macrophages. $H$, host brain; $V$, the third cerebral ventricle. (D): Higher magnification of light micrograph from (B) showing macrophages in the graft. (Scale bars $=$ (A) $50 \mu \mathrm{m} ;$ (B) $50 \mu \mathrm{m} ;$ (C) $10 \mu \mathrm{m} ;$ (D) $10 \mu \mathrm{m}$ ). 


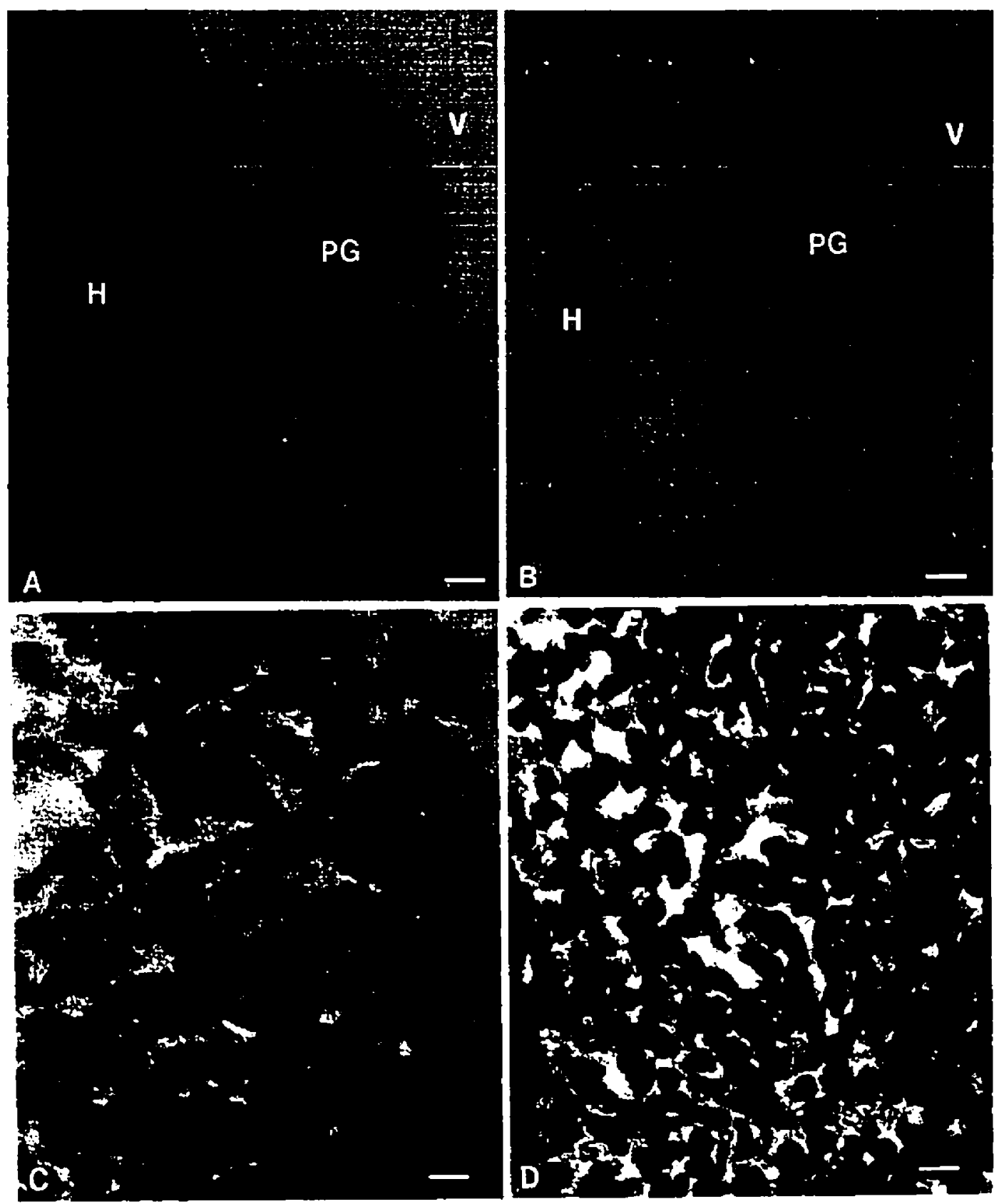




\section{Figure 2}

Electron micrographs showing pinealocytes (A) and macrophages (B) in the grafts. A, unmyelinated nerve fibers. (Scale bars $=$ (A) $5 \mu \mathrm{m} ;$ (B) $5 \mu \mathrm{m}$ ). 


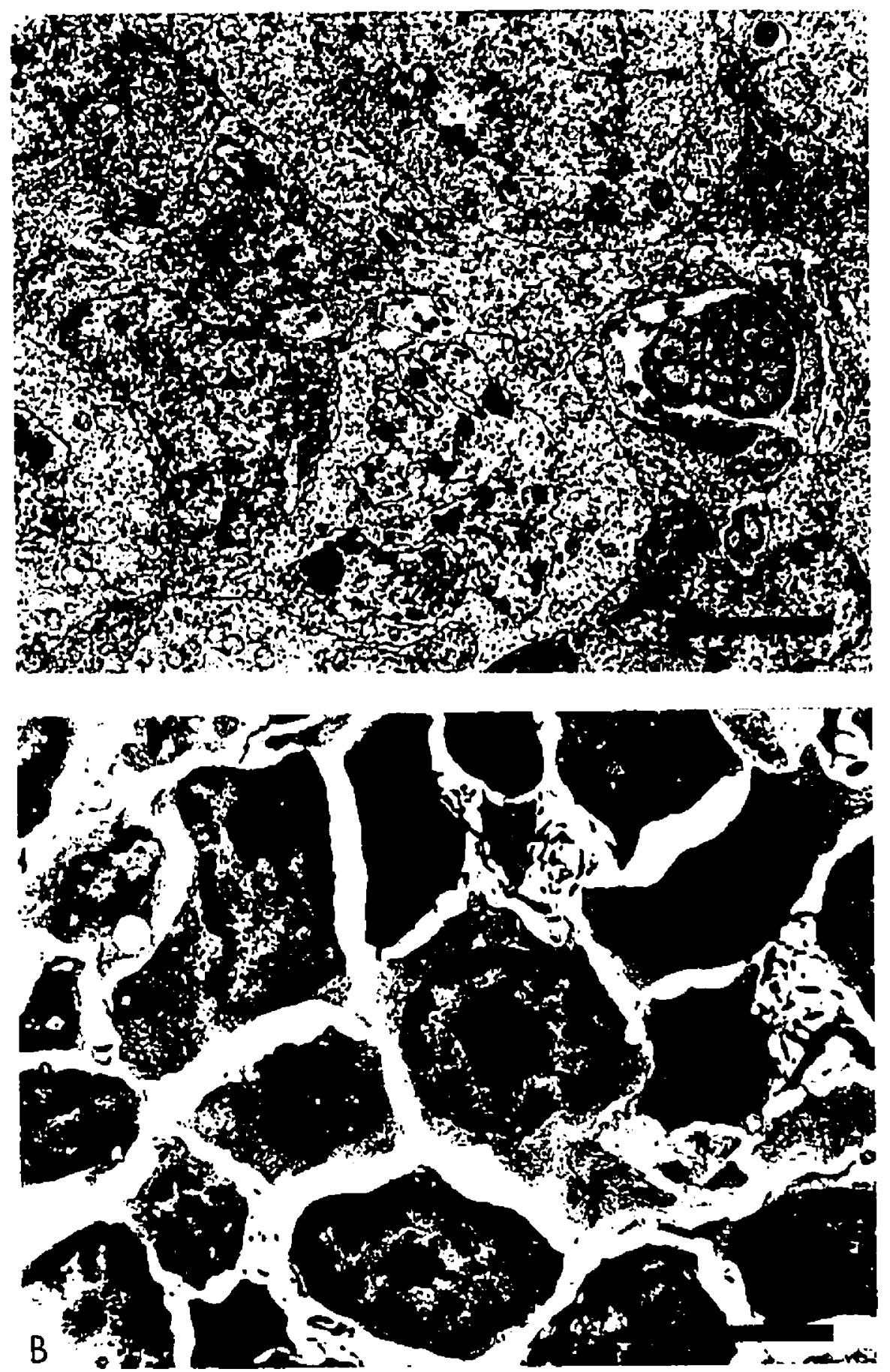


(1) SERUM MELATONIN CONCENTRATION (FIg. 3)

Pinealectomy caused a significant decrease in nighttime serum melatonin concentration in animals in group 2 (4.52 $\mathrm{pg} / \mathrm{ml})$ as compared to that in normal controls $(43.178 \mathrm{pg} / \mathrm{ml}$, $P<0.01)$. No significant difference was observed in nighttime serum melatonin concentration between pinealectomized rats and those receiving sham transplantation $(4.04 \mathrm{pg} / \mathrm{ml} ; \mathrm{p}>0.05)$. Animals with pineal transplants exhibited a significant increase in the nighttime serum melatonin concentration (24.30 $\mathrm{pg} / \mathrm{ml}$ ) compared to that of pinealectomized rats $(P<0.01)$ and to the pinealectomized rats which received sham transplants in group $3 \quad(P<0.01)$. A significant difference was still observed in nighttime serum melatonin concentrations between rats with pineal transplants and normal rats $(P<0.01)$.

(2) MORPHOLOGICAL OBSERVATIONS OF PINEAL GRAFTS IN THE THIRD CEREBRAL VENTRICLE.

1. Locations of the Grafts.

Pineal grafts in the third cerebral ventricle were commonly found to contact the host median eminence (Fig. 4A) as well as the lateral walls of the third cerebral ventricle (Fig. $4 \mathrm{~B}-\mathrm{C}$ ). In some cases, pinealocytes were found to migrate from the graft to the host brain (Fig. 4D; Fig. 5). Grafts in the third cerebral ventricle were surrounded by cerebrospinal fluid except where they contacted the host 
Figure 3

Nighttime serum melatonin concentration. G1, Group 1: animals in group 1 were normal control. G2, Group 2: animals in group 2 were pinealectomized rats which remained untreated (no-transplantation). G3, Group 3: animals in group 3 were pinealectomized and received sham transplants into the third cerebral ventricle. G4, Group 4: animals in group 4 were pinealectomized rats which received pineal transplants into the third cerebral ventricle. (*) $P<0.01$ versus G1. (\#) $P<0.01$ versus $G 2$. (t) $P<0.01$ versus $G 3$. 


\section{NIGHTTIME SERUM MELATONIN CONCENTRATION}

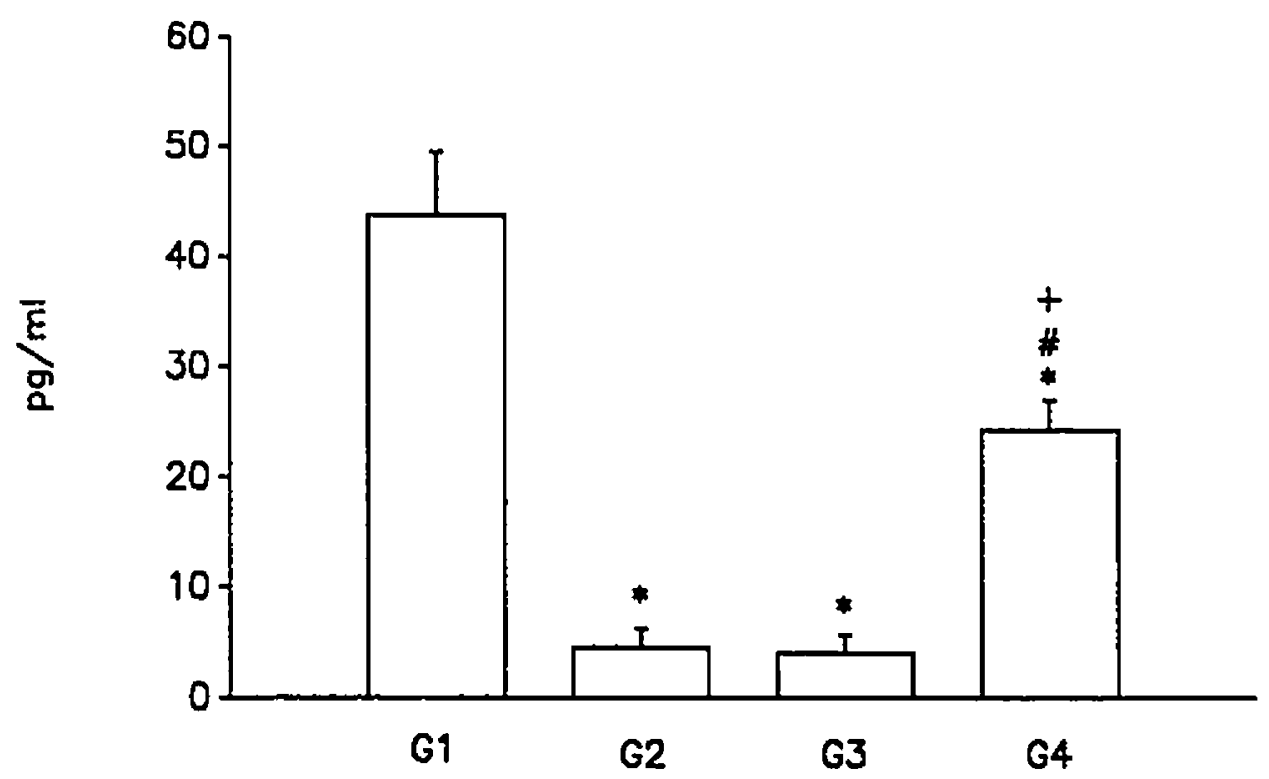


Figure 4

Iight micrographs showing locations of the pineal grafts in the third cerebral ventricle. (A) Fifty micrometer-thick section showing a pineal graft (PG) in the third cerebral ventricle (V) which contacts both the host median eminence (ME) and the lateral wall of the third cerebral ventricle (V) . Arrowheads indicate $\mathrm{TH}$-positive neurons in host hypothalamus (H). (B) Fifty micron section showing a pineal graft (PG) in the third cerebral ventricle (V) which contacts both lateral walls of the third cerebral ventricle, but not the median eminence. Some pinealocytes are found to migrate to the host hypothalamus (arrow). Arrowheads indicate TH-positive neurons in the host hypothalamus (H). (C) Semithin $1 \mu \mathrm{m}$ sections stained with toluidine blue showing a pineal graft (PG) in the third cerebral ventricle (V) which contacts only one side of lateral wall of the ventricle. (D) Semithin $1 \mu \mathrm{m}$ section showing pinealocytes (Pc) migrate from the graft (PG) to the host brain (H) through the lateral wall of the third cerebral ventricle (V). (Scale bars $=$ (A) $50 \mu \mathrm{m}$; (B) $60 \mu \mathrm{m}$; (C) $40 \mu \mathrm{m}$; (D) $10 \mu \mathrm{m})$. 

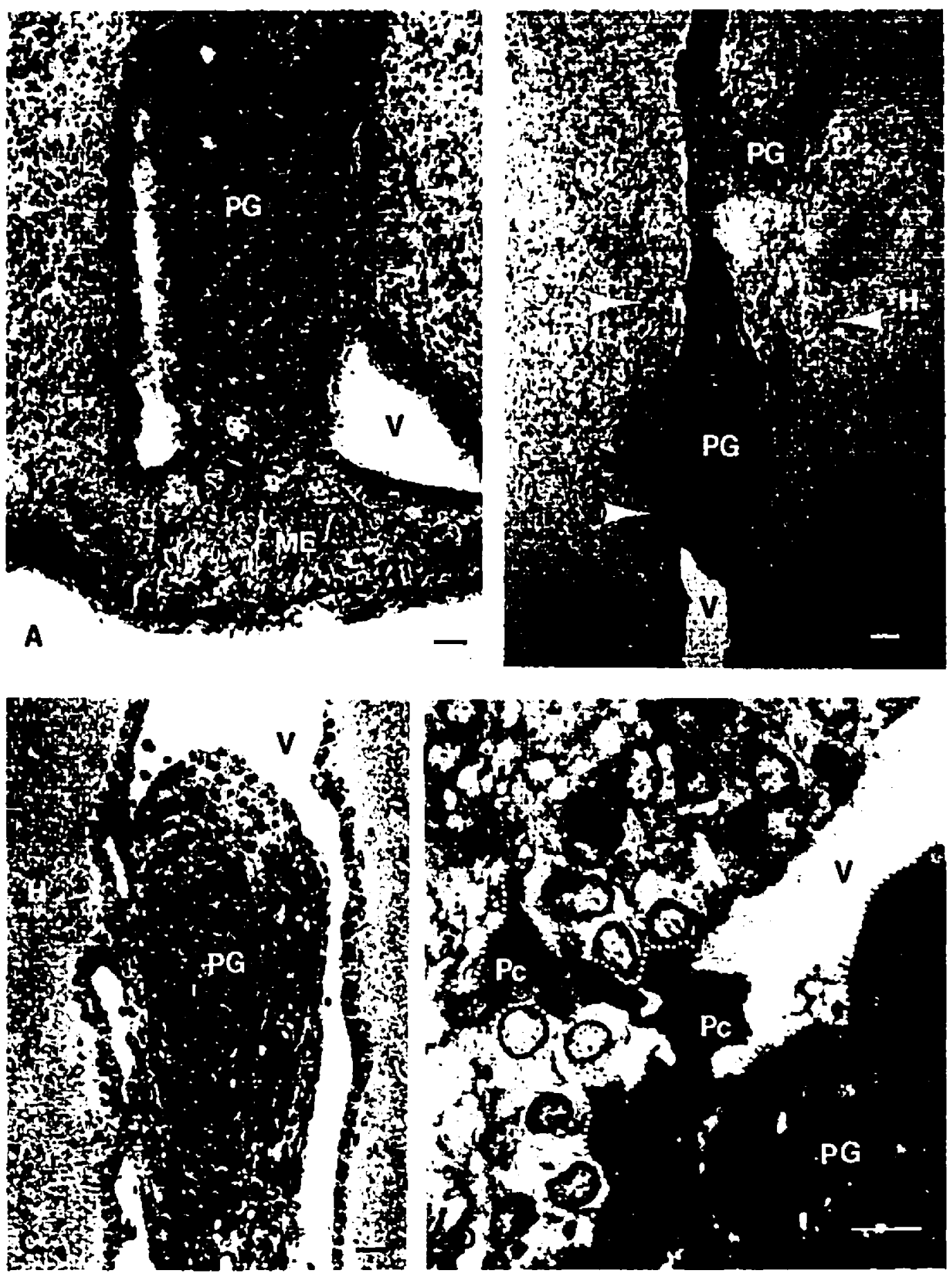


\section{Figure 5}

Electron micrograph showing a process of a pinealocyte (PC) migrating from the graft into the host brain (H) between two ependymal cells (Ep). Arrow indicates a synaptic ribbon. M, mitochondria; GA, Golgi Apparatus. (Scale bar $=3 \mu \mathrm{m}$ ). 


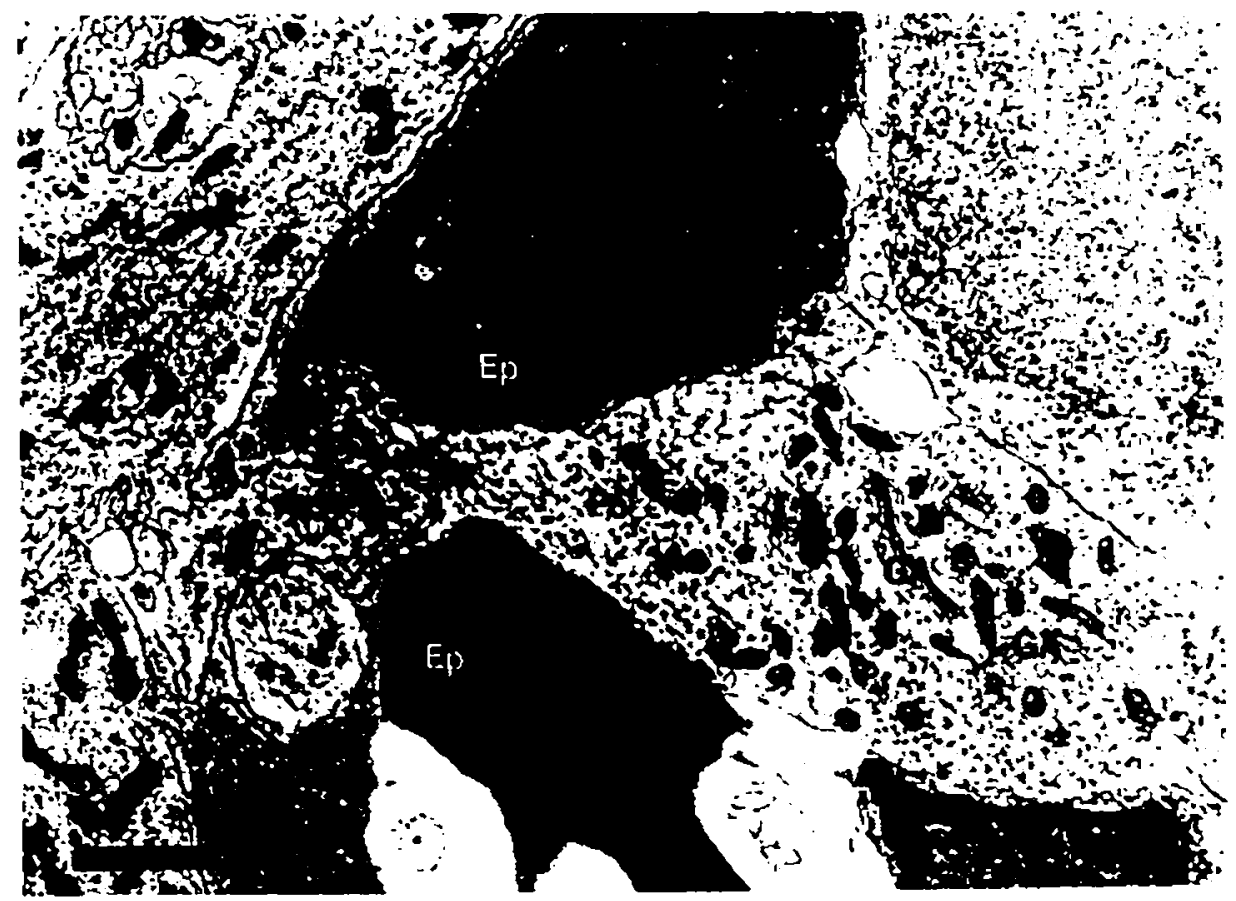


median eminence and lateral walls of the third cerebral ventricle (Fig. 4).

2. Vascularization of the Grafts.

All pineal grafts within the ventricle were found to be well revascularized. Blood vessels were observed to invade from the surrounding host brain into the grafts and became anastomostic with blood vessels within the grafts (Fig. 6A-Bc). Observation of semithin plastic sections with light microscopy revealed that capillaries in the grafts were found to be surrounded by viable pinealocytes (Fig. 6D-E). With transmission electron microscopy (TEM), capillaries of the grafts were surrounded by relatively and consistently wide perivascular spaces (Fig. $7 ; 8 ; 10 \mathrm{~A}$ ). Double basal lamina constituted the perivascular spaces (Fig. 7-8). Polar processes of pinealocytes were found to terminate on the abluminal basal lamina (Fig. 8). Some polar terminals of pinealocytes and nerve terminals were observed within the perivascular spaces (Fig. 19B). Almost all capillary endothelium in the grafts appeared to be fenestrated (Fig. 7-8). Occasionally, non-fenestrated capillaries with tight junctions between endothelial cells were found in the pineal grafts (Fig. 22B). However, this finding was rare and only occurred in peripheral zones of grafted pineal glands. 
Figure 6

Light micrographs showing vascularization of the pineal grafts in the third cerebral ventricle. (A), (B), (C) are 50 $\mu \mathrm{m}$ vibratome sections from the animal perfused with microfil. Pineal grafts (PG) are well vascularized. Blood vessels from the host hypothalamus are found to anastomose with blood vessels in the graft (arrows in $\langle A\rangle$ ). (D) and (E) are semithin $1 \mu \mathrm{m}$ sections. Asterisks indicate the bounds between the grafts (PG) and hosts (H). Abundant capillaries (C) were observed to be surrounded by pinealocytes within the grafts. $v$, the third cerebral ventricle. (Scale bars = (A) $1 \mathrm{~mm}$; (B) $0.5 \mathrm{~mm} ;$ (C) $1.5 \mathrm{~mm} ;$ (D) $50 \mu \mathrm{mi}$ (E) $10 \mu \mathrm{m}$ ). 

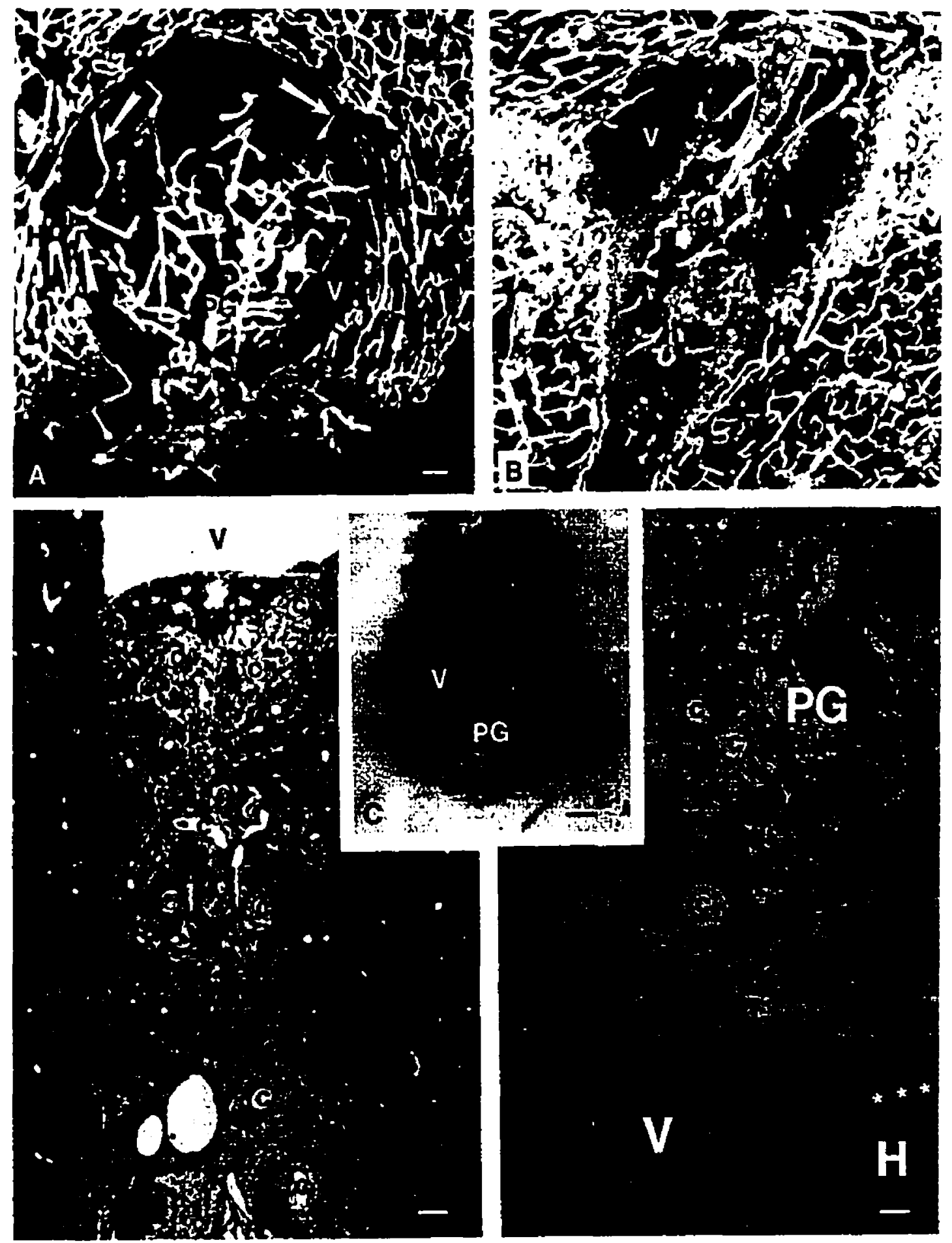
Figure 7

Electron micrographs showing fenestrated capillaries (c) in the grafts of the third cerebral ventricle. pores (arrows) are observed in the endothelial cells (En) of the capillaries. pinealocytes (PC) are found to terminate on the perivascular space (PS) of the fenestrated capillaries. SR, synaptic ribbon; G; glial cell; LD, lipid droplet. (Scale bars $=(A)$ $2 \mu \mathrm{mi}$ (B) $5 \mu \mathrm{m}$ ). 


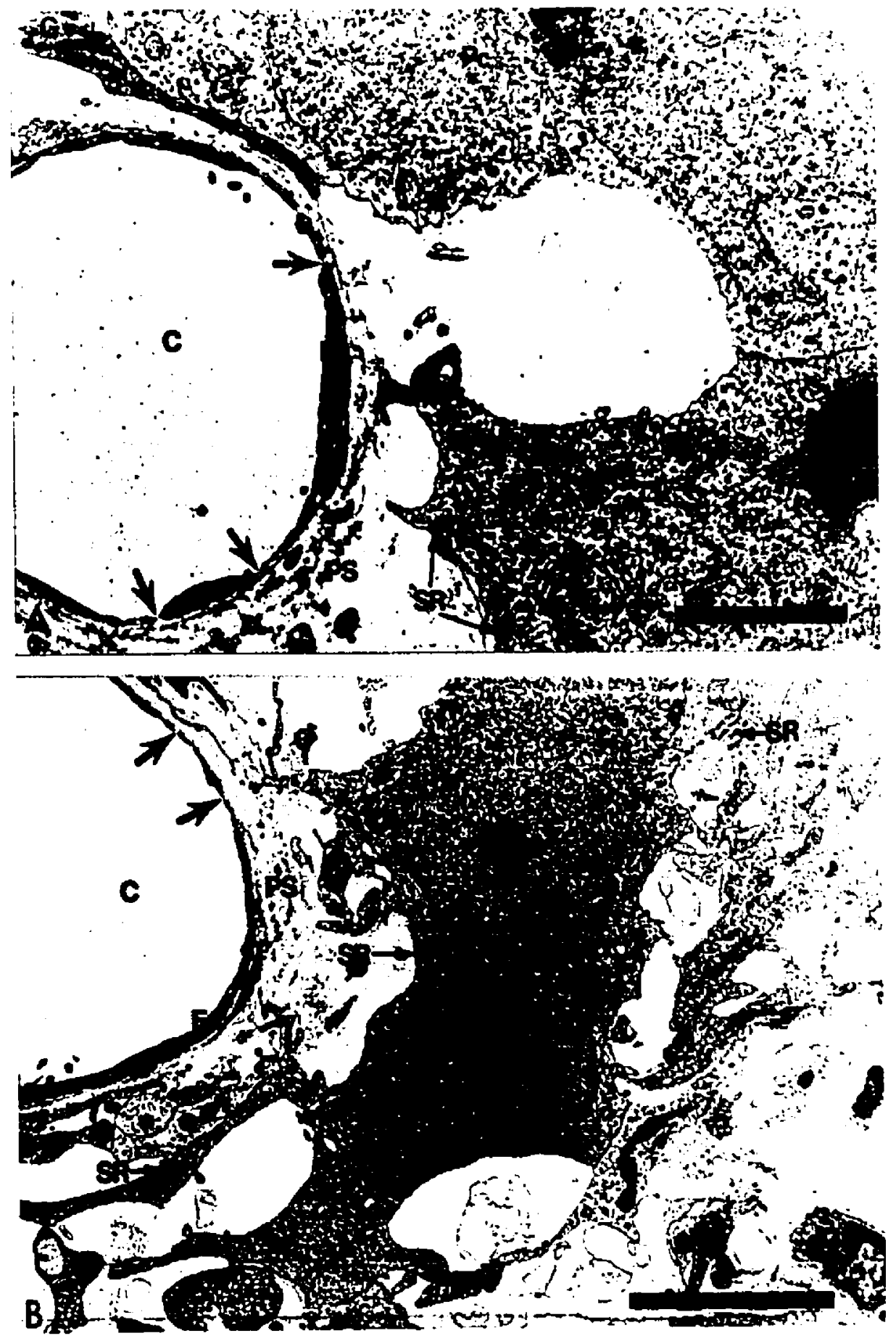




\section{Figure 8}

Electron micrographs demonstrating fenestrated capillaries (c) of a pineal graft in the third cerebral ventricle. Those capillaries are surrounded by consistently wide perivascular spaces (PS). The double layer basal lamina (open arrows in $\langle B\rangle$ ) are found to constitute the perivascular space. Polar processes (PP) of pinealocytes (PC) are observed to terminate on the basal lamina. Arrowheads indicate pores on the endothelial cells. Asterisks indicate nerve terminals in the graft which were commonly found in close juxtaposition with pinealocytes. LD, lipid droplet; Ly, lyosomes. (Scale bars $=$ (A) $5 \mu \mathrm{m} ;$ (B) $3 \mu \mathrm{m}$. 


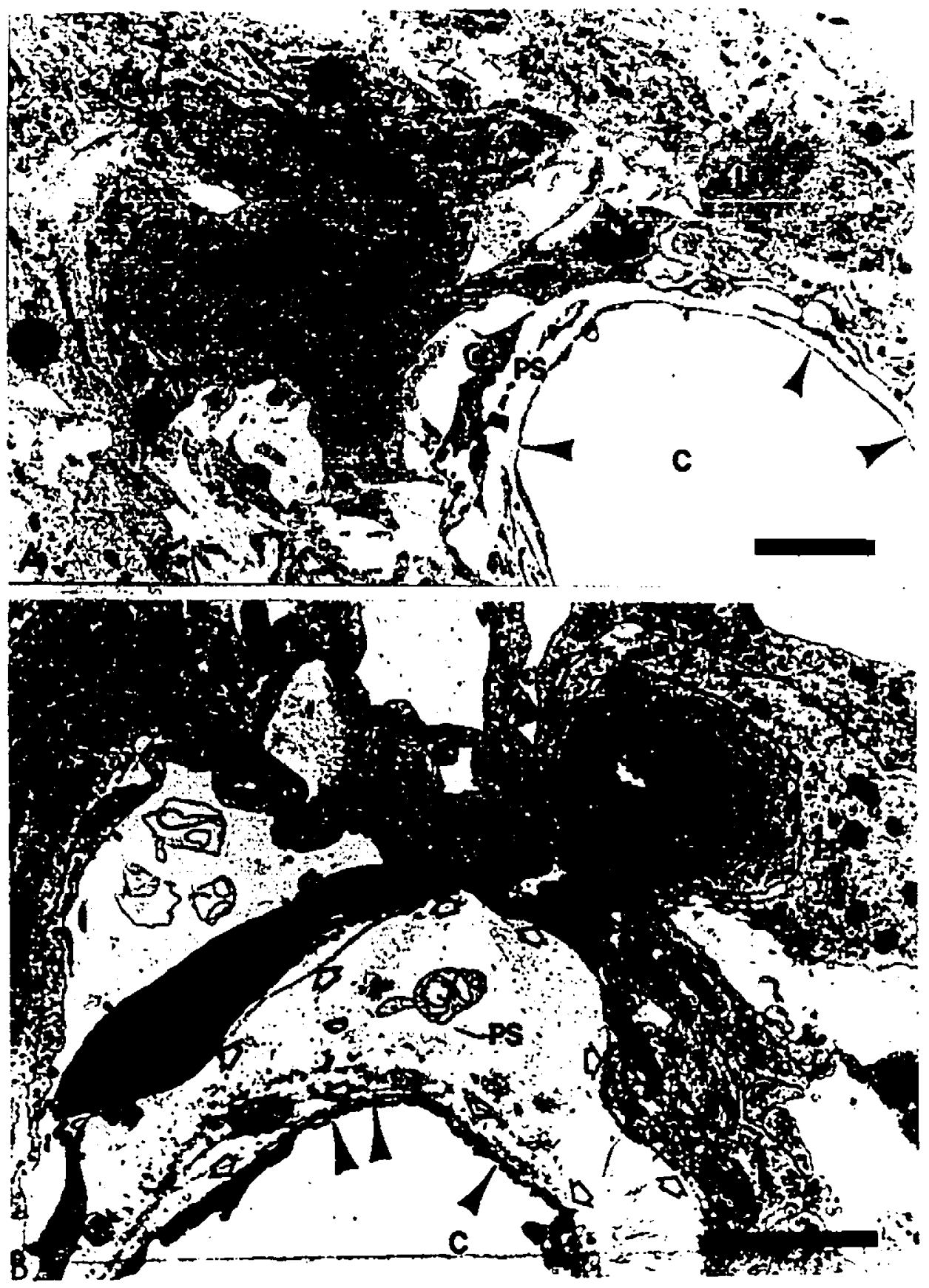


3. Pinealocytes in grafts

Consistent with the intact normal pineal gland, both light and dark pinealocytes were present in the grafts (Fig. 9). Pinealocytes in the grafts were arrayed individually or in clusters (Fig. 10; 11). The cells were polarized having characteristic cytoplasmic prolongations, the so-called polar processes. These processes arose from the perikaryon of the pinealocytes become tapered and formed distal segments (Fig. 10). Graft pinealocytes often formed a radial array (Fig. 11): Their polar processes often appeared tortuous and pursued a course of variable length before ending as a polar terminal upon the abluminal basal lamina of perivascular spaces (Fig. 10) or between pinealocytes (Fig. 11).

Ultrastructure of both light and dark pinealocytes in the pineal grafts were essentially similar.

\section{NUCLEUS}

Pinealocyte nuclei were irregular in shape (Fig. 12; 13; 14) and were characterized by invagination or clefting of their nuclear membranes (Fig. $12 ; 13$ ) as well as the presence of prominent nucleoli (Fig. $12 ; 13 ; 16 \mathrm{~A} ; 18$ ). The nucleoplasm of pinealocytes was highly electron-lucent (Fig. 12). The -dispersed chromatin was localized in an uneven marginal zone confluent with areas deeper within the nucleus (Fig. 13). Cytoplasmic invaginations into the nuclei were often observed. 


\section{Figure 9}

Electron micrographs showing dark (DP) and light (IP) pinealocytes in the grafts localized in the third cerebral ventricle. LD, lipid droplet; G, glial cell; Mac, macrophage; $M$, mitochondria; $N$, nucleus; $N$, Nucleoli. (Scale bars $=(A)$ $5 \mu \mathrm{m} ;$ (B) $5 \mu \mathrm{m}$ ). 

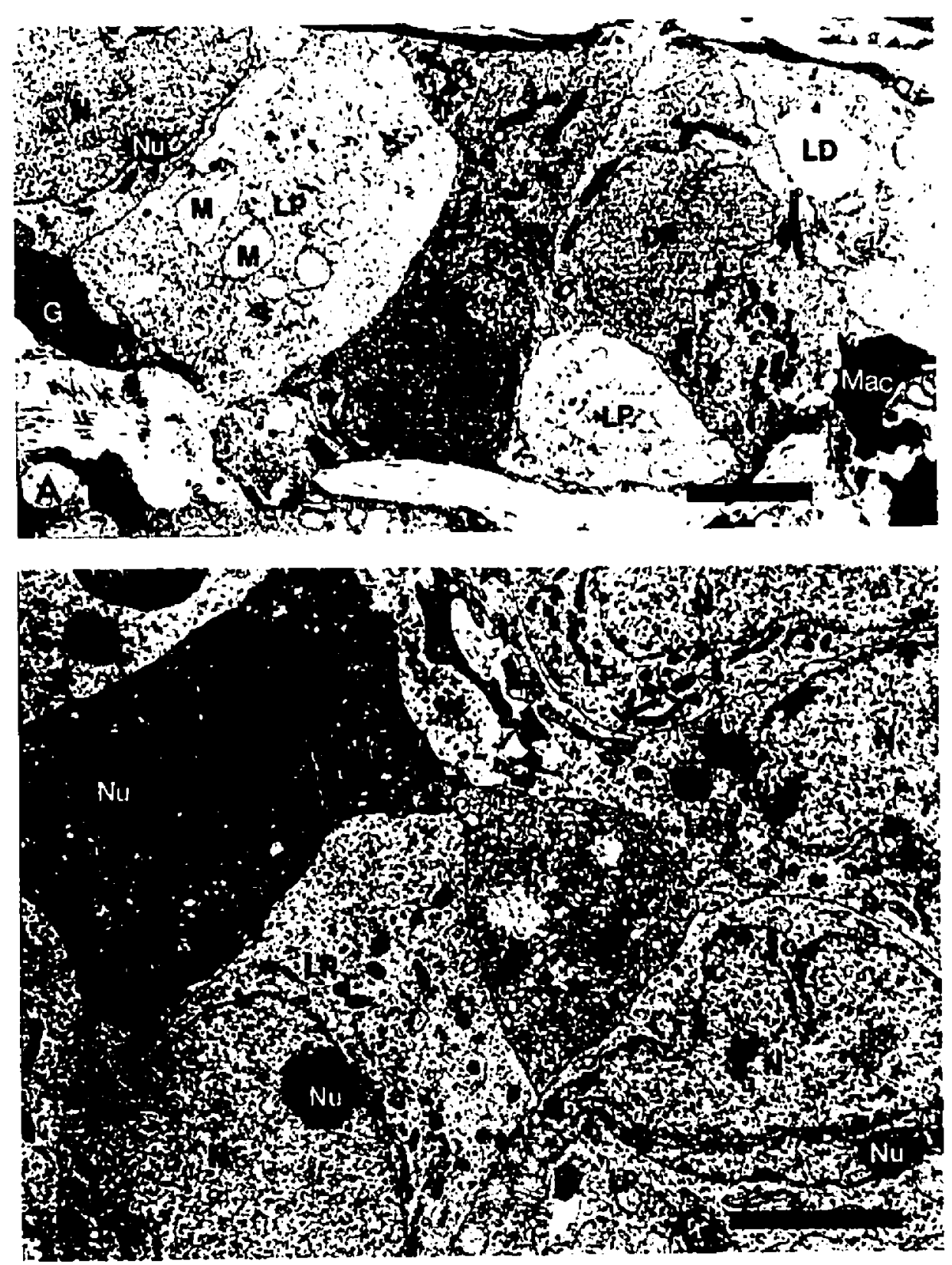
Figure 10

Electron micrographs showing the continuity of the perikaryal cytoplasm of the pinealocytes with polar processes (PP) which consist of the collicular segment (CS) and distal segment (DS). C, capillary; PS, perivascular space; $N$, nucleus; Nu, nucleoli; SR, synaptic ribbon. (Scale bar $=(\mathrm{A})$ $5 \mu \mathrm{m} ;$ (B) $5 \mu \mathrm{m}$ ). 


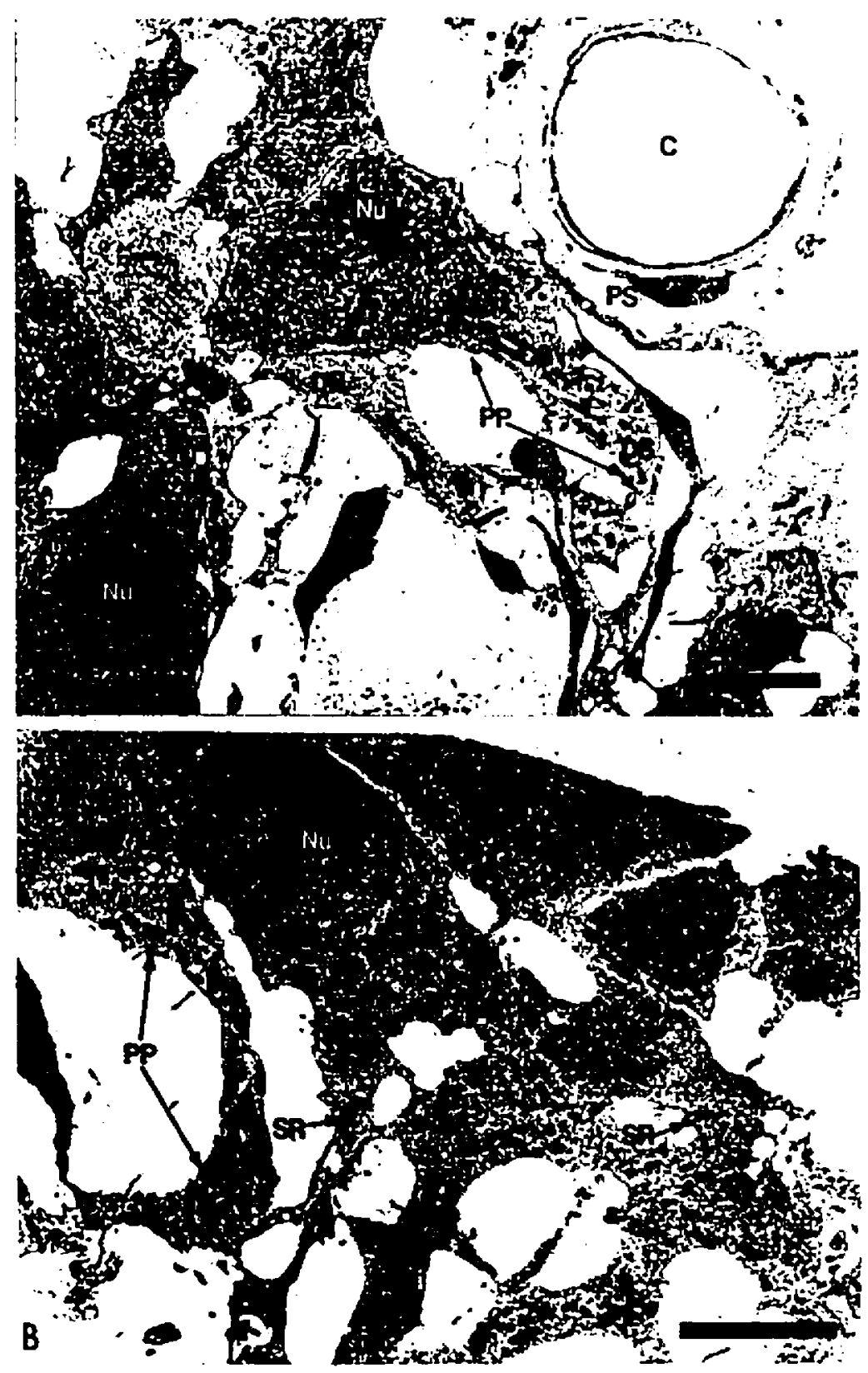


Figure 11

Electron micrographs demonstrating the disposition of pinealocytes in the graft. Micrograph (A) showing the radial disposition of the pinealocytes (PC) with their polar processes (PP) in the graft following transplantation into the third cerebral ventricle. Micrograph in (B) showing polar terminals (PT of pinealocytes end between polar processes (PP) of pinealocytes. $N$, nucleus of pinealocytes; SR, synaptic ribbon. Scale bars $=$ (A) $5 \mu \mathrm{m}$; (B) $3 \mu \mathrm{m}$ ). 

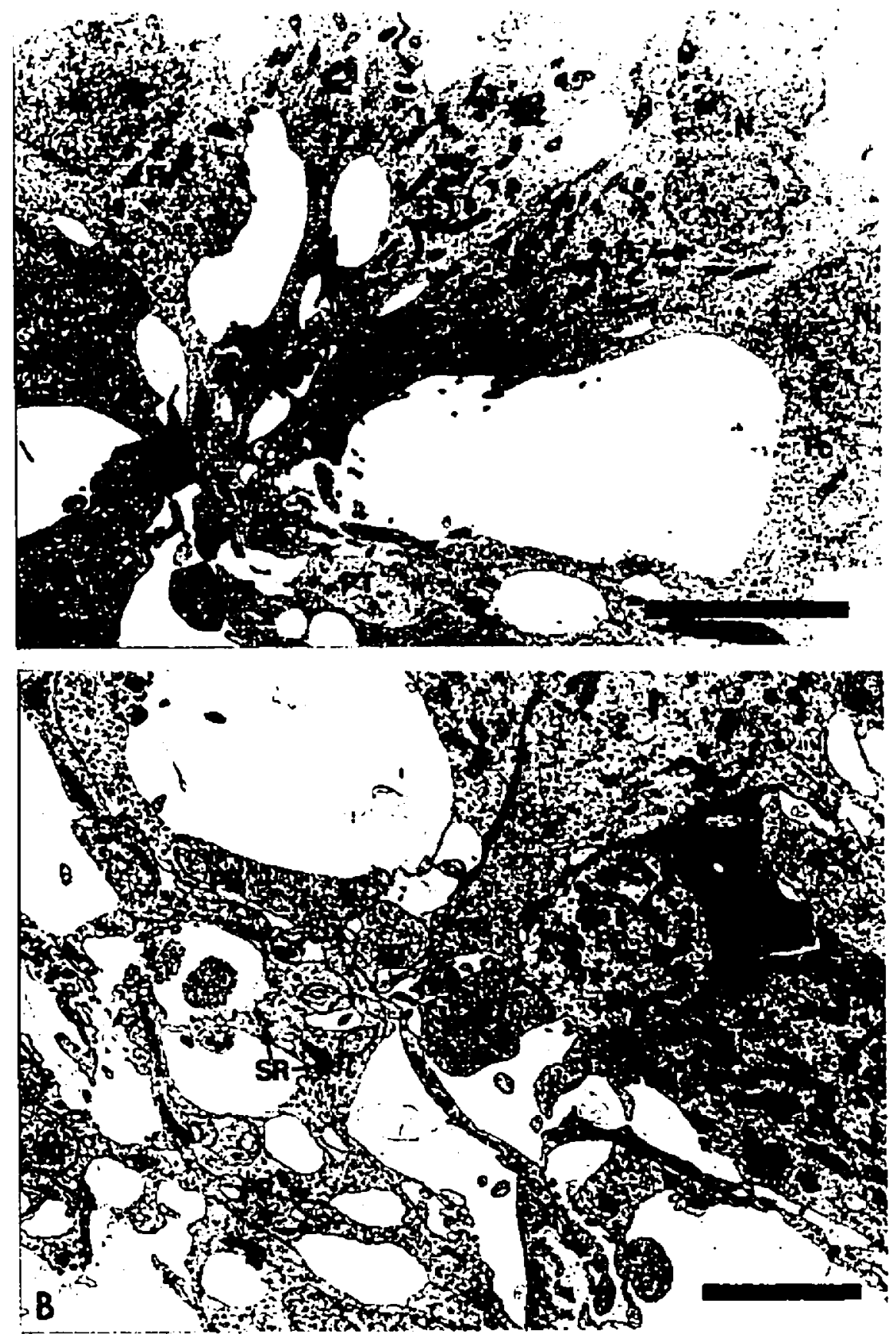
Figure 12

Electron micrograph showing the nuclel of pinealocytes in the graft following transplantation into the third cerebral ventricle. Nuclei (N) of pinealocytes are characterized by the folding of their nuclear membranes (arrowheads), and the presence of prominent nucleoli (Nu) . M, mitochondria; RER, rough endoplasmic reticulum; SR, synaptic ribbon; G, glial cell. (Scale bar $=5 \mu \mathrm{m}$ ). 


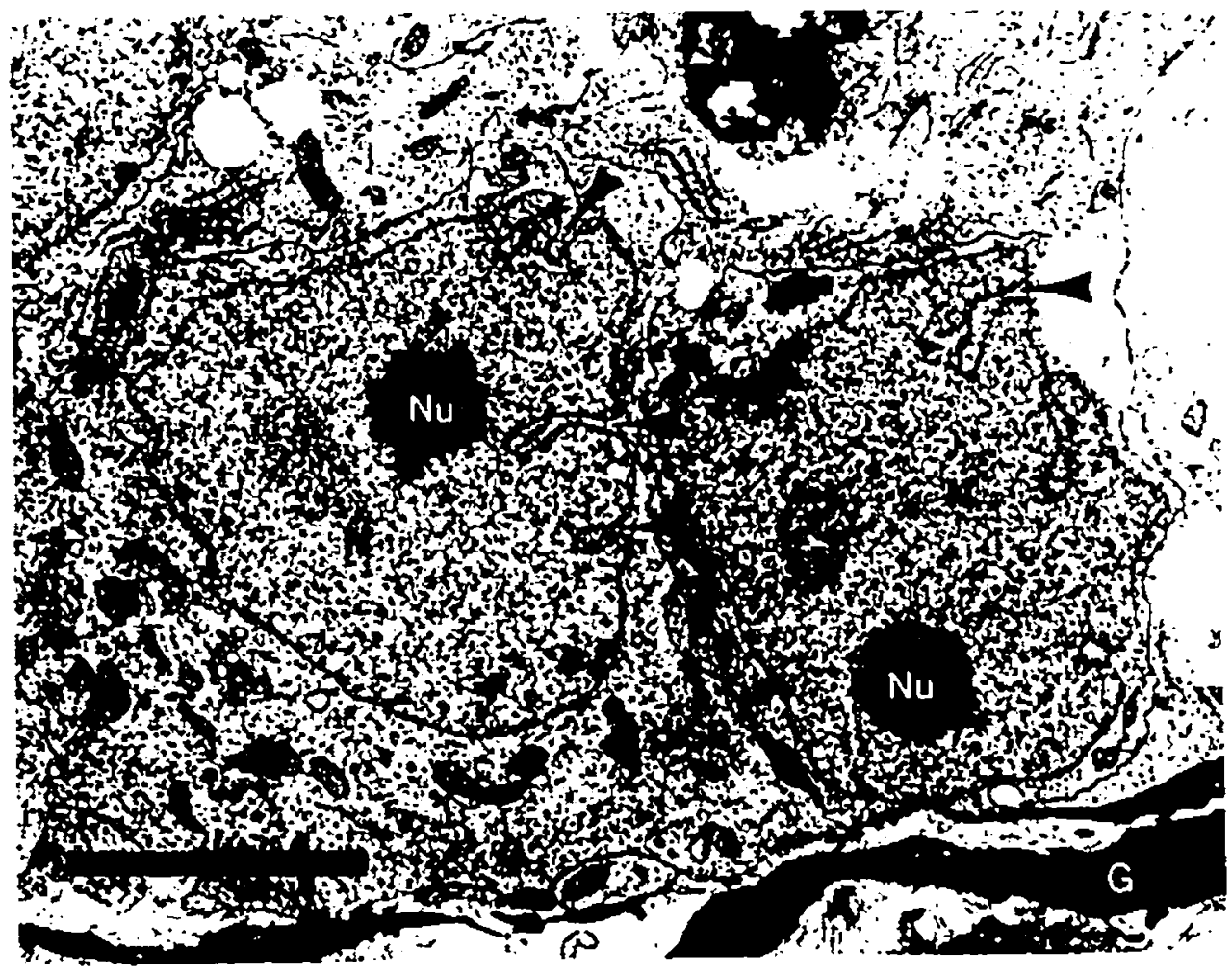


Figure 13

Electron micrographs showing the pinealocytes in the ventricular graft. The nucleoplasm of the pinealocytes are highly electronlucent. Chromatin (arrowheads) were localized in the uneven marginal zone of the nuclei. Typical folding of nuclear membrane is observed (arrows). A lipid droplet (LD) is present in the nuclear fold of the pinealocyte in the micrograph (B). Both pinealocytes in (A) and (B) contain large numbers of mitochondria (M) . FR, free ribosomes; $N$, nucleus; $N u$, nucleoli; RER, rough endoplasmic reticulum; SER, smooth endoplasmic reticulum; A, nerve axons. (Scale bars = (A) $2 \mu \mathrm{m}$, (B) $2 \mu \mathrm{m}$ ). 

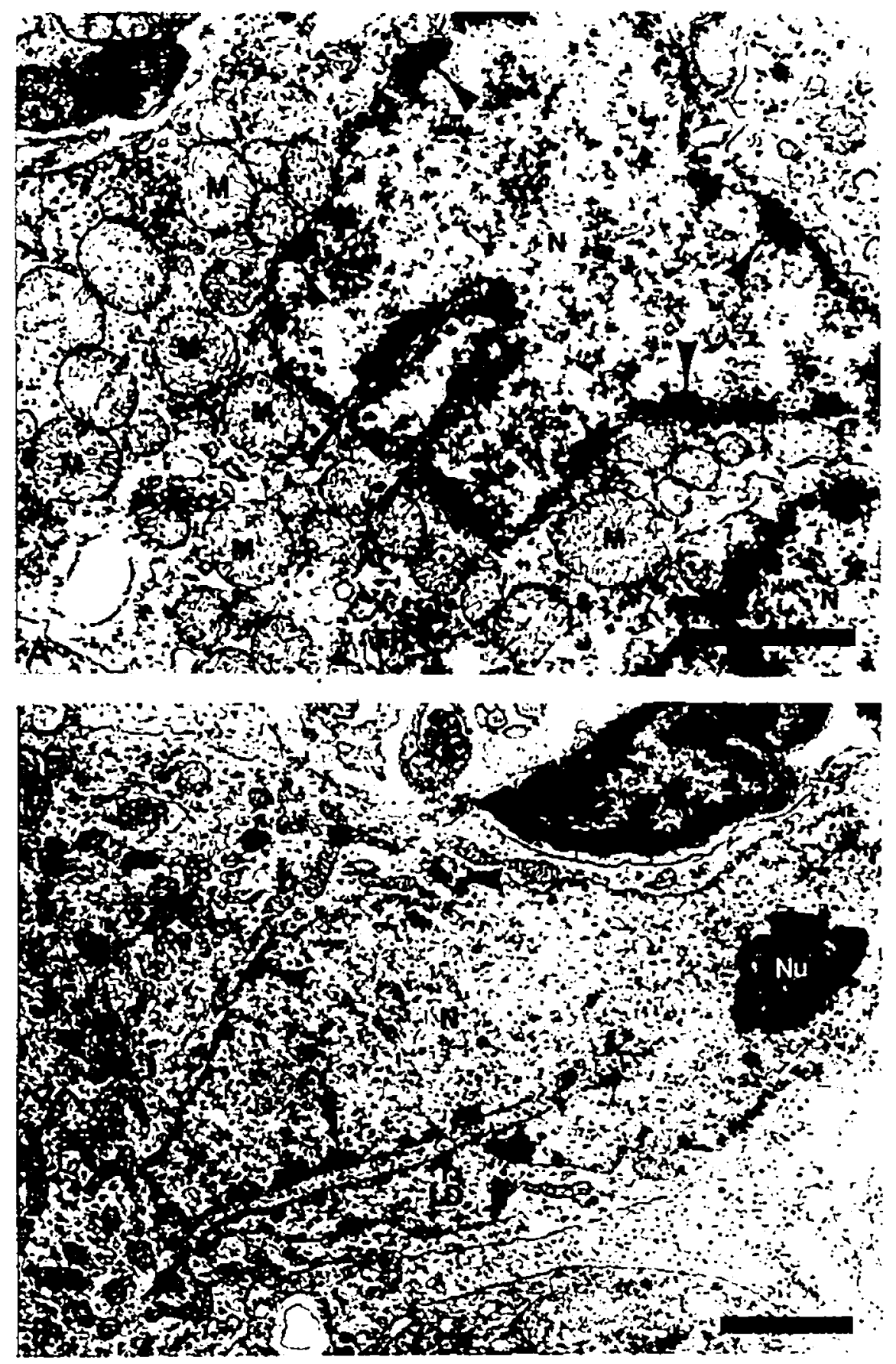
These were easily identified by their content of cytoplasmic organelles and by the fact that they were bound to membranes that were continuous with the nuclear envelope (Fig. 13B; 14A; 23A) .

CYTOPLASM

In addition to having organelles common to many other cell types, pinealocytes in the grafts demonstrated features indicative of active secretory processes, including dense-core and clear vesicles as well as vacuoles containing flocculent material. Distinctive structural characteristics of pinealocytes, such as synaptic ribbons and myeloid bodies, were often observed in grafted cells.

Free ribosomes were distributed throughout the cytoplasm including the polar processes (Fig. 13A; 15A; 21C). Only a minority of ribosomes were found associated with rough endoplasmic reticulum (RER, Fig. 15C; 17B). Centrioles were occasionally identified in the pinealocytes of the grafts (Fig. 14A-B), while Golgi apparati were well-developed and often observed in the pineal grafts. Flattened or dilated cisternae of the Golgi apparatus were associated with numerous vesicles of varying diameters (Fig. 14B; $15 ; 16 \mathrm{~A}$ ). Most of the vesicles were clear and measured 50-200 $\mathrm{nm}$ in diameter. Dense-core vesicles, 100-180 $\mathrm{nm}$ in diameter, were also present. As in most grafted pinealocytes, mitochondria were abundant (Fig. 13A; 14A; 16A; 17A). Some mitochondria were 


\section{Figure 14}

Electron micrographs showing organelles of the pinealocytes following transplantation into the third cerebral ventricle. (B) is the enlargement of the rectangular area in (A). Cn, centriole; GA, Golgi apparatus; LD, lipid droplet; $M$, mitochondria; $N$, nucleus; $\mathrm{PT}$, polar terminal of pinealocyte; SR, synaptic ribbon. Arrowheads in (B) indicate vacuoles containing a flocculent material. Asterisk shows a synaptic ribbon field. (Scale bars $=$ (A) $1 \mu \mathrm{m}$, (B) $0.5 \mu \mathrm{m}$, (C) $1 \mu \mathrm{m})$. 


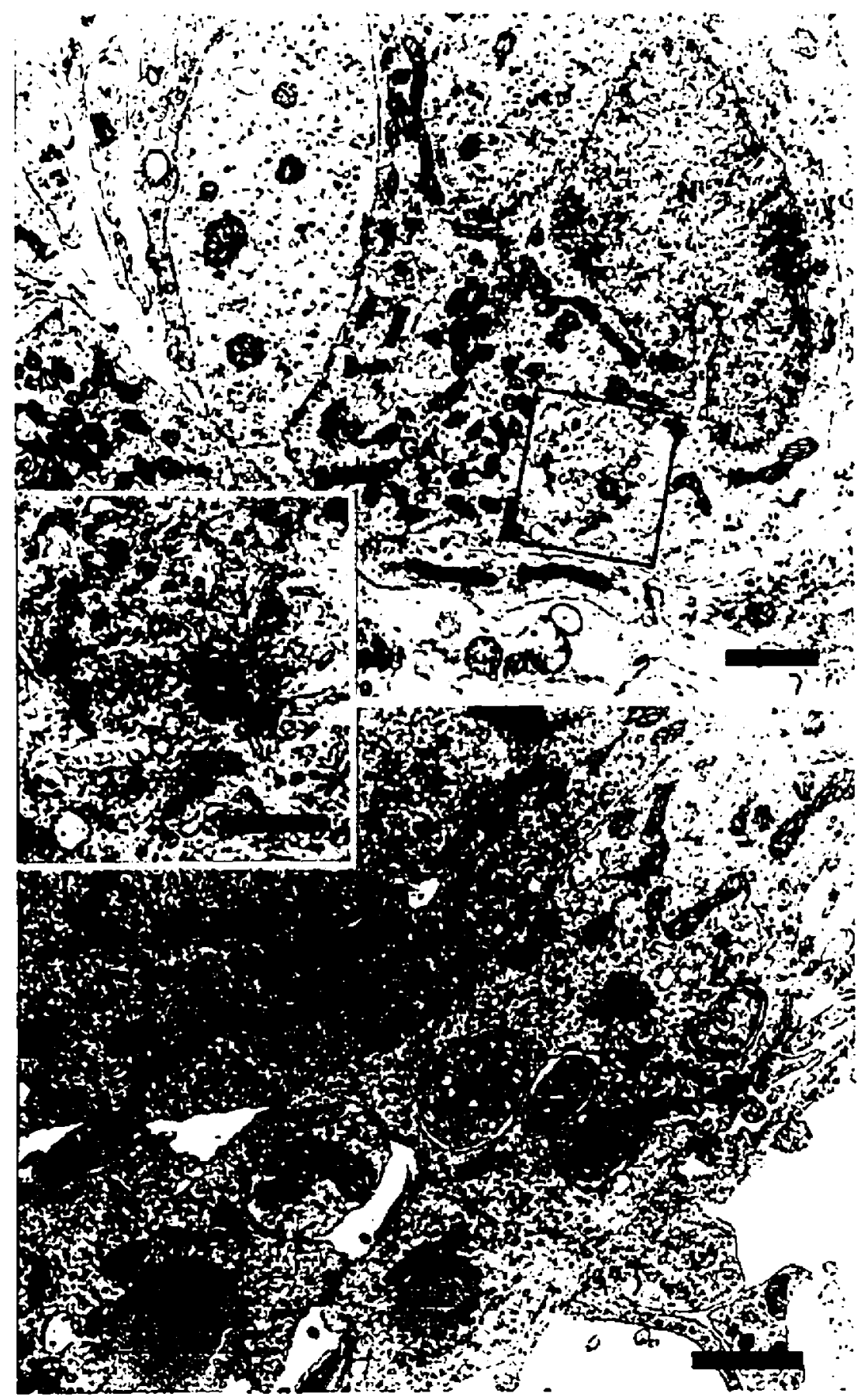


very large, 3-4 $\mu \mathrm{m}$ long and up to $2 \mu \mathrm{m}$ wide (Fig. 16B). The paired membranes of the mitochondrial envelope were difficult to trace continuously around many mitochondrial profiles (Fig. $13 \mathrm{~A} ; 17 \mathrm{~A})$.

Smooth and rough endoplasmic reticulum (SER and RER) were frequently observed in the pinealocytes of the graft. (Fig. 12; 13B; 15C; 16A; 23B). However, compared with Golgi apparatus and mitochondria, RER and SER were relatively fewer.

Other commonly observed organelles in the pineal grafts included lipid droplets (Fig. 14C-D; 15A; 20D), Iysosomes (Fig. 16A; 17B), and clear and dense-cord vesicles (Fig. 18; $19 A ; 20)$.

The most frequently observed distinctive organelles in the pinealocytes were synaptic ribbons and synaptic ribbon fields (Fig. 14C; 15A; 20D; 21; 23A). Synaptic ribbons consisted of a dense central core, $100 \mathrm{~nm}-150 \mathrm{~nm}$ in diameter. A ring of clear vesicles crowned the central core. Each vesicle was about $40-50 \mathrm{~nm}$ in diameter, and $20-30 \mathrm{~nm}$ from the neighboring vesicles and the central core (Fig. 21). Synaptic ribbons were found located in the perikaryon (Fig. 7A; 14C) as well as the polar processes (Fig. 10B; 11B) and polar terminals (Fig. 19C) of the pinealocytes. 
Figure 15

Electron micrographs exhibiting organelles of pinealocytes following transplantation into the third cerebral ventricle. GA, Golgi apparatus; FR, free ribosome; LD, lipid droplet: LY, lysosome: $M$, mitochondria; PS, perivascular space; C, capillary; En, endothelial cell; RER, rough endoplasmic reticulum; SER, smooth endoplasmic reticulum; SR, synaptic ribbon. Arrowheads in (A) indicate vacuoles containing flocculent material. (Scale bars $=$ (A) $1 \mu \mathrm{m} ;$ (B) $0.5 \mu \mathrm{m}$; (C) $1 \mu \mathrm{m})$. 


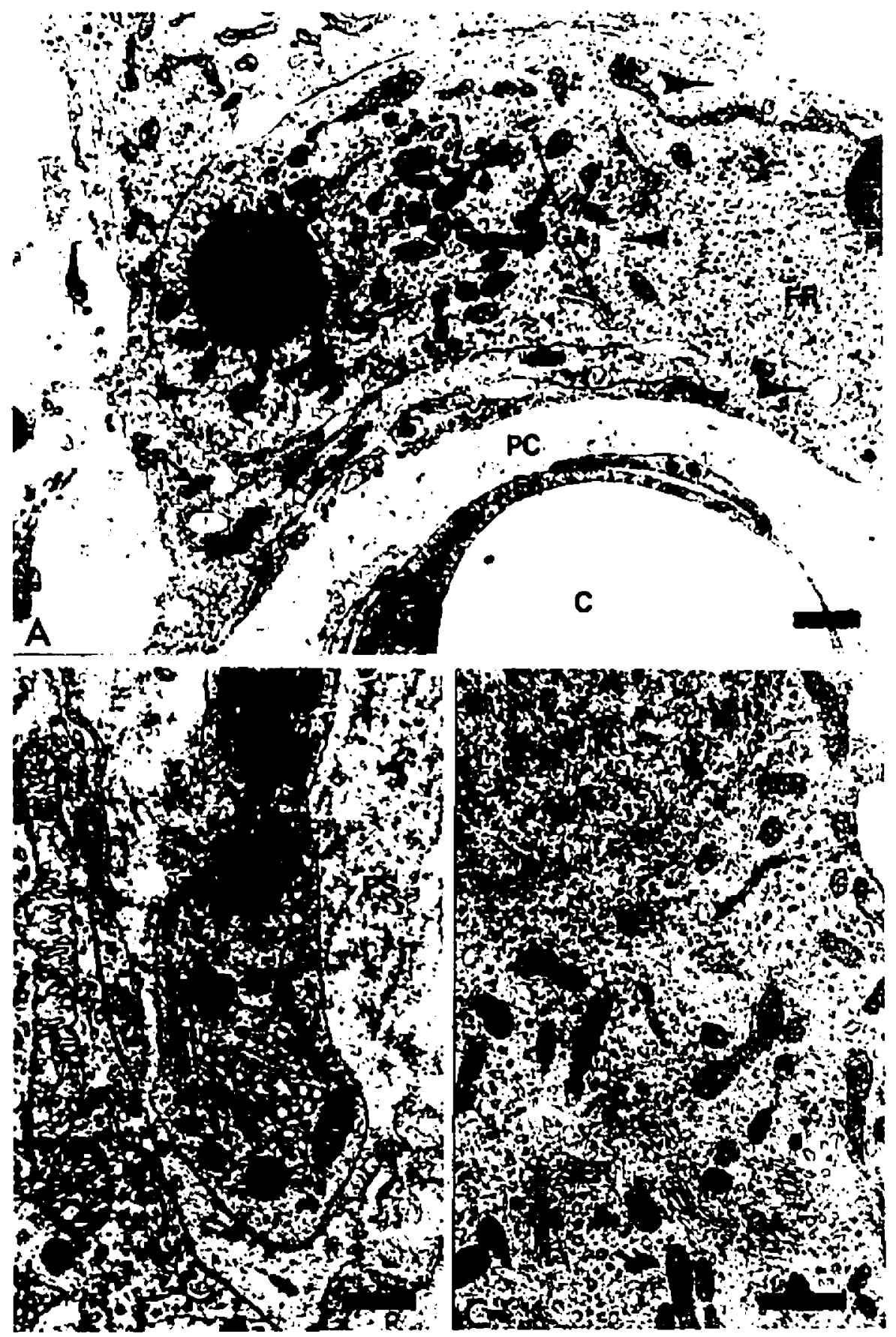


Figure 16

Electron micrographs showing organelles of pinealocytes following transplantation into the third cerebral ventricle. A very large mitochondrion $(M)$ is observed in (B). GA, Golgi apparatus: $M_{1}$, mitochondria; $N$, nucleus; $N u$, nucleoli; $L y$, lysosome; RER, rough endoplasmic reticulum, SER, smooth endoplasmic reticulum. (Scale bars $=$ (A) $1 \mu \mathrm{m}$, (B) $1 \mu \mathrm{m}$ ). 

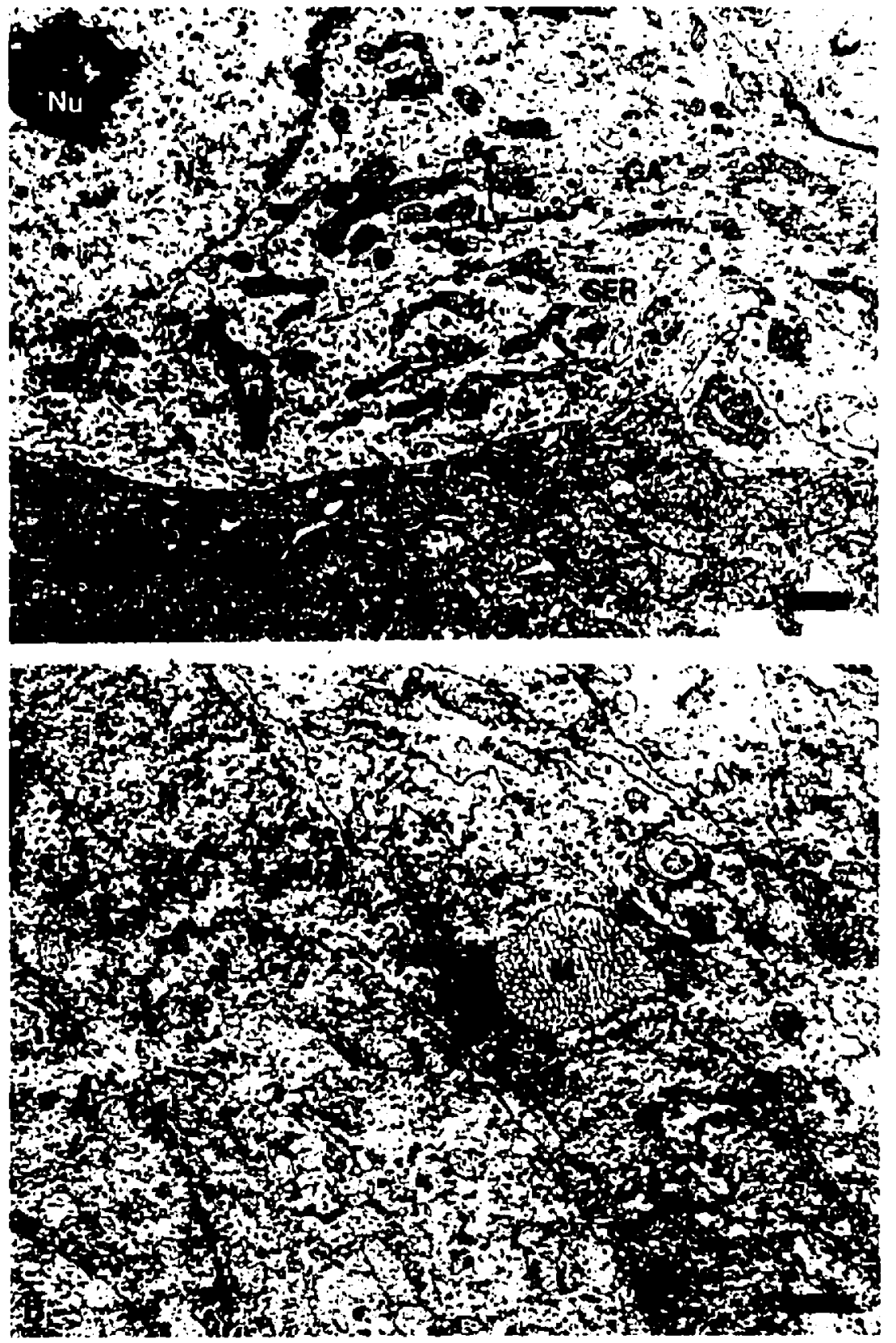
Figure 17

Electron micrographs showing organelles of the pinealocytes following transplantation into the third cerebral ventricle. DP, "Dark" appearing pinealocytes; LP, "Light" appearing pinealocyte; $N$, nuclei of pinealocytes; $\mathrm{Nu}$, nucleoIi; M, mitochondria; DCV, dense core vesicles; LY, Iysosome; RER, rough endoplasmic reticulum; PS, perivascular space; A, axons; VF, vacuoles containing flocculent material. Arrowheads in (B) indicate clear vesicles in the cytoplasm of pinealocyte. (Scale bars $=$ (A) $0.5 \mu \mathrm{m}$, (B) $1 \mu \mathrm{m}$ ). 

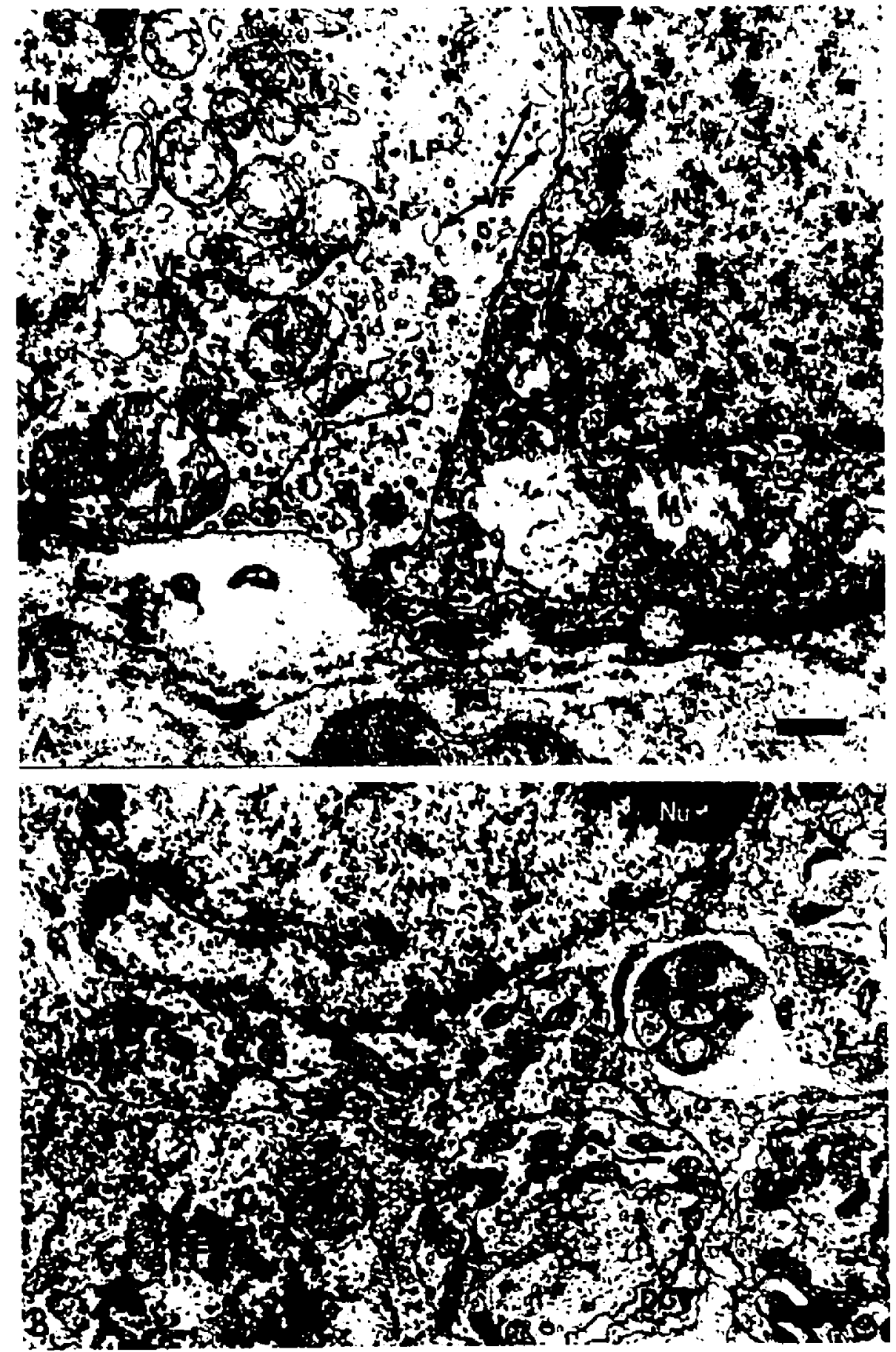
Vacuoles containing a flocculent material were often found in the pinealocytes of the grafts (Fig. 14; 17A; 19AB). other organelles of the pinealocytes found in the grafts included myeloid bodies (Fig. 22) and inclusion body (Fig. 23) .

POLAR TERMINAL OF THE PINEALOCYTES

Polar terminals of the pinealocytes in the grafts were found to terminate on the perivascular spaces (Fig. 8; 18; $19 A-B ; 20 C-D$ ) and in the intercellular spaces (Fig. 11). Some polar terminals were observed to terminate between pinealocytes (Fig. 19C-D; 20A-B; 23B). A typical polar terminal of pinealocytes was composed of large numbers of various sized clear vesicles (microvesicles), $40-200 \mathrm{~nm}$ in diameter, dense-core vesicles, and vacuoles containing flocculent material (Fig. 20). Some polar terminals also contained mitochodia (Fig. 19A). Occasionally synaptic ribbons were found in the polar terminals (Fig. 19C). The main difference between polar terminals and nerve endings was that the polar terminals contained large numbers of various sized clear vesicles (Fig. 20; 23B), while nerve terminals always contained equal sized clear vesicles (Fig. 2OB; 26). 
Figure 18

Electron micrographs showing the polar terminals of pinealocytes in the grafts. Polar terminals of pinealocytes (PT) terminate on the perivascular spaces (PS). Dense core vesicles (DCV) are present in the polar terminals. Arrowheads in (B) indicate belt desmosomes between polar terminals (PT) and polar process (PP), or between polar process and cytoplasm of the pinealocyte. $G$, glial cell; $N$, nucleus; $\mathrm{Nu}$, nucleoli; M, mitochondira. (Scale bars $=$ (A) $2 \mu \mathrm{m}$, (B) $1 \mu \mathrm{m}$ ). 

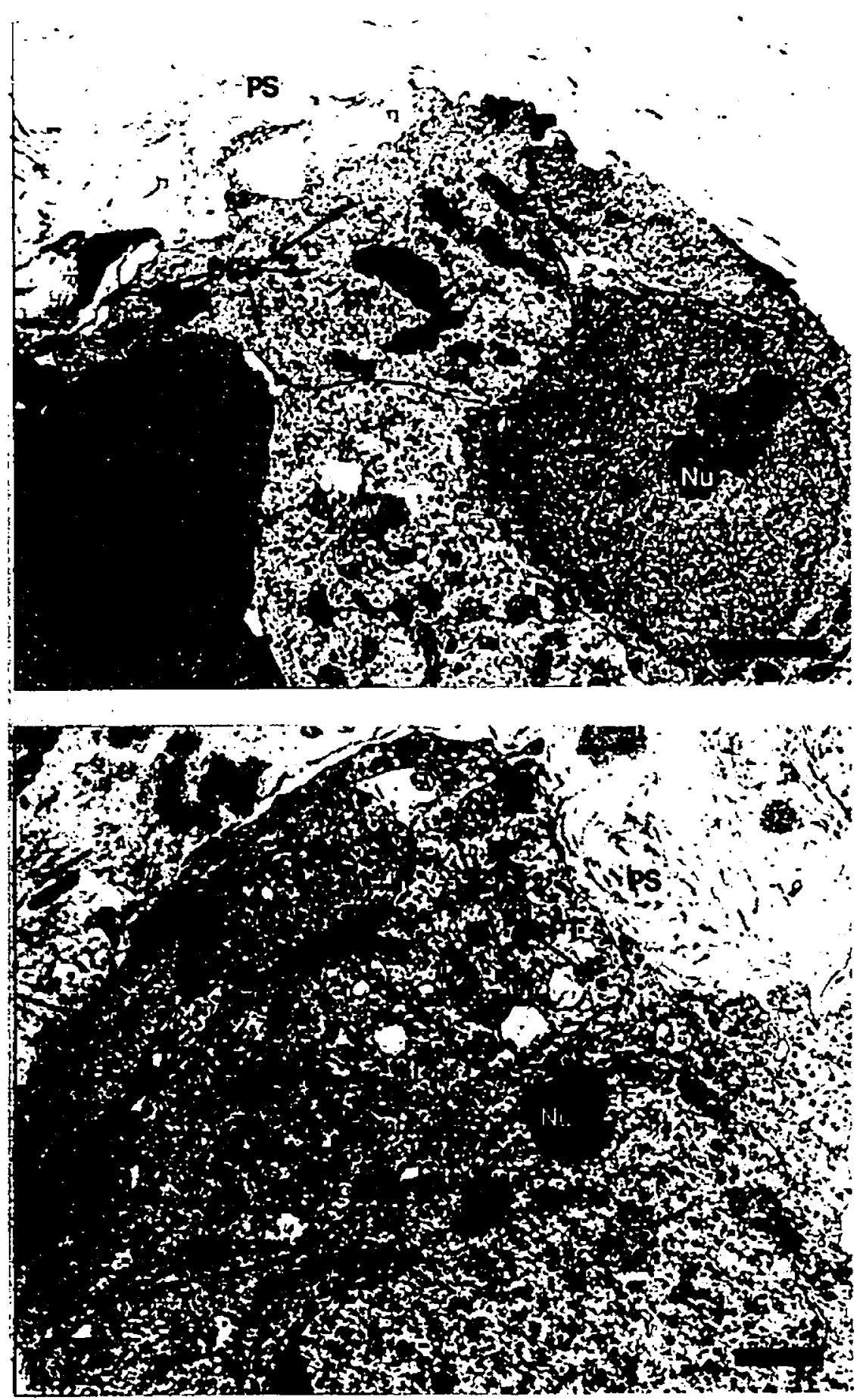
Figure 19

Electron micrographs showing polar terminals of pinealocytes in the grafts. (A) and (B) show that polar terminals (PT) are located within the perivascular spaces (PS). C, capillaries; En, endothelial cell of the capillaries; $M$, mitochondria; $N$, nucleus; PC, pinealocyte; $R$, red blood cell; SR, synaptic ribbon; VF, vacuoles containing a flocculent material. (C) and (D) show the polar terminals () T) between pinealocytes. The polar terminals contain large numbers of clear vesicles. A synaptic ribbon (SR) is present in a polar terminal in (C). Arrowhead in (C) indicates a belt desmosome. (Scale bars $=$ (A) $0.5 \mu \mathrm{m} ;$ (B) $1 \mu \mathrm{m} ;$ (D) $0.5 \mu \mathrm{m}$ ). 


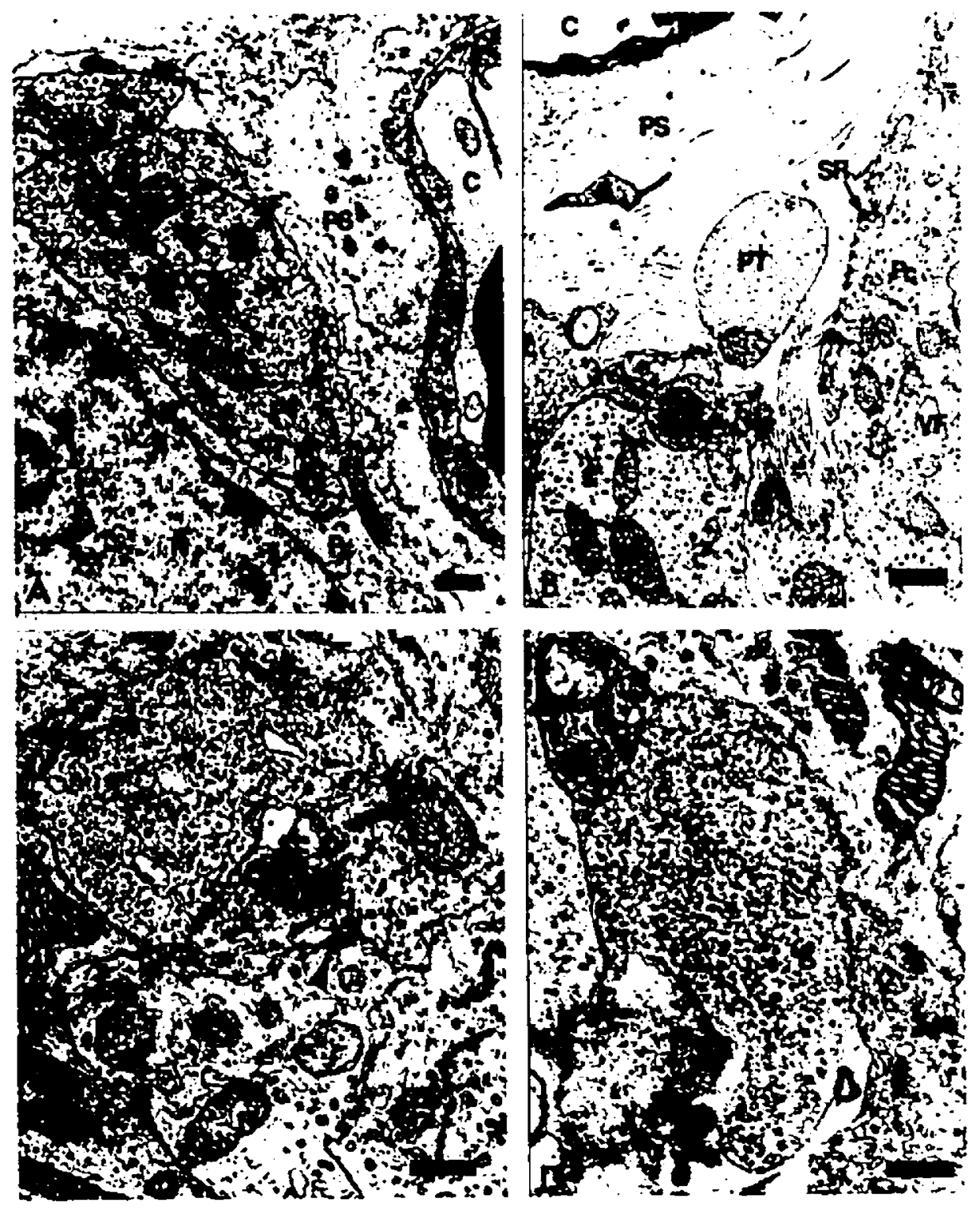


Figure 20

Electron micrographs showing the polar terminals of pinealocytes in the grafts. These polar terminals (PT) contain large numbers of clear vesicles (Arrowheads) and a few dense core vesicles (DCV). A, axons; DS, distal segment; LY, lysosome; LD, lipid droplet; $N$, nucleus; En, endothelial cell; SR, synaptic ribbon. (Scale bars $=$ (A) $1 \mu \mathrm{m}$, (B) $1 \mu \mathrm{m}$, (C) $0.5 \mu \mathrm{m}$, (D) $1.0 \mu \mathrm{m}$ ). 


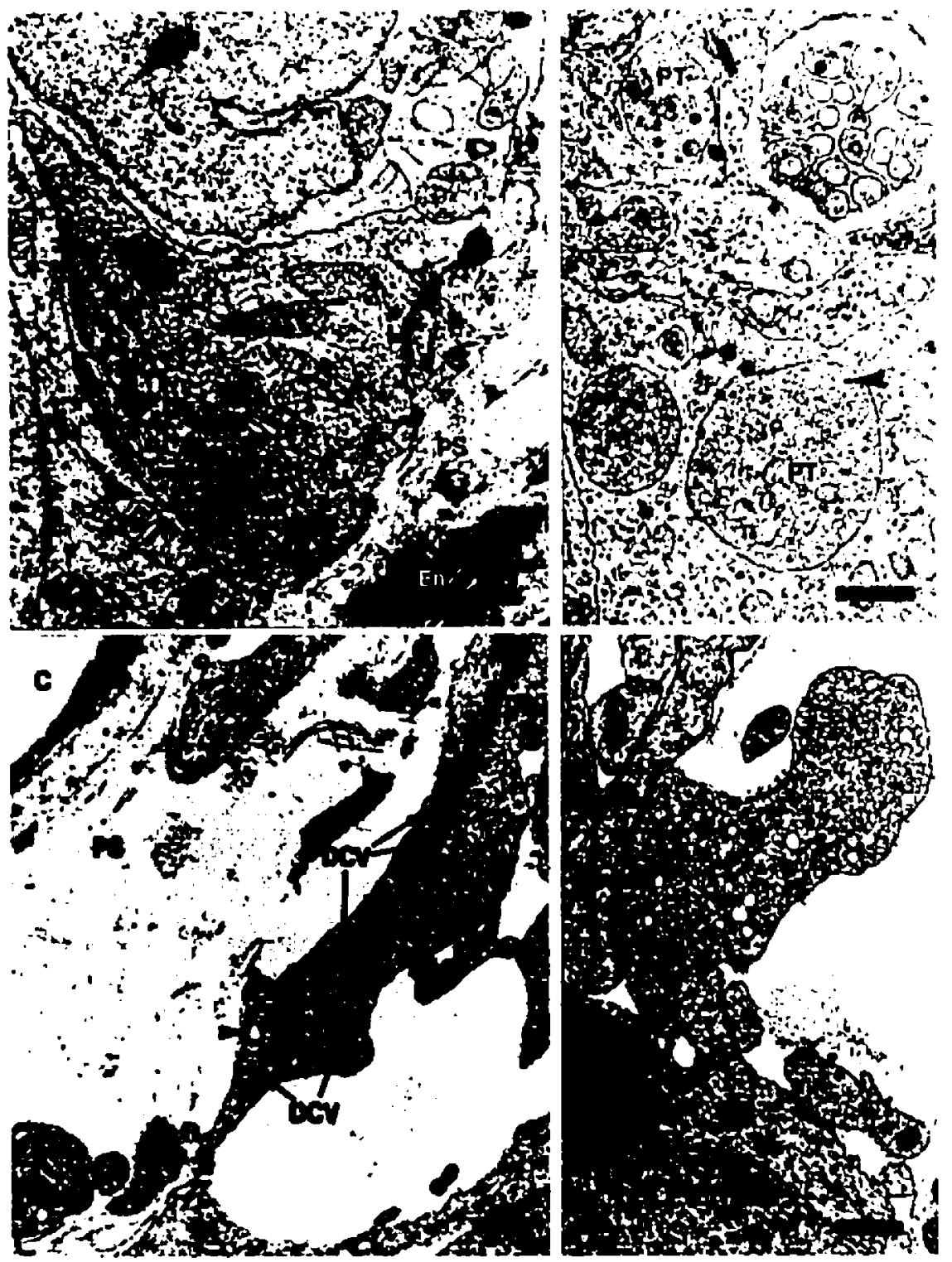


Figure 21

Electron micxographs of the graft in the third cerebral ventricle showing a distinctive organelle, the synaptic ribbon. (A) a cross section of a synaptic ribbon (arrow) is identified within the polar terminal (PT). (B) is the enlargement of the rectangular area from (A). A vacuole containing flocculent material (VF) is identified next to the synaptic ribbon (SR). (C) two cross sections of synaptic ribbons (SR) are found in the pinealocyte. A vacuole containing flocculent material (VF) is identified next to the synaptic ribbons. FR, free ribosomes; GA, Golgi apparatus; $M$, mitochondria; ID, lipid droplet. (Scale bars $=$ (A) $0.5 \mu \mathrm{m}$; (B) $0.5 \mu \mathrm{m} ;$ (C) $0.5 \mu \mathrm{m}$ ). 


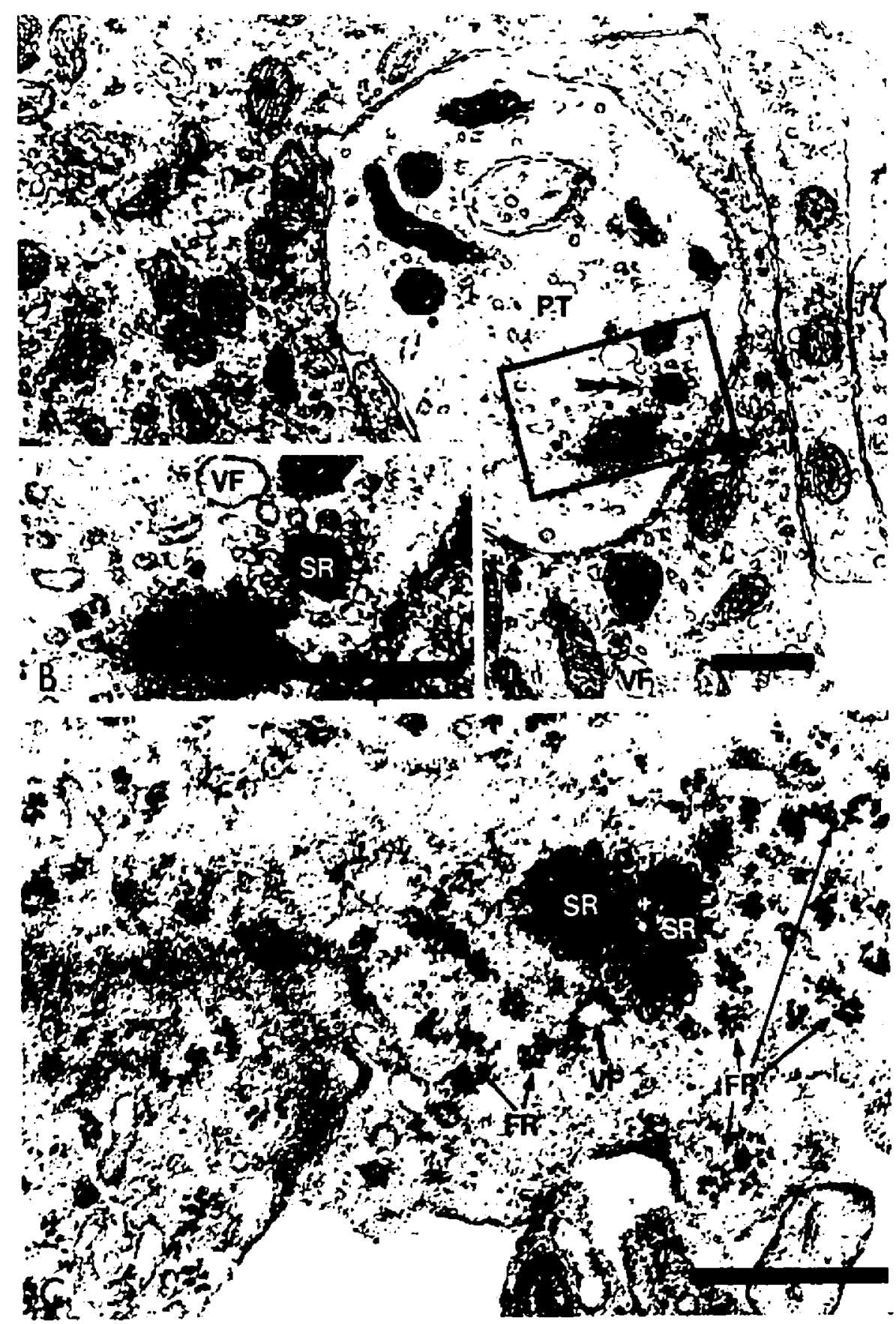




\section{Figure 22}

Electron micrographs of the pineal graft in the third cerebral ventricle showing organelles, such as, the myeloid bodies, in pinealocytes. MB, myeloid body; GA, Golgi apparatus; VF, vacuole containing flocculent material; PS, perivascular space; PP, polar processes of pinealocytes; $C$, capillary. Arrow in (B) indicates a tight junction between the endothelial cells of the capillary. (Scale bars $=$ (A) $1 \mu \mathrm{m}$; (B) $1 \mu \mathrm{m})$. 


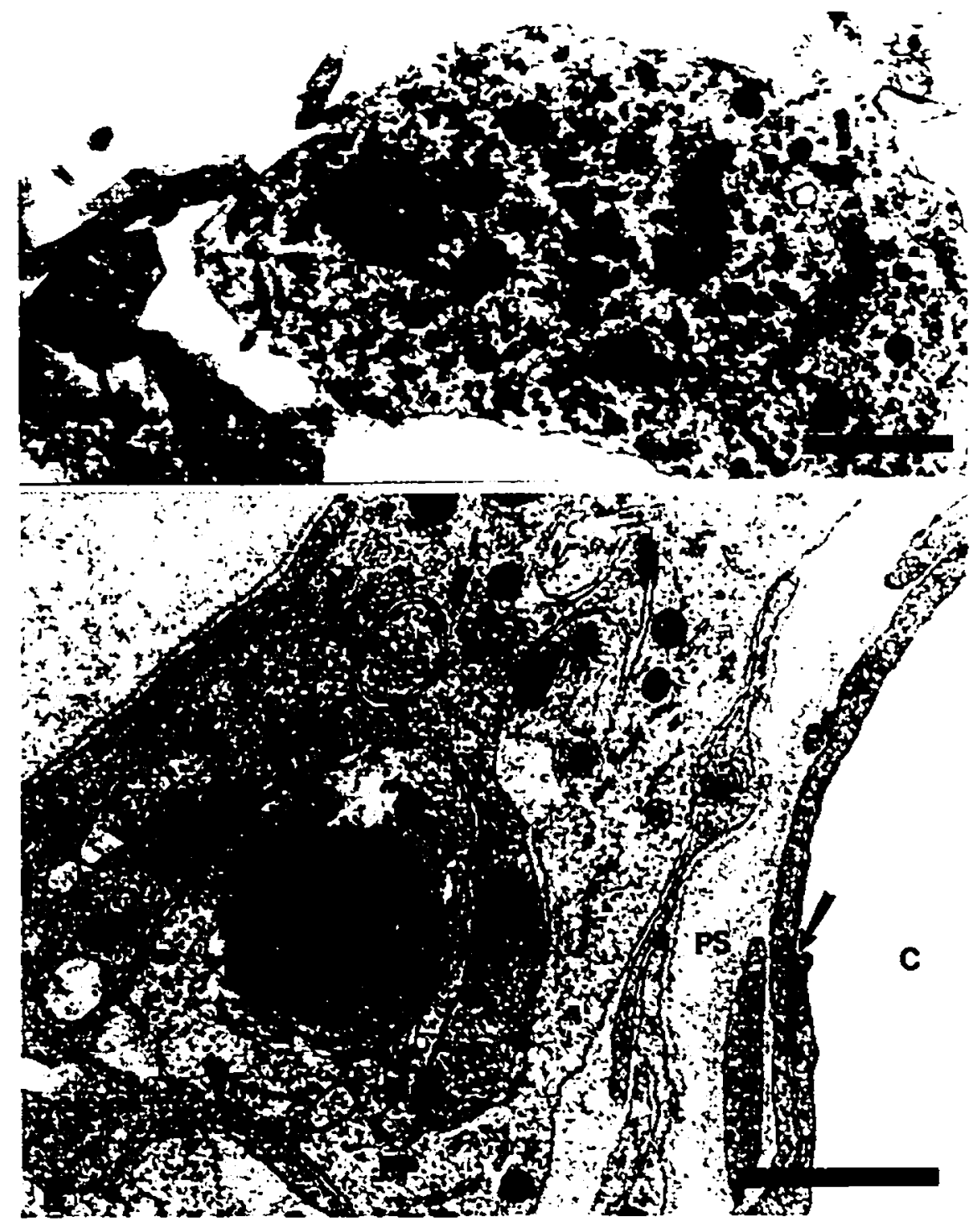


Figure 23

Electron micrographs of pineal graft in the third cerebral ventricle showing a distinctive organelle, the inclusion body (IB), in the pinealocyte. Asterisks in (A) indicate the cytoplasmic invagination of the nucleus. Two mitochondria (Arrowheads) are found within the folds of the nuclear membrane. $G$, glial cells; $M$, mitochondria; $N$, nucleus; IS intercellular space; PS, perivascular space; PT, polar terminal of pinealocytes; SER, smooth endoplasmic reticulum; SR, synaptic ribbon; VF, vacuole containing flocculent material. (Scale bars $=$ (A) $1 \mu \mathrm{m} ;$ (B) $1 \mu \mathrm{m}$ ). 

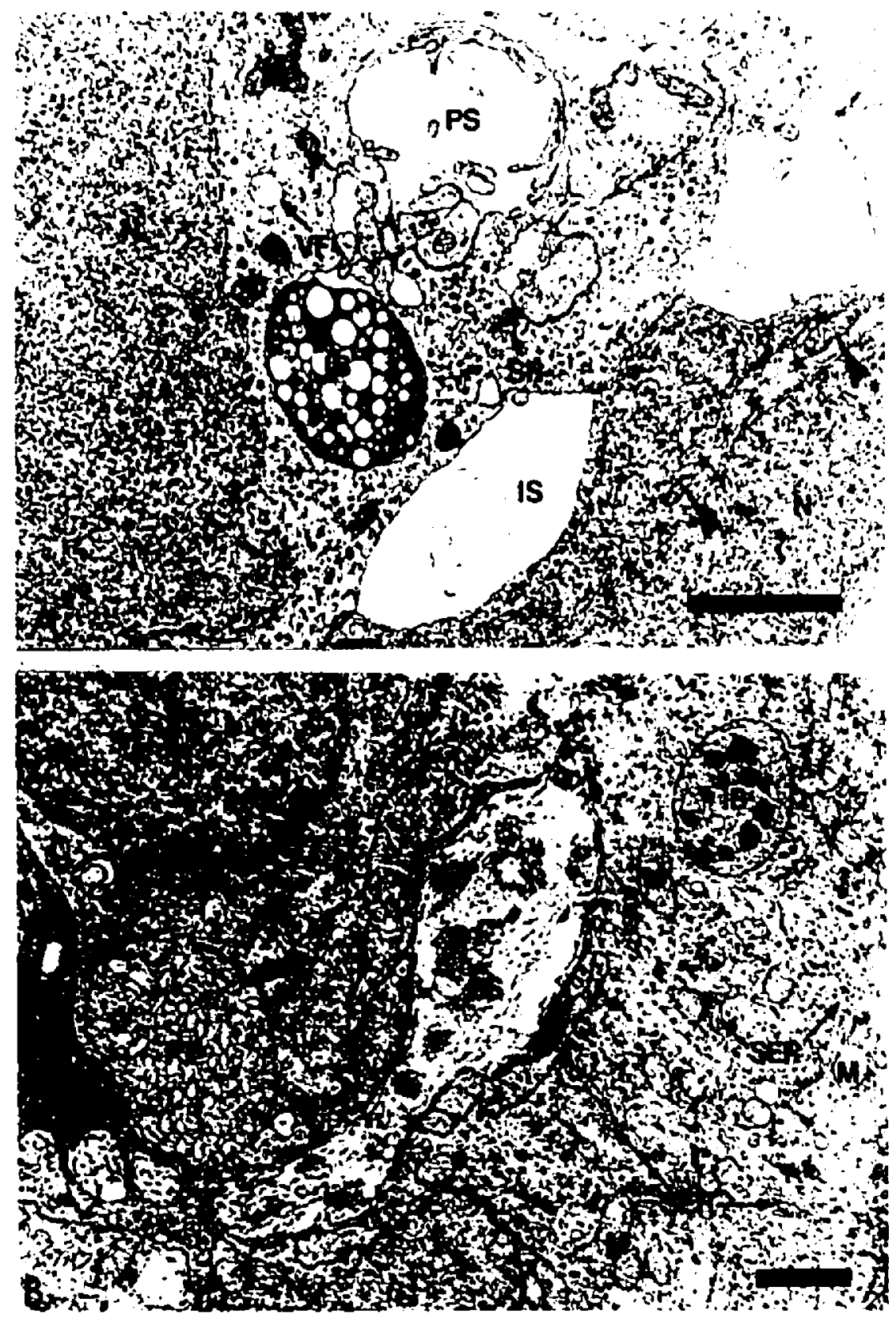
4. Innervation of the grafts

With light microscopic immunocytochemistry using antiserum against tyrosine hydroxylase (TH), TH-immunoreactive nerve fibers were densely distributed in the host hypothalamus. In most observed sections, these TH-immunoreactive nerve fibers appeared concentrated around the grafts but were not seen entering into the parenchyma of the graft (Fig. 24A). However, a few $T H$ positive nerve fibers were quite often observed in the core of the graft (Fig. 24A-D). In some cases, TH positive fibers were found to enter into the graft from the host median eminence below (Fig. 24C) . Occasionally, large numbers of $\mathrm{TH}$ immunoreactive nerve fibers were observed to grow into the graft from host hypothalamus through the lateral wall of the third cerebral ventricle adjacent to the paraventricular nuclei (Fig. 24B). TH positive nerve fibers were often present in some areas of parenchyma of the graft and totally lacking in other areas of the same graft (Fig. $24 A)$.

With transmission electron microscopy (TEM), bundles of unnyelinated axons were observed in the grafts. These axons were usually located within the perivascular space (Fig. 25B; $26 \mathrm{~A}$ ) or between pinealocytes (Fig. 17B; 25A). Consistent with - light microscopic findings, unmyelinated axons were only present in some perivascular spaces and not in others (Fig. $7 ; 8 ; 10 A)$. These unmyelinated axons and terminals were 
Figure 24

Light micrographs of fifty micrometer-thick vibratome sections of pineal grafts following transplantation into the third cerebral ventricle showing the innervation of the grafts. Sections were prepared for ICC with antisera against tyrosine hydroxylase (TH) and counterstained with cresyl violet. (A) TH positive nerve fibers in the host hypothalamus (H) appear concentrated around the pineal graft (PG) within the third cerebral ventricle. These $T H$ fibers are not seen entering the parenchyma of the graft. A few $T H$ positive fibers are observed in the core of the pineal graft (arrow). (B) Large numbers of $\mathrm{TH}$ positive nerve fibers (open arrows) are observed to enter into the pineal graft (PG) from the host hypothalamus $(\mathrm{H})$. Arrowhead indicates some pinealocytes which have migrated into the host brain. Asterisks show the boundary between the graft and the host. (C) $\mathrm{TH}$ fibers (arrowheads) are seen entering into the graft (PG) from the host median eminence (ME). Asterisks indicate the interface between the graft and the host. $v$, the third cerebral ventricle. (D) Th positive nerve fibers are observed between the pinealocytes in the graft (arrows). (Scale bars = (a) 50 $\mu \mathrm{m} ;$ (B) $25 \mu \mathrm{m} ;$ (C) $10 \mu \mathrm{m}$; (D) $10 \mu \mathrm{m})$. 

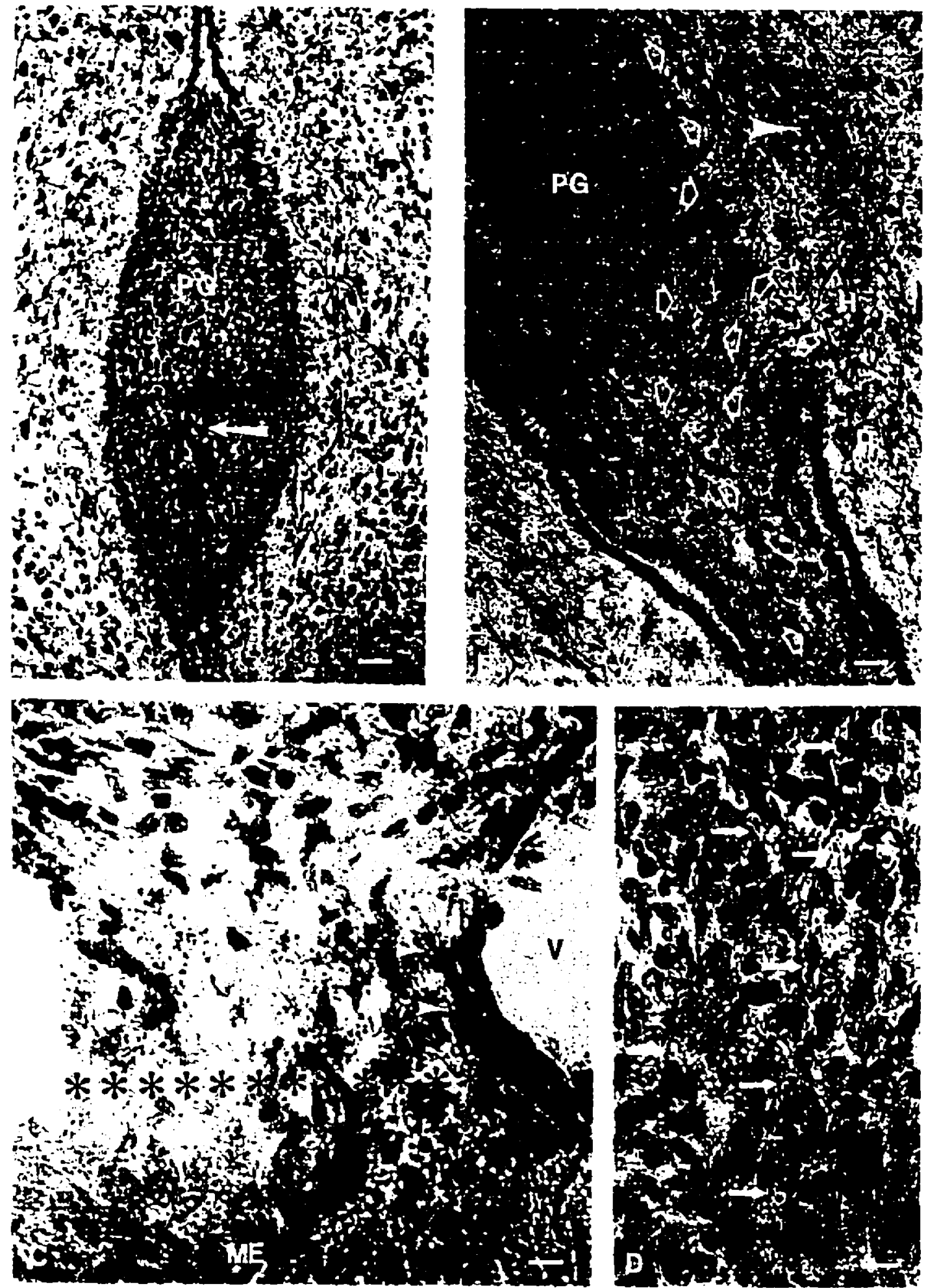
Figure 25

Electron micrographs of the pineal graft in the third cerebral ventricle showing the innervation of the graft. Bundles of unmyelinated axons (A) are found in the intercelIular space (IS) between the pinealocytes in (A) and within the perivascular space (PS) in (B). PC, pinealocytes; PP, polar processes; $M$, mitochondria. (Scale bars $=$ (A) $1 \mu \mathrm{m}$, (B) $1 \mu \mathrm{m})$. 


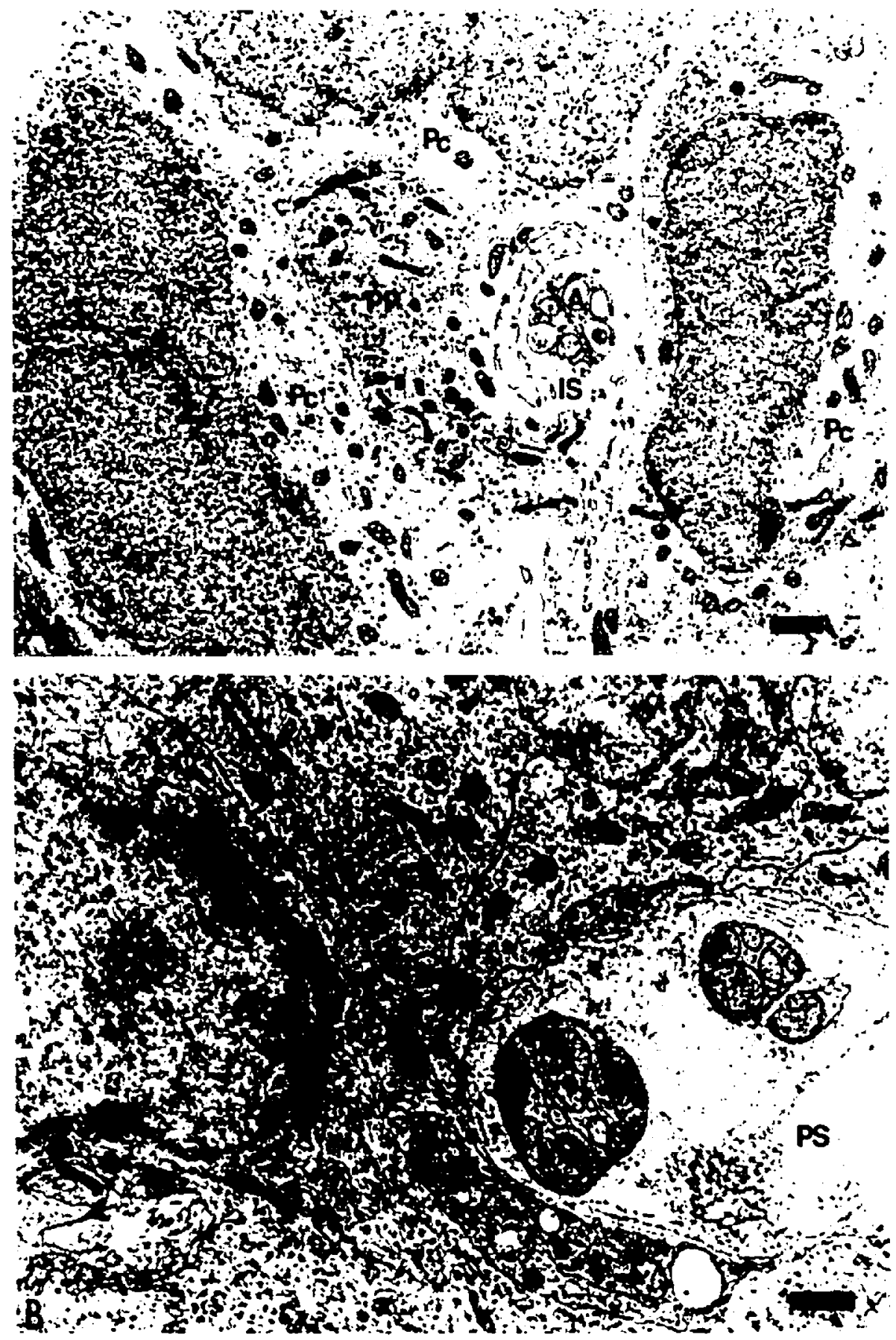


Figure 26

Electron micrographs of the pineal graft in the third cerebral ventricle demonstrating the innervation of the graft. (A) Bundies of unmyelinated axons (A) which contain clear and dense core vesicles are observed within the perivascular space (PS) of a capillary (C). G, glial cell; CF, collagen fibers. (B) Numerous apparent adrenergic nerve terminals (T) are observed within the perivascular space (PS) in the graft. (C) A polar process (PP) and a polar terminal (PT) of a pinealocyte and two adrenergic nerve terminals (T) are found in the perivascular space (PS). LD, lipid droplet; CF, collagen fibers. (Scale bars $=$ (A) I $\mu$ mi (B) $1 \mu m ;$ (C) $1 \mu \mathrm{m}$ ). 


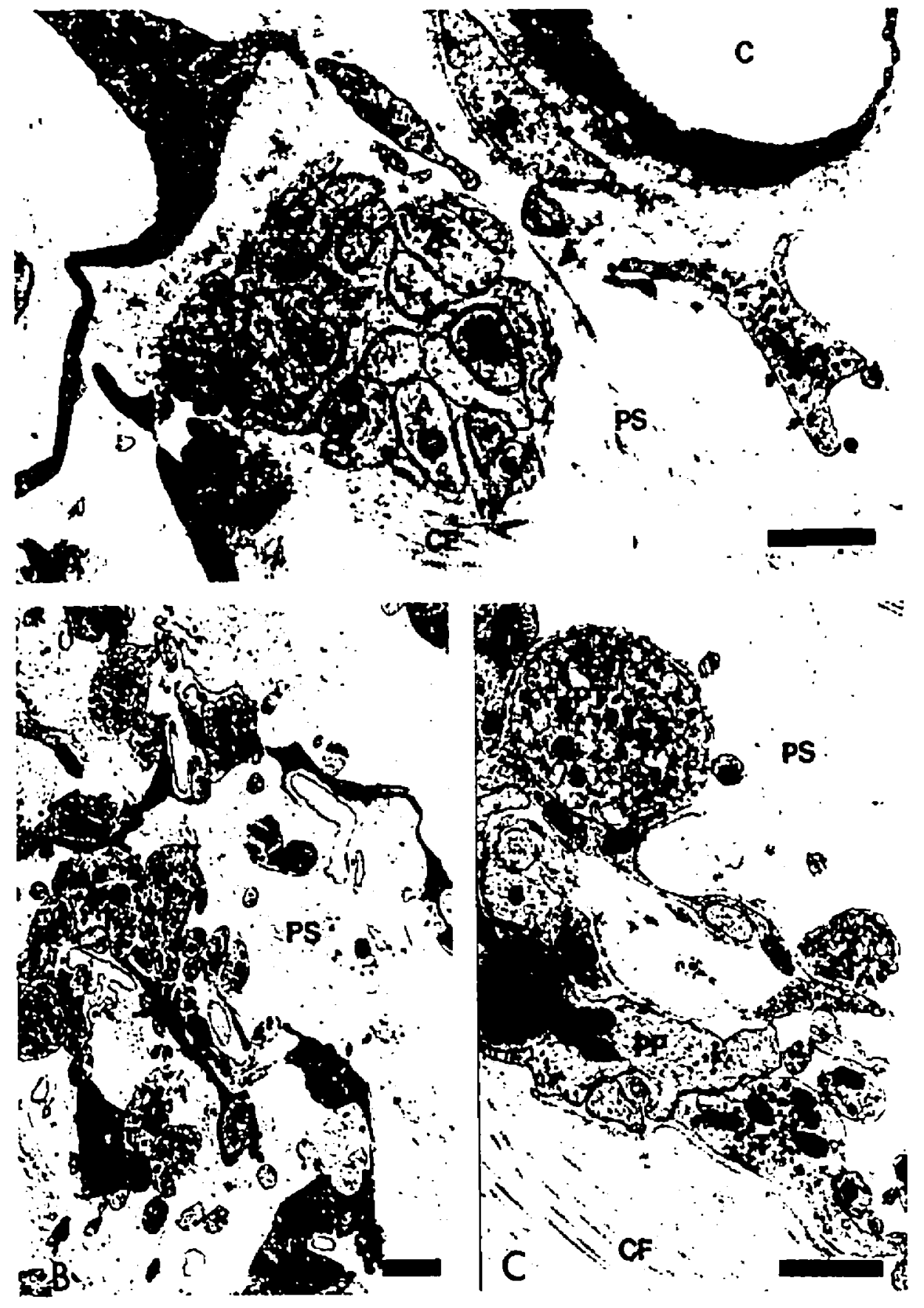


Figure 27

Electron micrographs of the pineal graft in the third cerebral ventricle. Apparent adrenergic nerve terminals (T) are found in close approximation with pinealocytes (PC). However, no true synapses are observed between them. $\mathrm{N}$, nucleus; $\mathrm{Nu}$, nucleoli. (Scale bars $=$ (A) $1 \mu \mathrm{m} ;$ (B) $1 \mu \mathrm{m} ;$ (C) $1 \mu \mathrm{m})$. 


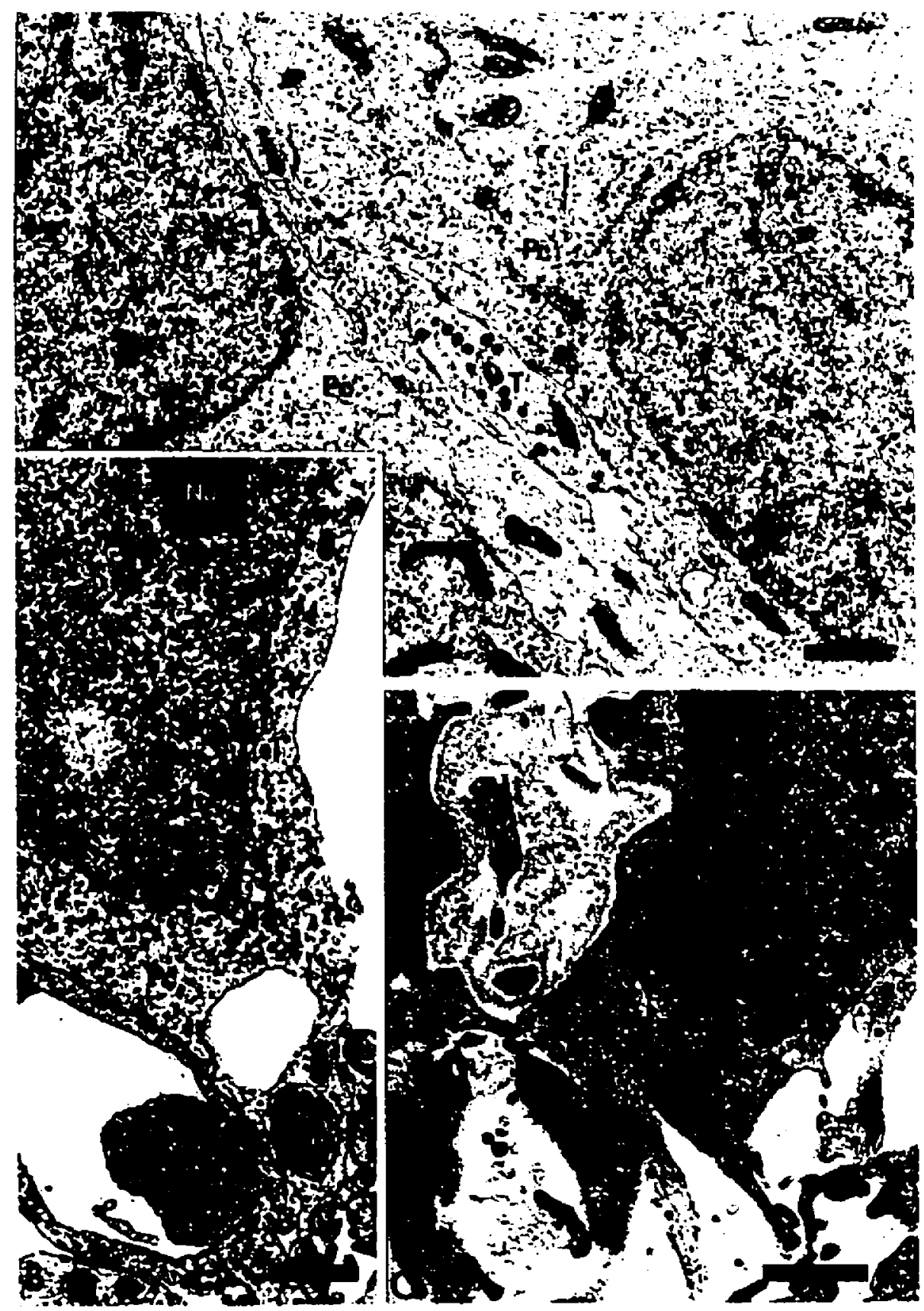


commonly observed to contain clear and dense-core vesicles (Fig. 26A-B-C). Apparent adrenergic nerve endings harboring numerous dense-core and clear vesicles were often found within the perivascular space and the intercellular space between pinealocytes (Fig. 26B-C). Although nerve endings appeared to physically terminate upon the pinealocytes, no true synapses could be identified (Fig. 27).

\section{DAY-NIGHT DIFFERENCE OF BERUY MELATONIN CONCENTRATION IN PINEALECTOMIZED RAT8 WITH PINEAL GRAFTING INTO THE TRIRD CEREBRAL VENTRICLE}

Seven of eight rats with pineal transplantation in this experiment met the criteria, i.e., pinealocytes survived and the grafts were located within the third cerebral ventricle. Figs. 28 and 29 demonstrate serum melatonin concentration of those animals and the normal controls as well as the pinealectomized rats without transplantation.

Nighttime serum melatonin concentration was significantly lower in pinealectomized rats of group $2(4.61 \mathrm{pg} / \mathrm{ml})$ than that of normal rats in group $1(44.96 \mathrm{pg} / \mathrm{ml}, \mathrm{p}<0.01)$. Pinealectomized rats with pineal transplantation in group 3 showed a significant increase in nighttime serum melatonin concentration $(19.86 \mathrm{pg} / \mathrm{ml})$ as compared with that of pinealectomized rats without transplantation in Group 2 ( $P<0.05)$. However, serum melatonin concentrations in those pineal 
Figure 28

Nighttime serum melatonin concentration after transplantation of pineal gland into the third cerebral ventricle. G1; (Group 1) animals in group 1 were normal controls. G2; (Group 2) animais in group 2 were pinealectomized rats which remained untreated (no-transplantation). G3; (Group 3) animals in group 3 were pinealectomized rats which received pineal transplants into the third cerebral ventricle. (*), $P<0.01$ versus $\mathrm{GI} ;(+), \mathbf{P}<0.05$ versus $\mathbf{G 2}$. 
NIGHTTIME SERUM MELATONIN COMCENTRATION

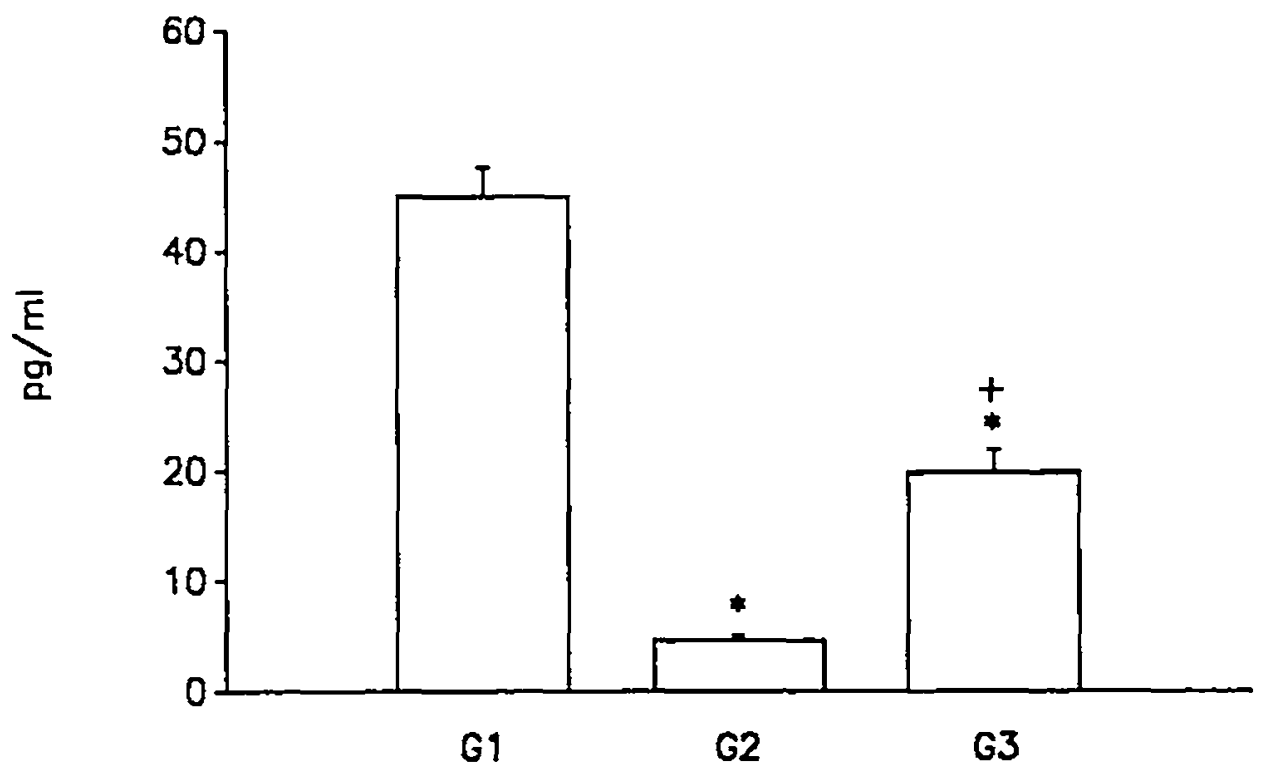




\section{Figure 29}

Day-night difference of serum melatonin concentration after transplantation of pineal gland into the third cerebral ventricle. GI; (Group 1) animals in group 1 were normal controls. G2; (Group 2) animals in group 2 were pinealectomized rats which remained untreated (no-transplantation). G3; (Group 3) animals in group 3 were pinealectomized rats which received pineal transplants into the third cerebral ventricle.

Day-night melatonin concentration was significantly different in the animais of group 1 , no day-night difference was observed in the other two groups. (*) $P<0.01$ versus daytime. 


\section{DAY-NIGHT SERUM MELATONIN CONCENTRATION}

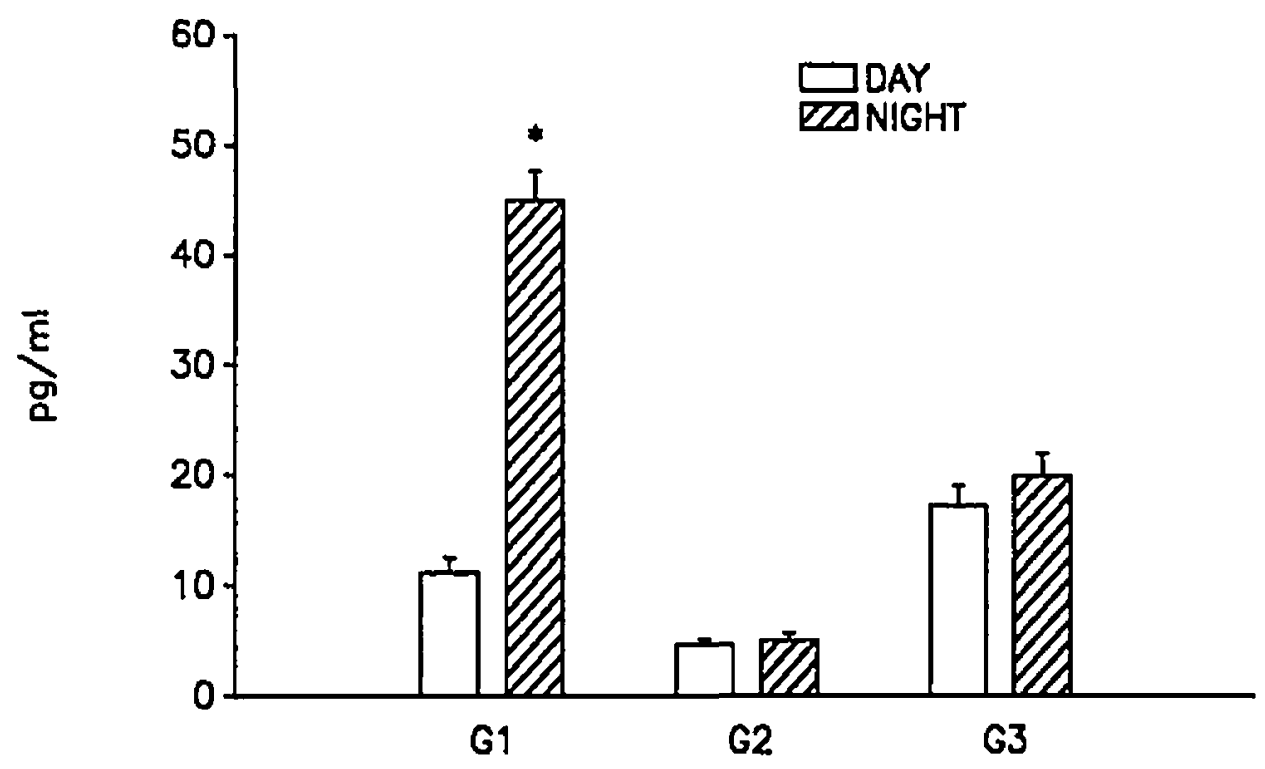


grafted rats was still significantly lower than that in the normal controls $(P<0.01)$ (Fig. 28).

Serum melatonin concentrations in samples from normal animals demonstrated a significant increase during nocturnal collections as compared to those garnered during the day time (P<0.01; Fig. 29). Although pineal transplantation in the third cerebral ventricle caused a significant increase in serum melatonin concentration, no day-night differences in serum melatonin concentrations were observed ( $P>0.05 ;$ Fig. 29).

3. FUNCTIONAL PARAMETERS AND BTRUCTURAL CORRELATES OF PINEAL GRAFTS FOLIOWING TRANBPLANTAMION INTO THE BELECTED 8ITES: THE THIRD CEREBRAL VENTRICLE, IN 8ITU (WHERE THE RINEAL GLAND IS NORMALEY LOCATED), THE ANTERIOR CHAMBER OF THE BYE, AND UNDER THE CAPSOLE OF THE RIDNEY.

All data were garnered from animals which met the following criteria: (1) pinealocytes survived in the grafts, (2) the graft was located in one of the following locations-1) the third cerebral ventricle (Fig. 3OA); 2) the anterior chamber of the eye (Fig. 30C); 3) beneath the renal capsule (Fig. 30D); or 4) between the cerebral cortex and the cerebel- lar cortex and above the tectum (Fig. 30B). 
Figure 30

Light micrographs showing the pineal grafts within the selected sites. (A), A pineal graft (PG) in the third cerebral ventricle (V). The graft is found to contact the lateral walls and the median eminence (ME) of the host (H) . (B), A pineal graft (PG) located between the cerebral cortex (Ce) and the cerebellum (Cb) and above the tectum. (C), A pineal graft (PG) located in the anterior chamber of the eye (AC) and contacting the host cornea (Co) above and iris (Ir) below. (D), A pineal graft (PG) in the renal capsule. Kd, kidney. (Scale bars $=$ (A) $50 \mu \mathrm{m} ;$ (B) $100 \mu \mathrm{m} ;$ (C) $40 \mu \mathrm{m} ;$ (D) $50 \mu \mathrm{m})$. 

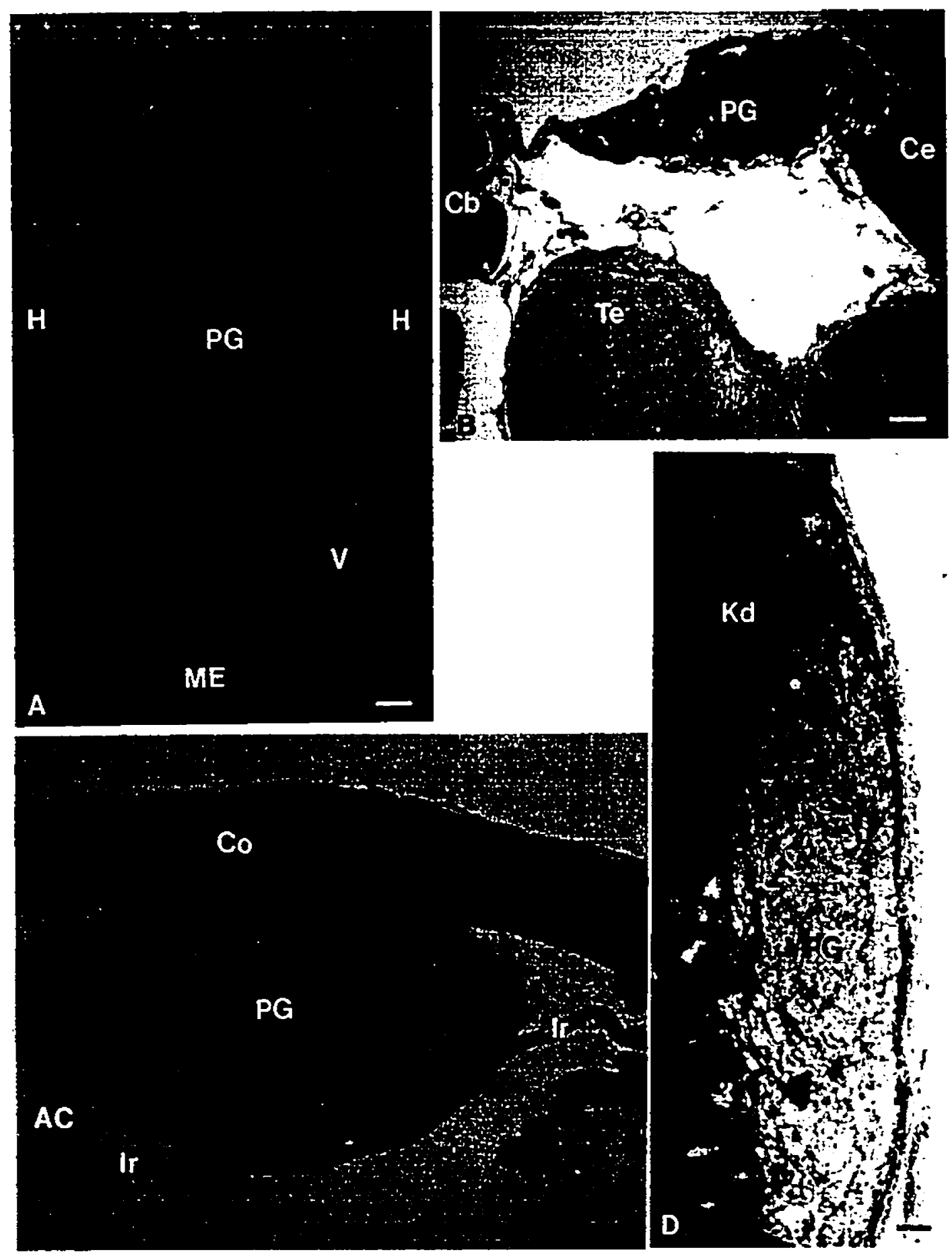


\section{(1) SERUM MELATONIN CONCENTRATION}

Fig. 31 shows nighttime serum melatonin concentration. Group 1 was the normal control (6 rats). Group 2 consisted of pinealectomized rats without treatment (no-transplantation, 8 rats). Animals in group 3 were pinealectomized rats which received pineal transplantation into the third cerebral ventricle. (Seven of eight rats were found to have surviving grafts within the third cerebral ventricle.) Group 4 were pinealectomized rats with pineal glands grafted in situ. In this latter case, only 5 of 8 host rats met the criteria. Half of the rats in group 5 , in which pinealectomized rats received pineal transplantation beneath the renal capsule, met the criteria. Animals in group 6 were pinealectomized rats with pineal transplantation into the anterior chamber of the eye. All animals in group 6 ( 8 rats) met the criteria.

Nighttime serum melatonin concentration of pinealectomized animals in group $2(7.36 \mathrm{pg} / \mathrm{mI})$ was significantly lower than that of the normal controls in group $1(46.97 \mathrm{pg} / \mathrm{ml}$, $P<0.01)$. No significant difference was observed in nighttime serum melatonin concentration between pinealectomized rats in group 2 and those receiving pineal transplantation in situ in group $4(18.53 \mathrm{pg} / \mathrm{ml}, \mathrm{P}>0.05)$ as well as those receiving pineal transplantation beneath the renal capsule in group 5 $(18.99 \mathrm{pg} / \mathrm{ml}, \mathrm{P}>0.05)$. Animals in group 3 with pineal grafts in the third cerebral ventricle, and those in group 6 with pineal transplants into the anterior chamber of the eye 
Figure 31

Nighttime serum melatonin concentration after transplantation of pineal gland into selected sites. G1; (Group 1) animals in group 1 were normal controls. G2; (Group 2) animals in group 2 were pinealectomized rats which remained untreated (no-transplantation). G3; (Group 3) animals in group 3 were pinealectomized rats which received pineal transplantation into the third cerebral ventricle. G4; (Group 4 ) animals in group 4 were pinealectomized rats with pineal transplantation in situ. G5; (Group 5) animals in group 5 were pinealectomized rats which received pineal transplantation beneath the renal capsule. G6; (Group 6) animals in group 6 were pinealectomized rats with pineal transplantation into the anterior chamber of the eye. (*) $\mathrm{P}<0.01$ versus $G 1$; (\#) $\mathbf{P}<0.05$ versus $\mathbf{G 2}$. 
NIGHTTIME SERUM MELATONIN CONCENTRATION

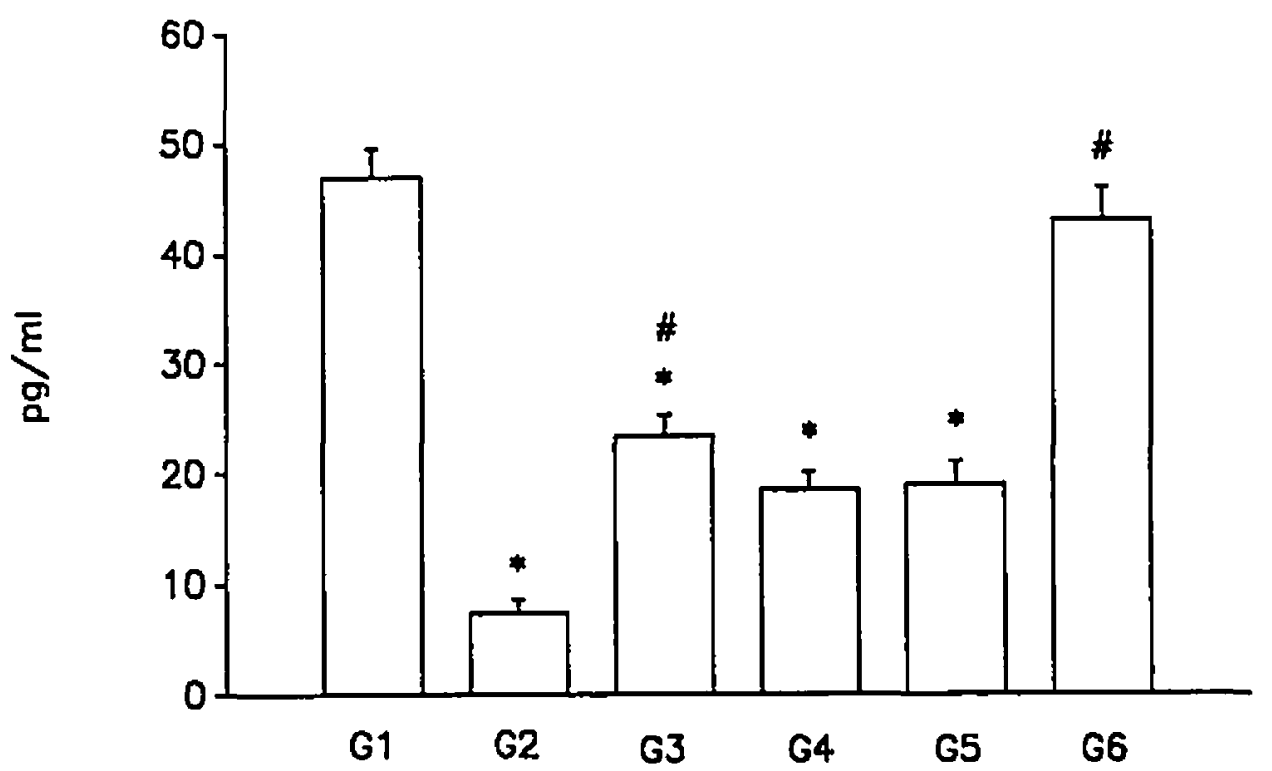


demonstrated a significant increase in the serum melatonin concentration when compared to that of pinealectomized animals in group $2 \quad(P<0.05)$. No significant difference was observed in serum melatonin concentration between animals receiving pineal transplantation into the anterior chamber of the eye $(43.09 \mathrm{pg} / \mathrm{ml})$ and that of normal controls $(46.97 \mathrm{pg} / \mathrm{ml}$, P>0.1).

Fig. 32 shows the day-night difference in serum melatonin concentration. Significant day-night differences in serum melatonin concentration with the higher level during the night was observed in the nomal control animals $(P<0.01)$. Although both pineal transplants into the third cerebral ventricle and the anterior chamber of the eye resulted in a significant increase in nighttime serum melatonin concentration, significant day-night difference in serum melatonin concentration with the higher levels at night was observed only in those animals that had received pineal transplants into the anterior chamber of the eye $(P<0.05)$. However, the difference between day and night in group 6 with pineal transplants into the anterior chamber of the eye was not as large as that in the normal control of group 1 . The day-night ratio of serum melatonin concentration was 1:2 in the former and 1:3.6 in the latter. Paradoxically, day time serum melatonin concentration in animals with pineal transplantation beneath the renal capsule was significantly higher than the nighttime one (day time $35.25 \mathrm{pg} / \mathrm{ml}$, nighttime $18.99 \mathrm{pg} / \mathrm{ml}$. $\mathrm{P}<0.05)$. No day- 
Figure 32

Day-night difference in serum melatonin concentration after transplantation of pineal gland into the selected sites. GI; (Group 1) animals in group 1 were normal controls. G2; (Group 2) animals in group 2 were pinealectomized rats which remained untreated (no-transplantation). G3; (Group 3) animals in group 3 were pinealectomized rats which received pineal transplants into the third cerebral ventricle. G4; (Group 4) animals in group 4 were pinealectomized rats with pineal transplants in situ. G5; (Group 5) animals in group 5 were pinealectomized rats which received pineal transplants beneath the renal capsule, G6; (Group 6) animals in group 6 were pinealectomized rats which received pineal transplants into the anterior chamber of the eye. (*) in G5 and G6, $P<0.05$ versus day time. (*) in $G 1, P<0.01$ versus day time. 
DAY-NIGHT SERUM MELATONIN CONCENTRATION

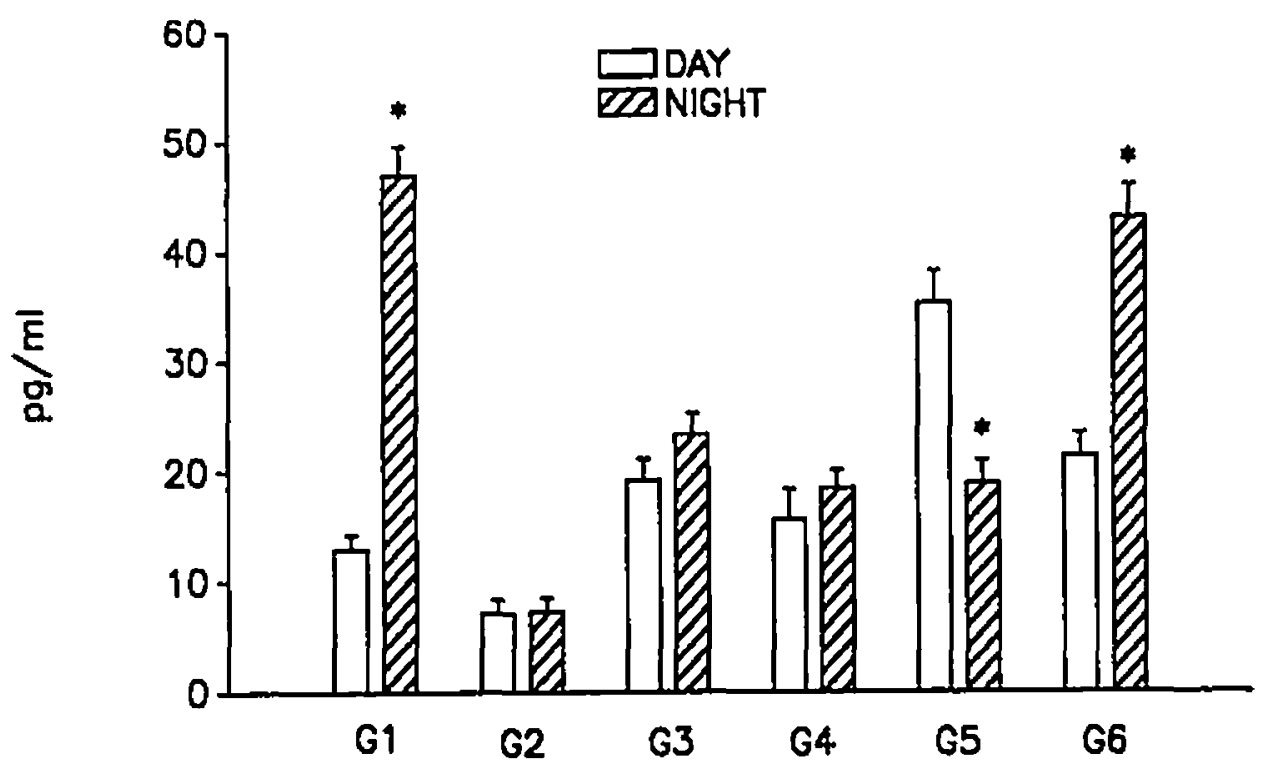


night differences were observed in serum melatonin concentration in the rest of the experimental groups.

(2) MORPHOLOGICAL OBSERVATION OF PINEAL GRAFTS FOLLOWING GRAFTING INTO SELECTED SITES.

Pinealocyte survival was optimal in the new locations eight weeks following grafting (Fig. 33-36). Fenestrated capillaries were observed throughout the grafts within these sites (Fig. 34-36). Ultrastructural characteristics of the pinealocytes in the four graft sites were similar, although, the reinnervation of the grafts was significantly different.

As seen with light microscopy, the richest $\mathrm{TH}-\mathrm{immuno}$ reactive nerve fibers were within the grafts transplanted into the anterior chamber of the eye. Those $\mathrm{TH}$ positive fibers formed a network throughout the whole graft (Fig. 37B) which was similar to that in the normal intact pineal gland (Fig. 37A). Innervation of pineal grafts in the third cerebral ventricle appeared more restricted with $T H$-immunoreactive fibers found only in select regions of the graft (Fig. 37C). Innervation of pineal grafts following transplantation in situ had a similar pattern to that of grafts following transplantation to the third cerebral ventricle. No TH-immunoreactive nerve fibers were observed within the grafts placed beneath the renal capsule (Fig. 37D) . 
Figure 33

Electron micrographs demonstrating the ultrastructural appearance of pirealocytes (PC) following transplantation into the anterior chamber of the eye (AC). DCV, dense core vesicle; GA, Golgi apparatus; Ly, lysosome; $M$, mitochondria; $N$, nucleus; $\mathrm{Nu}$, nucleoli; SR, synaptic ribbon. (Scale bars $=$ (A) $3 \mu \mathrm{m} ;$ (B) $2 \mu \mathrm{m}$ ). 

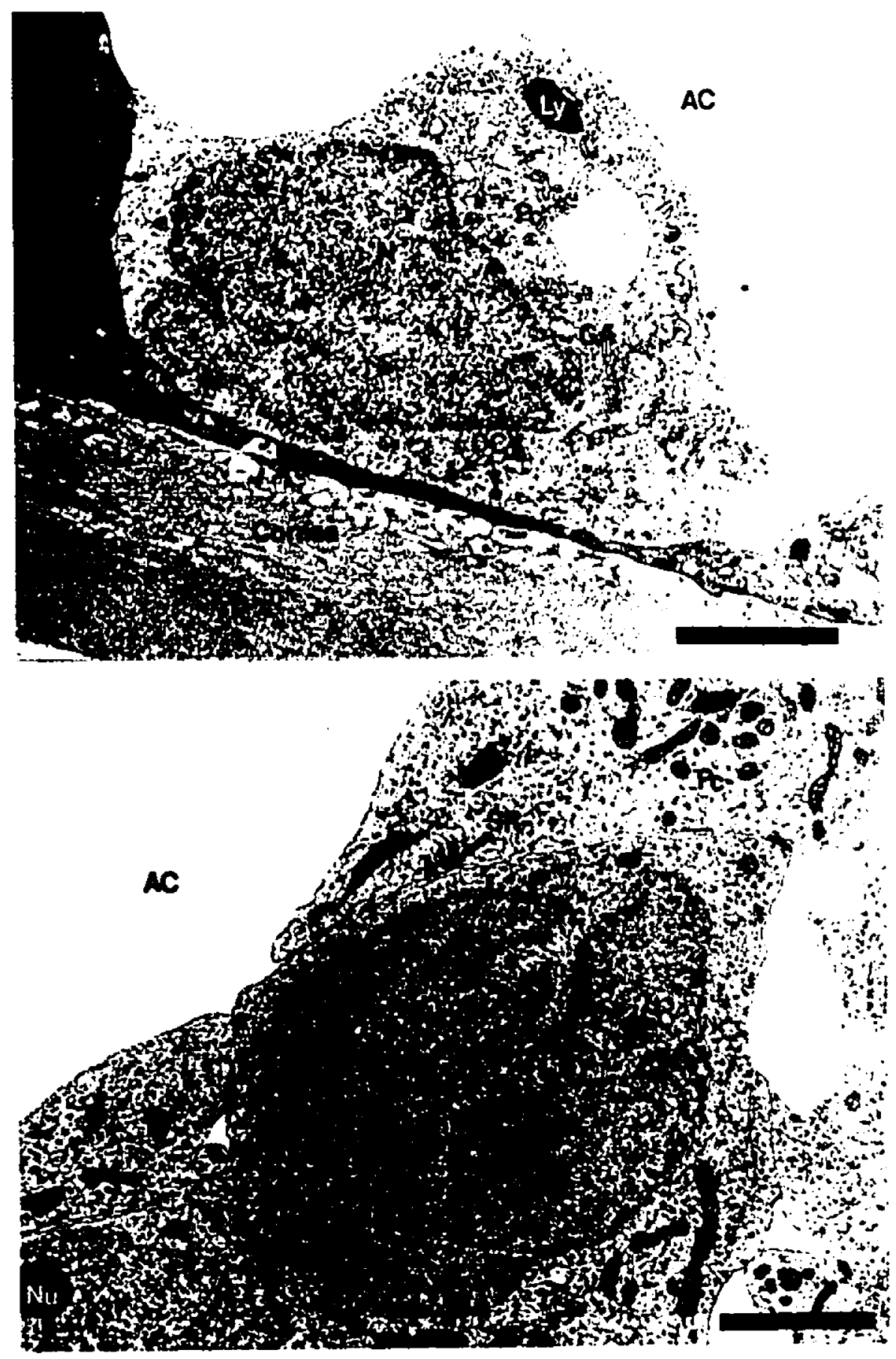
Figure 34

Electron micrographs of a pineal graft in the anterior chamber of the eye. Pinealocytes (PC) in (A) and (B) are found to be surrounded by the fenestrated capillaries (C). Large numbers of unmyelinated axons (A) are observed within the perivascular spaces (PS). Arrows indicate pores in the endothelial cells (En) of fenestrated capillaries. ID, lipid droplet; Ly, lysosome; $R$, red blood cell; $M$, mitochondria. Electron micrograph in (C) showing a fenestrated capillary (C) with an adjacent perivascular space (PS) in the graft of the anterior chamber of the eye. Arrows indicate pores in the endothelial cell. (Scale bars $=$ (A) $5 \mu \mathrm{m} ;$ (B) $1 \mu \mathrm{m} ;$ (C) 0.5 $\mu \mathfrak{m})$. 

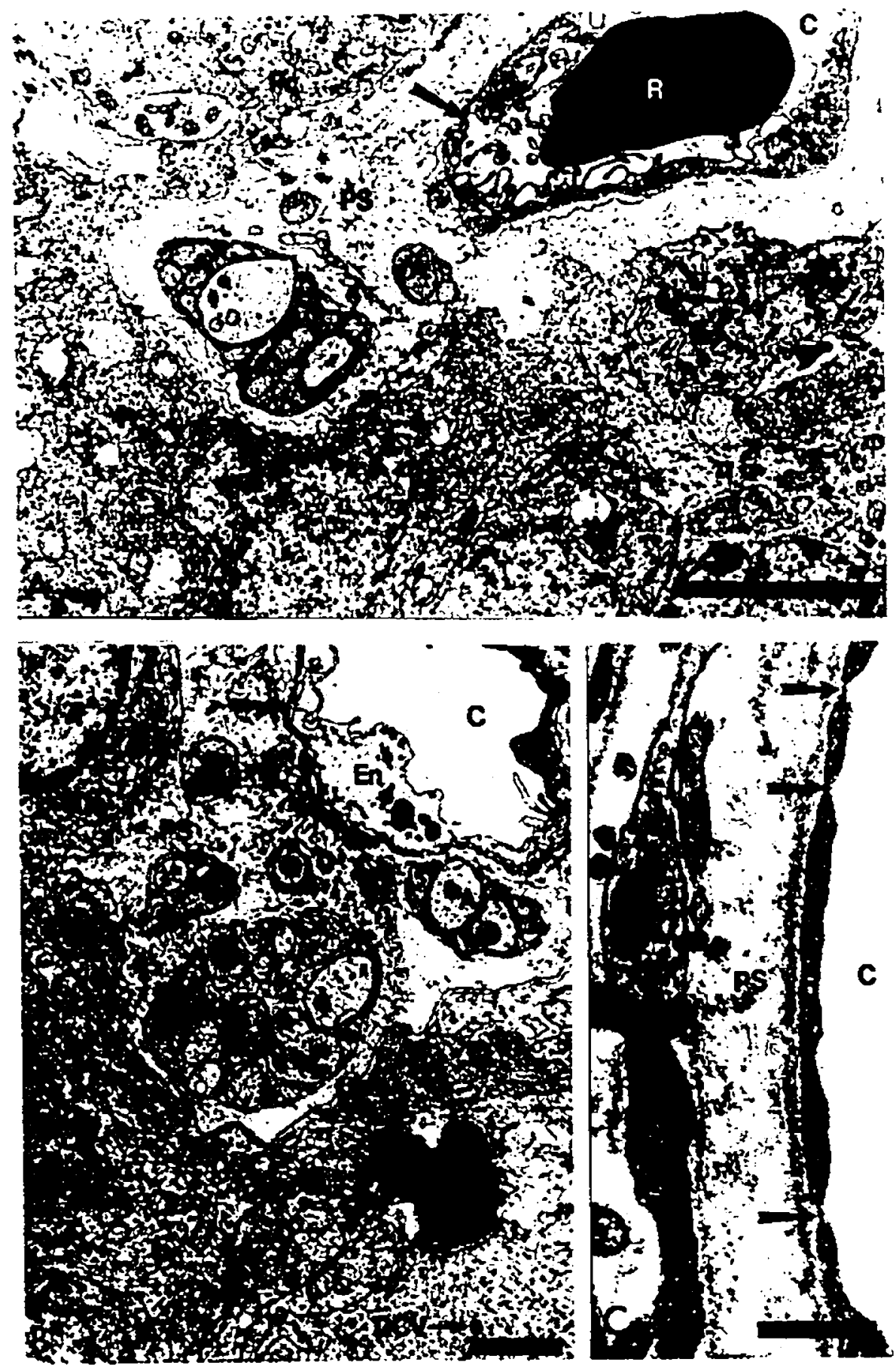
Figure 35

Electron micrograph in (A) showing pinealocytes (PC) in a graft transplanted in situ. A fenestrated capillary (C) with pores (arrows) in the endothelial (En) is observed in the graft. The double layer basal lamina (open arrows) are found to constitute the wide perivascular spaces (PS). ID, Iipid droplet; PP, polar process of pinealocyte; SR, synaptic ribbon. Electron micrograph in (B) showing pinealocytes (PC) in a graft following transplantation into the third cerebral ventricle. C, fenestrated capillary; En, endothelial cell of the capillary; ID, lipid droplet; IS, intercellular space; PS, perivascular space. (Scale bars $=$ (A) $5 \mu \mathrm{m}$; (B) $5 \mu \mathrm{m}$ ). 


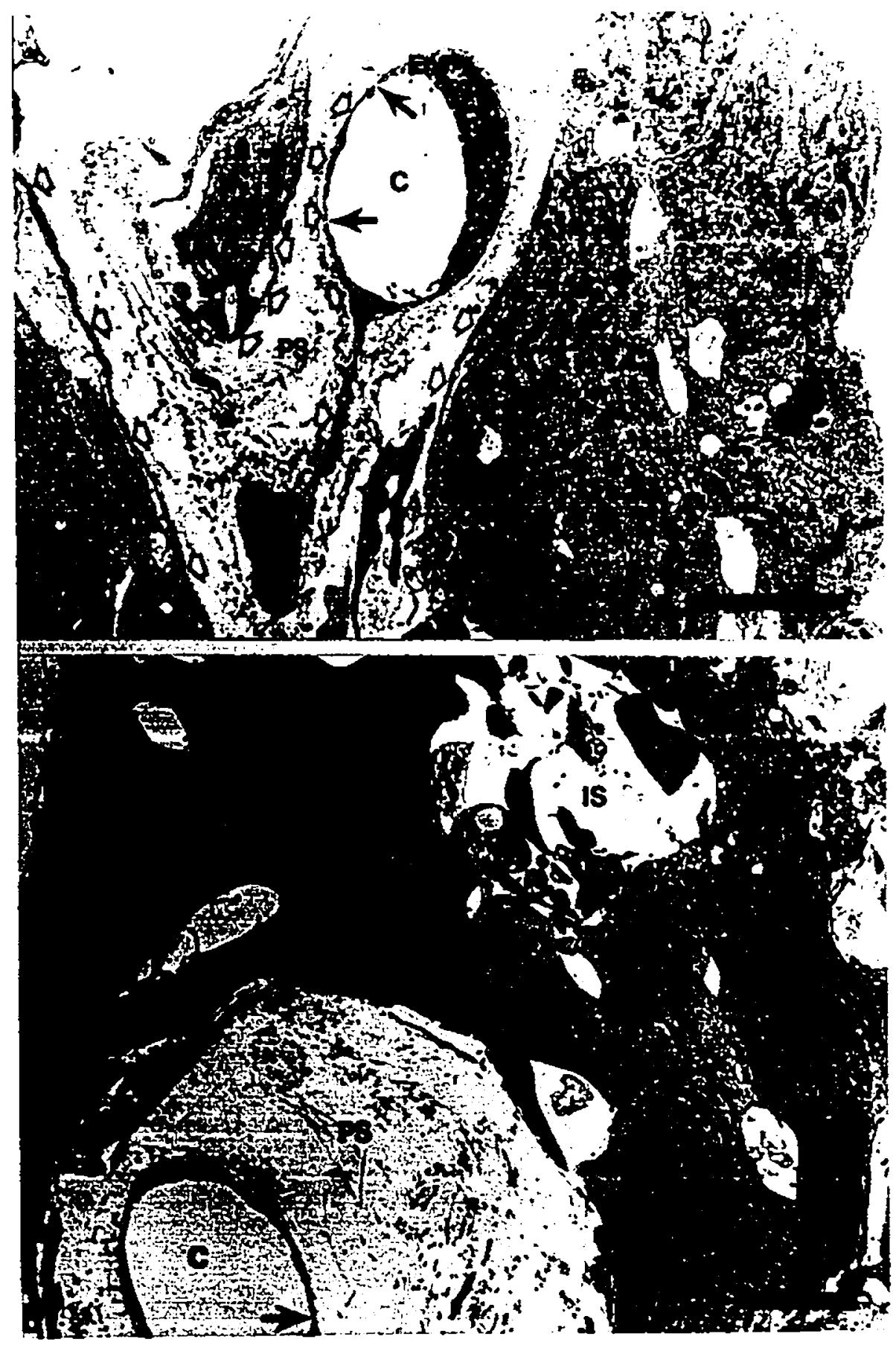


Figure 36

Electron micrographs showing pinealocytes in the graft following transplantation beneath the renal capsule. Pinealocytes (PC) are observed to surround a fenestrated capillary (C) which is characterized by wide perivascular spaces (SP) and pores in the endothelial cell (arrowheads). UItrastructure of pinealocytes in the grafts beneath the renal capsule are similar to those in the third cerebral ventricle. DP, dark appearing pinealocyte; LP, light appearing pinealocyte; PP, polar processes of pinealocytes; $M$, mitochondria; SR, synaptic ribbon; $R$, red blood cell. (Scale bars $=(A) 4 \mu \mathrm{m}$; (B) $4 \mu \mathrm{m}$ ). 

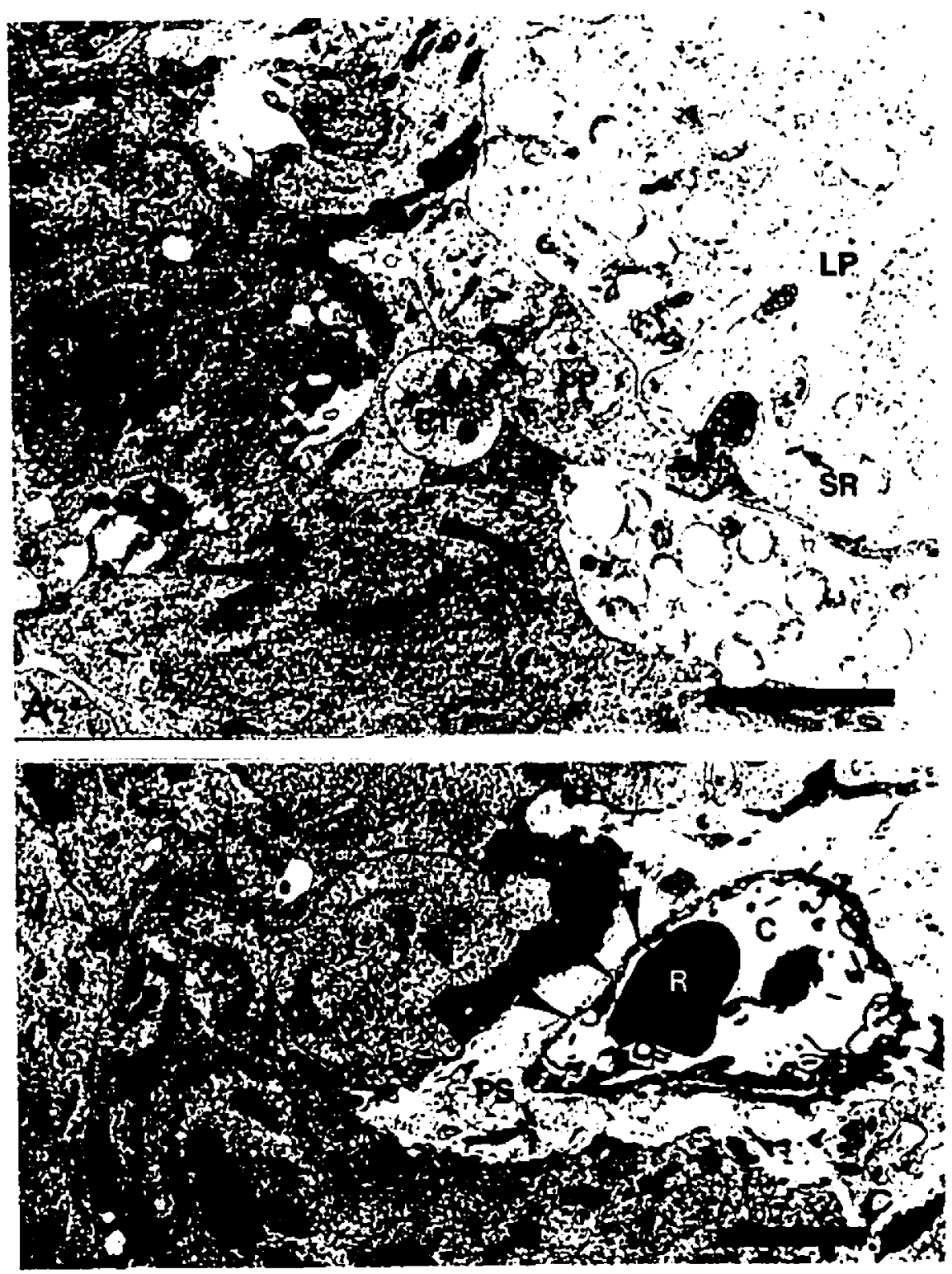


\section{Figure 37}

Light micrographs showing the innervation of the pineal tissues after transplantation into the selected sites. FIfty micrometer thick vibratome sections were prepared for ICC with antisera against tyrosine hydroxylase (TH) and counterstained with cresyl violet. (A) is a fifty micron section from a normal, intact pineal gland. TH-positive nerve fibers are found distributed throughout the entire gland. (B) is a fifty micron section from a graft in the anterior chamber of the eye. TH-positive nerve fibers form a network throughout the entire graft which is similar to that in (A). (C) is a fifty micron section from a graft in the third cerebral ventricle. TH-positive nerve fibers appear more locally distributed. These TH fibers are only found in some regions but not in other regions. (D) is a fifty micrometer-thick section from a graft under the renal capsule. No TH-positive nerve fibers are found in the graft. (Scale $=(A),(B)$, (C), (D) $10 \mu \mathrm{m}$ ). 

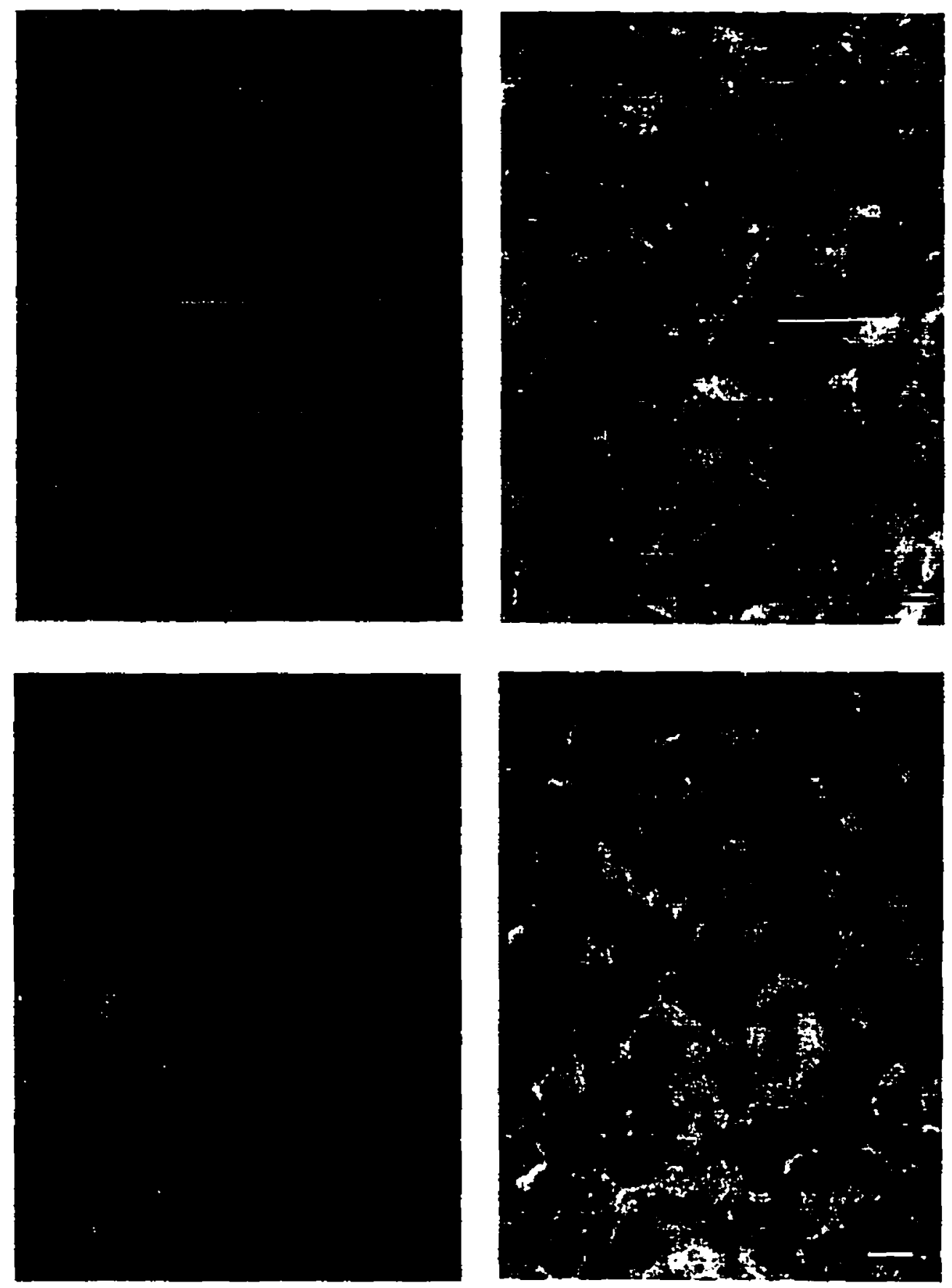

Reproduced with permission of the copyright owner. Further reproduction prohibited without permission. 
Transmission electron microscopy revealed large numbers of unmyelinated axons in pineal grafts which were transplanted into the anterior chamber of the eye (Fig. 34A-B; 38-41). Bundles of unmyelinated nerve fibers were found in virtually every perivascular space examined (Fig. 38-40). It was apparent that those unmyelinated nerve fibers entered and distributed throughout the grafts via blood vessels (Fig. 40). In some regions (usually in the area where the graft attached to the host iris) large bundles of neurites containing many unmyelinated and few myelinated nerve axons were observed (Fig. 41).

Myelinated axons were not observed in the grafts which were transplanted into the third cerebral ventricle, in situ, or under the renal capsule. Unmyelinated axons were often found within the grafts that were located in the third cerebral ventricle and in situ. However, those axons were occasionally observed within the perivascular space of the grafts but most perivascular spaces did not contain axon profiles (Fig. $7 ; 8 ; 10 A ; 35 B$ ). In the grafts located beneath the renal capsule, no neurites were observed (Fig. 36B). 
Figure 38

Electron micrographs showing the innervation of pineal graft following transplantation into the anterior chamber of the eye. Bundles of unmyelinated axons (A) are observed in the perivascular space and between the pinealocytes (PC). C, capillaries; G, glial cell; R, red blood cell. (Scale bars $=$ (A) $10 \mu \mathrm{mi}$ (B) $2 \mu \mathrm{m}$ ). 


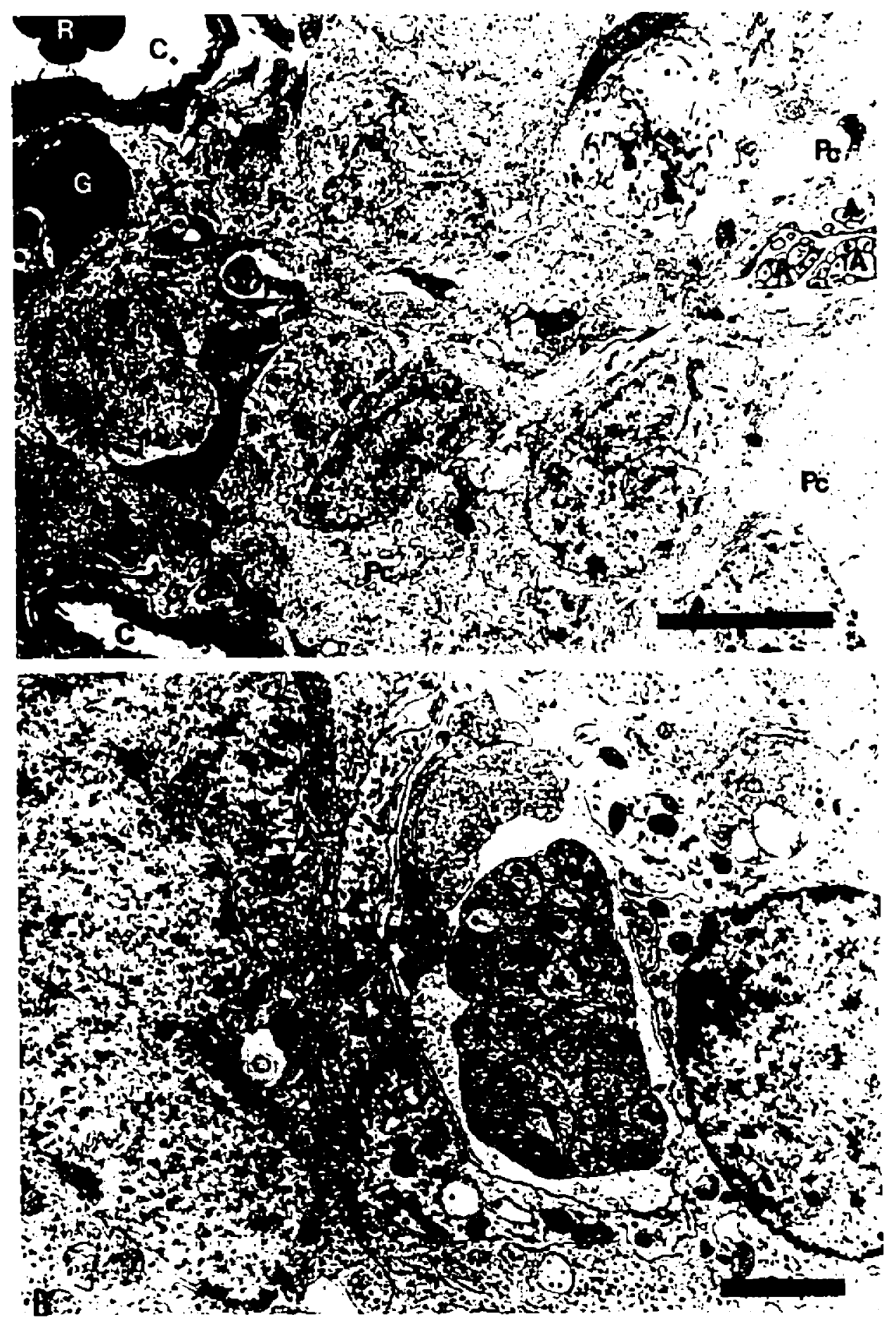


Figure 39

Electron micrographs showing the innervation of pineal grafts following transplantation into the anterior chamber of the eye. Bundles of unmyelinated axons (A) are found between the pinealocytes (PC) in the grafts. PS, perivascular space; $\mathrm{SR}$, synaptic ribbon. (Scale bars $=$ (A) $3 \mu \mathrm{m} ;(B) 3 \mu \mathrm{m}$ ). 


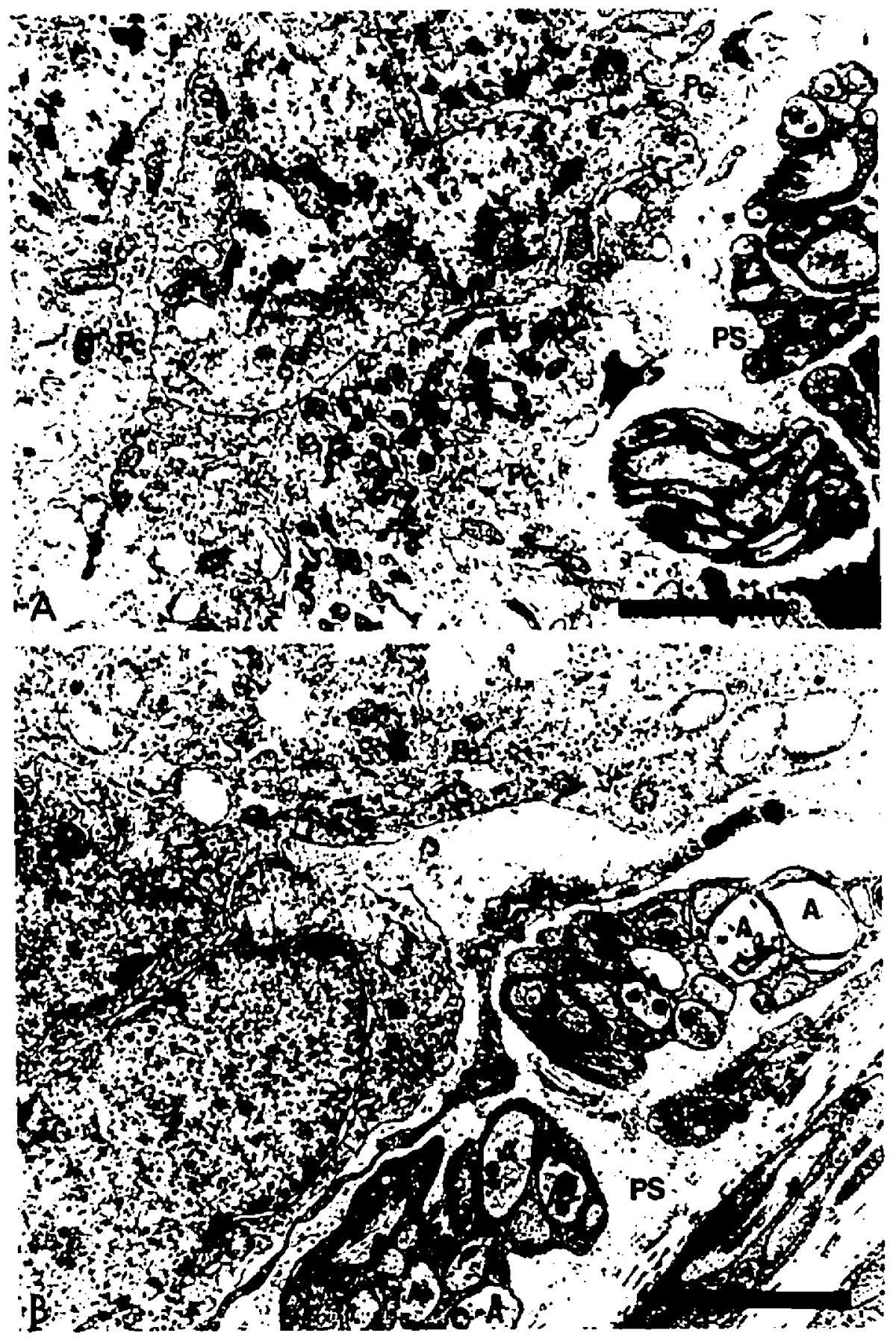




\section{Figure 40}

Electron micrographs demonstrating the innervation of pineal grafts following transplantation into the anterior chamber of the eye. Unmyelinated axons (A) seem to enter into and distribute throughout the graft following vascular ramifications within the graft. Electron micrograph in (A) is a longitudinal section through a perivascular space (PS) showing the longitudinal section of bundles of unmyelinated axons (A) within the perivascular space. Electron micrograph in (B) is a cross section through a capillary (C) showing the cross section of bundles of unmyelinated axons (A) within the perivascular space (PS). PC, pinealocytes. (Scale bars $=(A)$ $5 \mu \mathrm{m} ;$ (B) $4 \mu \mathrm{m}$ ). 

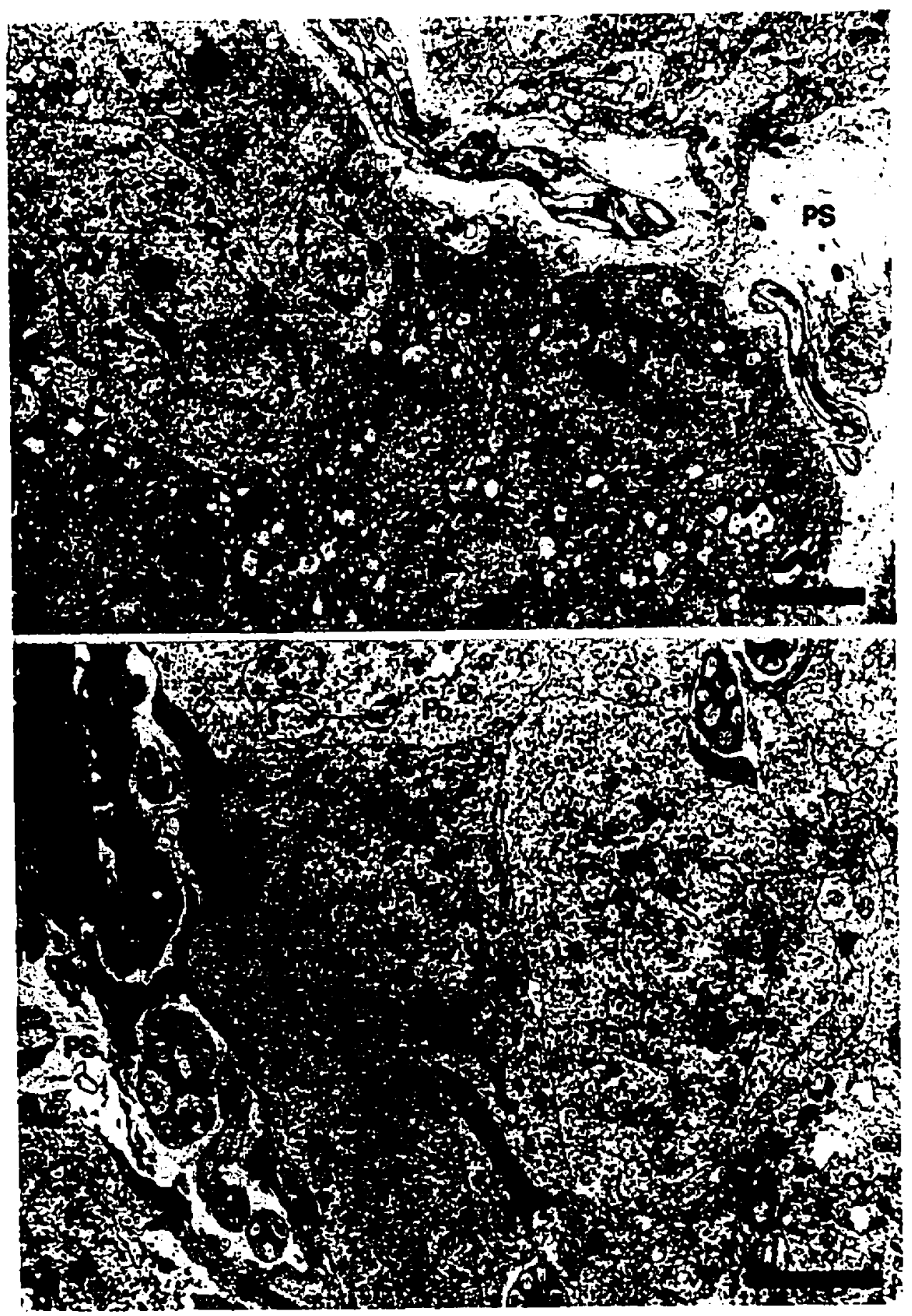


\section{Figure 41}

Electron micrographs showing the innervation of the pineal graft following transplantation into the anterior chamber of the eye. In the peripheral regions of the pineal graft, especially in the region where the graft is attached to the host iris, large bundles of nerve (A, $B$, and $C$ ) containing many unmyelinated (A) and several myelinated (S) axons are observed. G, glial cell; SC Schwann cell; PG, pineal graft. (Scale bars $=$ (A) $1 \mu \mathrm{m} ;$ (B) $5 \mu \mathrm{m} ;$ (C) $4 \mu \mathrm{m}$ ). 


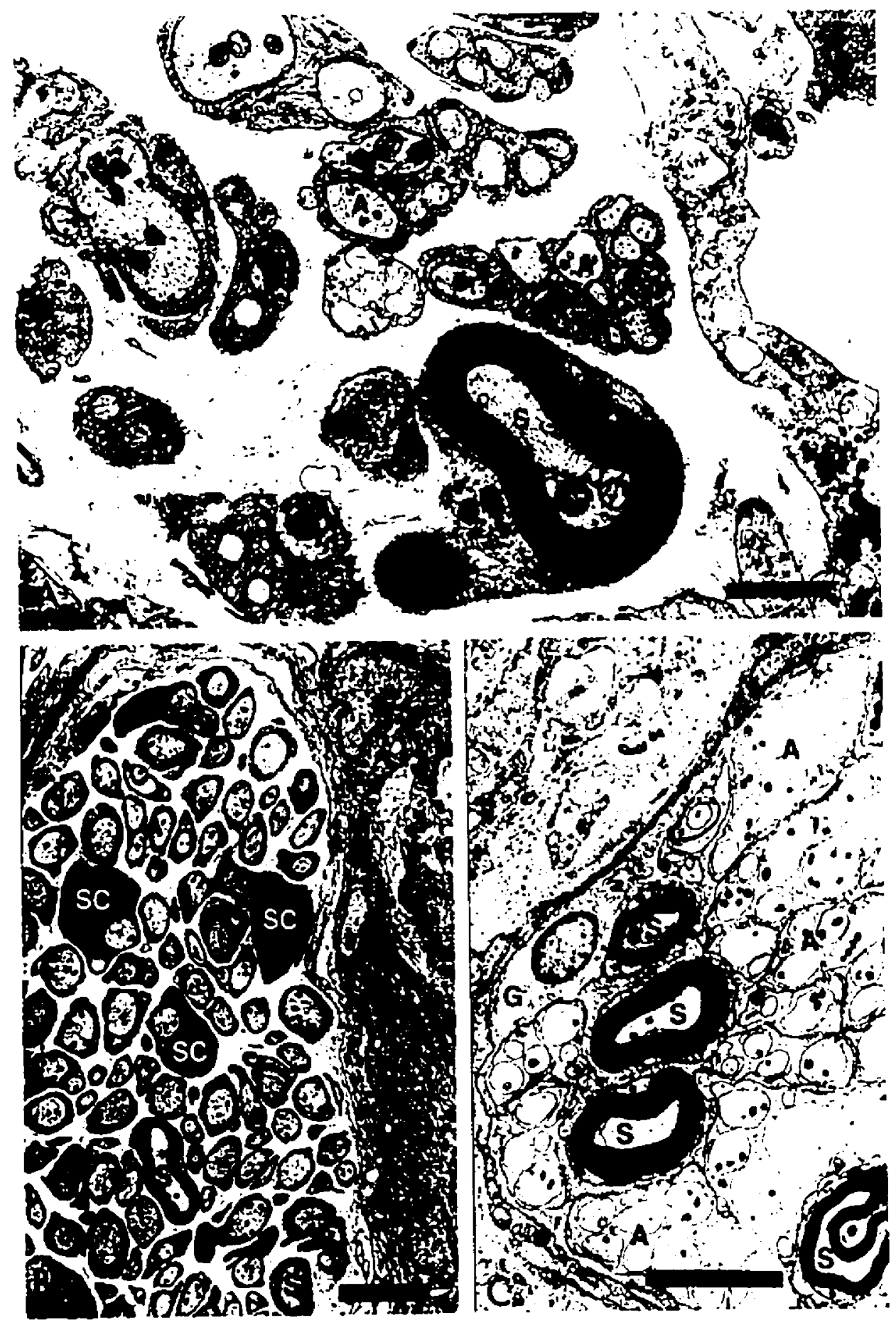


4. EFFECTS OF REIMNERVATION FROH THE 8ORERIOR CERVICAL GANGLION ON THE FUNCTIONAI RECOVERY OP PINEAL GRAFTS FOLLOWING TRANBPLANTATION INTO THE ANTERIOR CHAMBER OF THE EYE.

Grafts analyzed in this experiment met the following criteria: 1) They were located in the anterior chamber of the eye and pinealocytes appeared normal. 2) In the group of animals whose superior cervical sympathetic ganglia (SCG) were removed before pineal transplantation, Horner's syndrome (constriction of the pupils and ptosis) was present.

\section{(1) SERUM MELATONIN CONCENTRATION (FIG. 42)}

Pineal glands grafted into the anterior chamber of the eye in pinealectomized rats with an intact SCG resulted in a significant increase in nighttime serum melatonin concentration $(34.42 \mathrm{pg} / \mathrm{ml})$ as compared to that in pinealectomized animals without any treatment $(7.61 \mathrm{pg} / \mathrm{ml}, \mathrm{P}<0.01)$. Furthermore, a significant day-night difference with higher levels at night were observed in serum melatonin concentration in the animals which received pineal transplants into the anterior chamber of the eye with an intact SCG $(P<0.05)$. After the removal of SCG, there was no difference in nighttime serum melatonin concentration as compared with pinealectomized rats which remained untreated $(P>0.05)$. In addition, there were 
Figure 42

Day-night serum melatonin concentration following transplantation of the pineal gland into the anterior chamber of the eye. G1; (Group 1) animals in group 1 were normal intact controls. G2; (Group 2) animals in group 2 were pinealectomized rats which remained untreated (no-transplantation). G3: (Group 3) animals in group 3 were pinealectomized rats which received pineal transplantation into the anterior chamber of the eye. G4; (Group 4) animals in group 4 were pinealectomized rats whose superior cervical sympathetic ganglia (SCG) were also removed before pineal transplantation into the anterior chamber of the eye. (+) $P<0.01$ versus $G 2$. (\#) in $G 1 \quad p<0 . .01$ versus day time. (\#) in $G 3$ $P<0.05$ versus day time. 


\section{DAY-NIGHT SERUM MELATONIN CONCENTRATION}

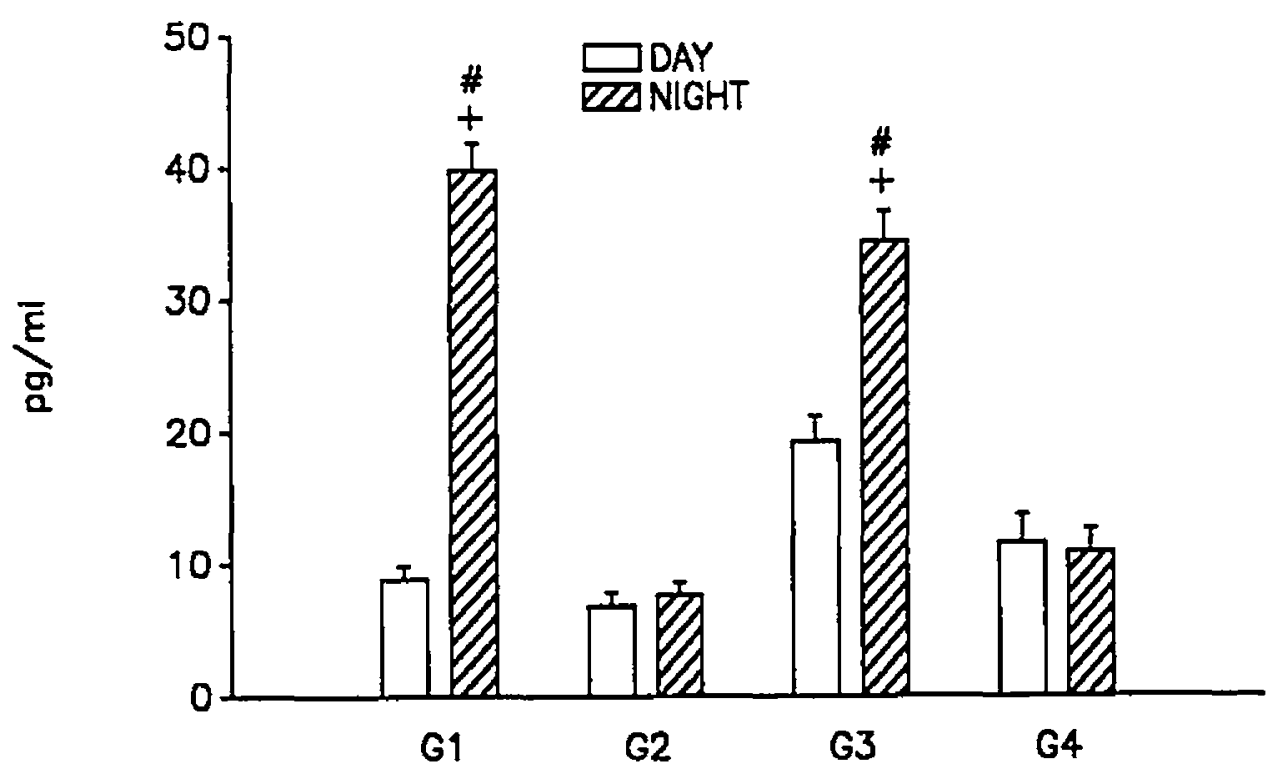


no day-night differences in serum melatonin concentration $(P>0.05)$.

(2) MORPHOLOGICAL OBSERVATIONS OF PINEAL GRAFTS OF HOSTS IN WHICH SCG HAS BEEN REMOVED ONE WEEK BEFORE PINEAL TRANSPLANTATION.

Morphological characteristics of capillaries in pineal grafts in the pinealectomized - ganglionectomized animals were similar to those in animals with intact SCG. The ultrastructural organization of pinealocytes in both groups was similar. However, synaptic ribbons were more frequent in the ganglionectomized animals than in animals with intact scGs. Many synaptic ribbons were found to form a synaptic ribbon field (Fig. 43). No nerve fibers or terminals were found within the perivascular spaces or intercellular spaces of those grafts (Fig. 44). 
Figure 43

Electron micrographs of the pineal graft transplanted into the anterior chamber of the eye of pinealectomized ganglionectomized host rats. These grafts exhibit a distinctive organelle, the synaptic ribbon, in pinealocytes. In both (A) and (B) as well as in (C) many synaptic ribbons are found to form a synaptic ribbon field (SRF). A vacuole containing flocculent material (VF) is identified next to the synaptic ribbon field (SRF) in (B). LD, lipid droplet; DCV, dense core vesicles; $M$, mitochondria; VF, vacuoles containing a flocculent material; CF, collagen fibers; Is intercellular space. Arrowhead in (A) indicates microtubules. (Scale bars $=$ (A) $1 \mu \mathrm{m}$, (B) $1 \mu \mathrm{m}$, (C) $0.5 \mu \mathrm{m}$ ). 


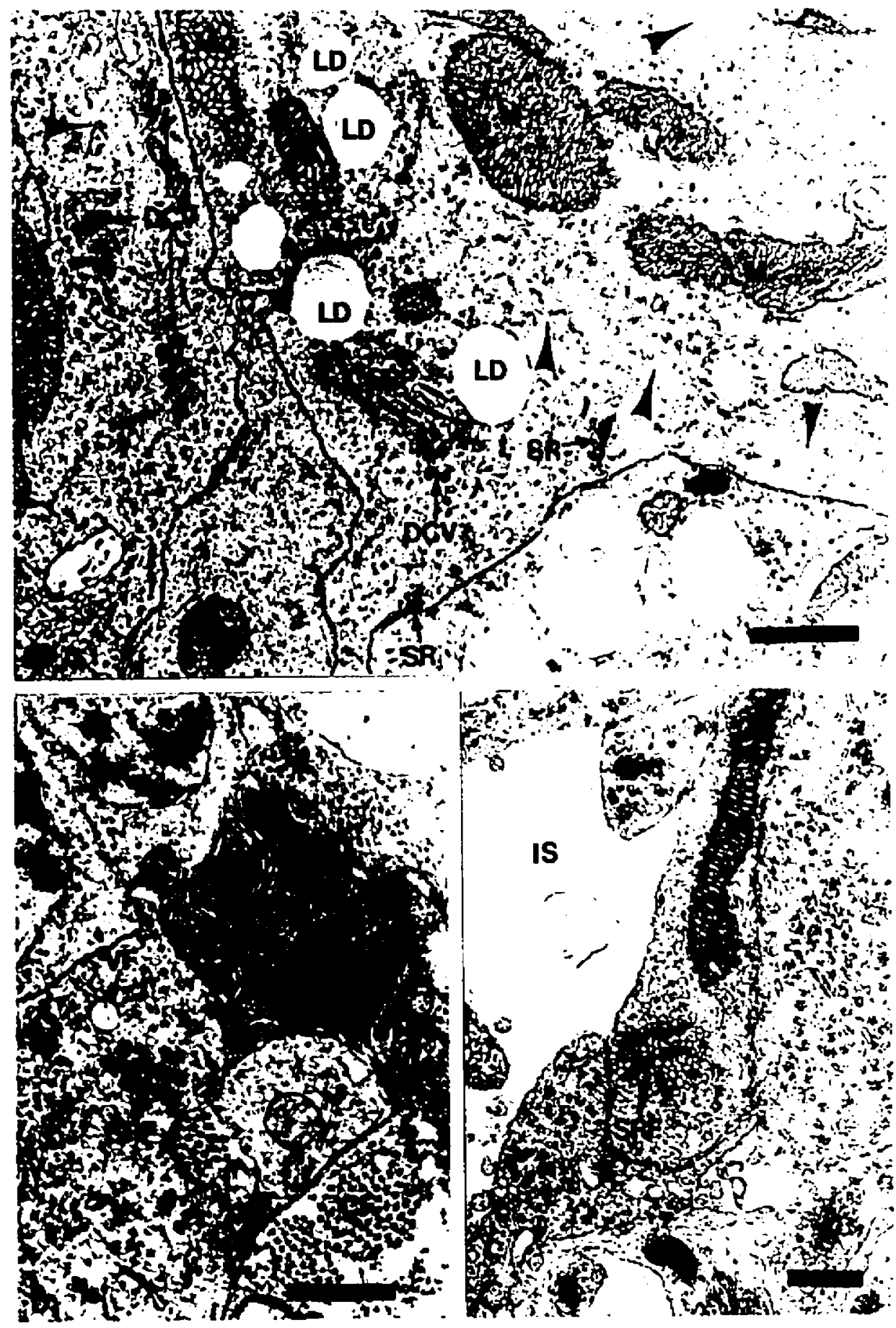


Figure 44

Electron micrographs showing the ultrastructure of the pineal grafts following transplantation into the anterior chamber of the eye in the pinealectomized and ganglionectomized host rats. Pinealocytes (PC) survive well in these grafts. Pinealocytes of such grafts surround fenestrated capillaries (C). Pores (arrowheads in B) are observed in the endothelial cells (En). A wide perivascular space (SP) is found to surround the fenestrated capillary. However, there are no nerve fibers found within the perivascular space nor between pinealocytes. DCV, dense core vesicles; G, glial cell; GA, Golgi apparatus; M, mitochondria; PP, polar process of pinealocytes; SR, synaptic ribbon; LY, lysosome; $R$, red blood cell. (Scale bars $=$ (A) $4 \mu \mathrm{m}$; (B) $2 \mu \mathrm{m}$ ). 


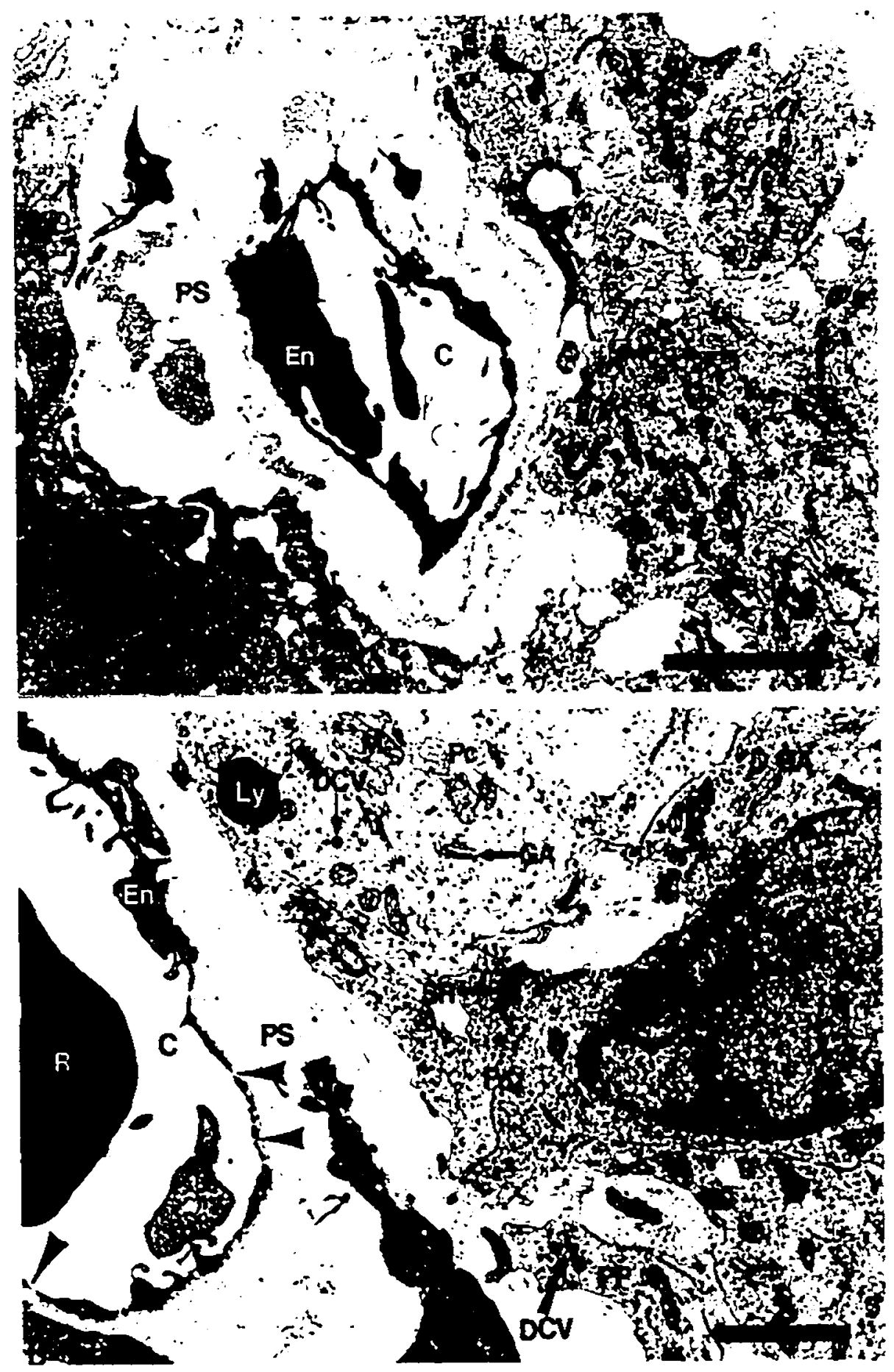




\section{DIsCUBgION}

\section{VABCULARIZATION OF THE PINEAL GRAPTB}

There are great variations in the occurrence and organization of endothelial fenestrae in the pineal gland of even closely related species. Endothelial fenestrae have been observed in the pineal gland of the rat (Milofsky, 1957; Wolfe, 1965), mouse (Ito and Matsushima, 1968), and golden hamster (Clabough, 1971); however, the capillary endothelium is reportedly not fenestrated in the cat (Duncan and Micheletti, 1966; Wartenberg, 1968), guinea pig (Lues, 1971), pocket gopher (Sheridan and Reiter, 1973), monkey (Wartenberg, 1968) and cow and sheep (Anderson, 1965). Only a few fenestrated capillaries are found in the rabbit pineal gland (Romijn, 1973).

Even within the species that have fenestrated capillary endothelial cells in the pineal gland, there is considerable variation in the frequency with which the fenestrae occur as well as regional differences within the gland itself. In the rat, a rich capillary network exists within the parenchyma of the pineal gland. A majority of the capillaries are lined by a fenestrated endothelium. However, occasionally non-fenestrated capillaries are found in the proximal portion of the rat pineal gland (Matsushima and Reiter, 1975). 
The present study has demonstrated that pineal grafts are revascularized following transplantation into several different sites, including the third cerebral ventricle, in situ, the anterior chamber of the eye, and the renal capsule. Moreover, almost all capillaries in the pineal graft are fenestrated, regardless of their anastomotic continuity with host vessels in different locations. Previous investigations have shown that fetal hypothalamic transplants do not exhibit fenestrated capillaries throughout the graft parenchyma, although pineal graft capillaries apparently anastomose with the fenestrated capillaries of the underlying host median eminence (Scott and Sherman, 1984; scott et al., 1988). These results appear to support the concept that the graft tissue dictates the phenotypic expression of endothelial cells inhabiting the graft (Broadwell et al., 1987; Broadwell, 1990). In a recent study by McNulty et al. (1991), pineal glands of neonatal rats were grafted into lesion cavities in the cerebral cortex of newborn rats for periods of 1 to 5.5 months. Transplant vasculature consisted of fenestrated endothelia with wide perivascular spaces that were permeable to endogenous IgG. These findings further support the concept that transplant vascular differentiation and physiology is determined by the graft and not the host tissue. However, at the periphery of the pineal graft transplant capillaries tended to have continuous endothelia similar to those of host cortex and are impermeable to endogenous IgG (McNulty, 1991). Although rare, non-fenestrated capillaries were occasionally 
found in the peripheral zone of pineal grafts in the present study. This would serve to suggest that host vessels penetrated the graft for some distance before anastomosis with the existing capillaries of the graft.

\section{ULTRABTRUCTURAL CHARACTERIGTICB OF PINEALOCXTES FOLLOTING TRANBPLANTATION.}

The ultrastructural organization of pinealocytes in the intact pineal gland has been well investigated (Wolfe, 1965; Reiter, 1981; Calvo and Boya, 1984; Matsushima et al., 1979). The ultrastructural features of pinealocytes in pineal grafts, however, have not yet been studied in detail. A major question to be confronted is whether pinealocytes maintain normal ultrastructural characteristics following transplantation. The present investigation has provided in great detail, the ultrastructural characteristics of pinealocytes following grafting into various sites. Pinealocytes in the grafts appear to contain numerous organelles with the same fine structural characteristics as those observed in pinealocytes of intact glands. Moreover, ultrastructural characteristics of pinealocytes are similar within all grafts following transplantation into different locations. Morphological findings of the present study demonstrate that pinealocytes survive and become functionally active following transplantation into the new locations. 
The high metabolic activity of pinealocytes in the grafts is suggested by the presence of a euchromatic nucleus, a prominent nucleolus, clefting of the nuclear envelope, numerous mitochondria, relatively abundant endoplasmic reticulum, free ribosomes and prominent Golgi apparati.

Morphological correlates of putative secretory processes were observed in the pinealocytes of the grafts. The first type is neurosecretory-like (Golgi apparatus--dense-core vesicles), and the second is ependymal-like (rough endoplasmic reticulum-vacuoles containing flocculent material) (Pévet, 1977, 1979; Pévet and Karasek, 1977; Karasek, 1981-1983). Many authors believe that both dense-core vesicles and vacuoles containing flocculent material may represent at least part of the secretory material on the pineal gland (Sheridan and Reiter, 1973; Welsh and Reiter, 1978; Collin, 1979; Matsushima et al., 1979; Pévet, 1979; Karasek, 1981, 1983; Vollrath, 1981; Karasek et al., 1982a, b). Both dense-core vesicles and vacuoles containing flocculent material were frequentiy observed in the pinealocytes of the graft in the present study. This further suggests that pinealocytes are capable of normal functional activity following transplantation into the new locations. In the present investigation, abundant clear vesicles are often found in the pinealocytes, especially in the terminals of the pinealocyte processes, which demonstrate a follicular arrangement. It has been suggested that clear vesicles also may represent a component 
of the pineal secretory processes (Romijn, 1973; Welsh et al., 1979; Karasek, 1981).

The presence of lipid droplets has been reported in pinealocytes of many species. It has been suggested that the parenchymal lipid content is linked to the gland's functional activity (Bostelman, 1968; Gusek et al., 1965). Those authors proposed that this lipid is the morphological correlate of the pineal secretory product (Bostelman, 1968; Demartino et al., 1963). A rich lipid content has been found to exist in functionally active pineal glands (Bostelman, 1968). Moreover, lipid droplets were observed to be expelled into the perivascular space where they enter the vascular network (Gusek et al., 1965). These findings further support the idea that lipid droplets may be involved in the pineal secretory mechanism. In the present investigation, no evidence of lipid expulsion was found and lipid droplets were not identified in either the perivascular or intercellular spaces. However, lipid droplets were often found in the cytoplasm of the pinealocytes in the grafts. Lipid droplets as well as lysosomes are more probably involved in general cell metabolism (Quay, 1974), although lysosomes have been suggested to be involved in the secretory processes of the pinealocytes by some authors (Wolfe, 1965; Karasek, 1981).

The function of the most distinctive organelle of pinealocytes, the synaptic ribbon, is still unclear. However 
several hypothesizes have been proposed. The first hypothesis is that synaptic ribbons (SR) are involved in intercellular communication between adjacent pinealocytes (Vollrath and Huss, 1973; Vollrath, 1981). The second hypothesis is that SR formation may be related to the regulation of beta-adrenergic receptors of the pinealocytes (King and Dougherty, 1982 $a, b)$. Injection of isoproterenol (a Beta-adrenergic receptor agonist) has been found to cause a significant increase in Erequency of SR of the rat (McNulty et al., 1989). The third hypothesis is that $S R$ may function as storage inclusions for some of the secretory products of the gland (Theron et al., 1981). However, this hypothesis has not been biochemically tested. Recent investigations appear to support the second hypothesis (e.g., there is a functional relationship between SR and pineal adrenergic nerves). Numerical changes in SR have been reported under various experimental conditions, including changes in dark:light cycle (Lues, 1971; Vollrath and Huss, 1973; Vollrath and Howe, 1976; Hewing, 1980b; King and Dougherty, 1982b), blinding (Kurumado and Mori, 1980), sympathectomy (Romijn, 1975, 1976; King and Dougherty, 1982a; Karasek et al., 1982c) and pharmacological manipulation of adrenergic function (Vollrath and Howe, 1976; King and Dougherty, 1982a, b). A compensatory increase in SR number in response to the loss of adrenergic innervation may be related to a similar compensatory increase in the activity of beta-adrenergic receptor mechanisms following adrenergic denervation of pinealocytes (Cantor et al., 1981). 
In the present study, synaptic ribbons in transplanted pineal glands are structuraliy similar to those in intact pineal glands. This seems to indicate that pinealocytes of the grafts re-establish a functional relationship with host adrenergic innervation. Moreover, ganglionectomy appears to increase numbers of $S R$ in the graft, which further suggests that there is a functional relationship between the pineal grafts and the host sympathetic nerves.

Myeloid bodies were first identified within the pinealocytes by samarashinghe et al. (1983). These bodies are usually lenticular in shape, are formed by an array of flattened membranous cisterna, and not bounded by a limiting membrane (Samarasinghe et al., 1983). The function of myeloid bodies is still unclear. They may be involved in the pinealocyte secretory processes (Erlich and Apuzzo, 1985; Reiter, 1981). Myeloid bodies were occasionally found in pineal grafts in the present investigation. Their significance in pineal function requires further elucidation.

Inclusion bodies were first reported in the mammalian pinealocytes by Matsushima et al. (1979). In the present study, grafted pinealocytes frequently contained inclusion bodies regardless of graft location. It has been postulated that the nucleolus-like inclusion bodies may be involved in the formation of neurotubules or neurofilaments in neuro- 
secretory cells (LeBeux, 1971; LeBeux et al., 1971), however, the significance of these structures in pinealocytes is obscure.

As previously discussed, pinealocytes in the grafts appear to maintain their functional activity. Morphological characteristics of pinealocytes in grafts indicate that pinealocytes are able to synthesize and release their intrinsic hormone, melatonin. However, only under certain conditions were pinealocytes observed to reestablish their functional capacity for melatonin synthesis and release. clearly, grafted pinealocytes have the potential to synthesize and release their hormone, yet to initiate this process certain conditions must be established. Among these critically important conditions are specific grafting sites as well as the reinnervation of the grafts.

\section{ERPECTS OP PINEAL GRAFTING BITES ON FUNCTIONAL RECOVERY}

Among the four selected grafting sites (the third cexebral ventricle, in situ, the anterior chamber of the eye, and under the renal capsule) increases in serum melatonin were observed only when the pineal gland was grafted into the third cerebral ventricle or into the anterior chamber of the eye. Day-night differences in serum melatonin concentrations, with the higher levels at night was only observed when pineal glands were grafted into the anterior chamber of the eye. 
These results indicate that although pinealocytes demonstrate the structural correlates of activity following transplantation into various new locations, only certain host locations can foster recovery of function as reflected by recovery of melatonin synthesis and release following transplantation.

Transplantation of the pineal cland into the third cerebral ventricle.

The third cerebral ventricle is one location where pineal grafts exhibited restoration of nighttime melatonin synthesis and release. In normal pineal glands active exchange between the gland and cerebrospinal fluid (CSF) may occur in a number of submammalian and mammalian species (Hewing, 1978, 1980a, 1982: Hoffman, 1970; Quay, 1970; Reiter et al., 1975; Smith et al., 1976). Pinealocytes directly exposed to the CSF may constitute a mechanism for exchange between CSF and the pineal gland, a possible function of these CSF-contacting cells being direct secretion into the CSF. Substances secreted in such a way would be transported into either the blood circulation or to the hypothalamus which is regarded as the main target organ for pineal hormones (Vollrath, 1981). Melatonin, generally accepted as a primary pineal hormone, has been found in the CSF of various species (Smith et al., 1976; Hedlund et al., 1977; Rollage et al., 1978; Reppert et al., 1979; Reiter, 1986b, $)$. In some species, melatonin concentration in CSF was found to be twice as high as in the blood plasma during the 
day. During the night, the increase in melatonin Ievels was 17-fold in the CSF, but only six-fold in the plasma (Hedlund et al., 1977). These findings demonstrate that the CSF may play an important role as a vehicle for the distribution and release of pineal hormones (Rodriguez, 1975).

Cerebrospinal fluid serves to sequester a variety of solutes from the cerebral parenchyma. Hence, the cerebral ventricular system serves as an excellent site for the transplantation of neural tissue (Scott and Sherman, 1984; scott, 1985; scott et al., 1988). Despite a large number of investigations dealing with neural grafting within the cerebral ventricular system, little data exist with respect to the intraventricular transplantation of pineal tissue. In a recent study by Brightman et al. (1985), pineal glands were cotransplanted with fragments of SCG into the $I V^{\text {th }}$ cerebral ventricle of pinealectomized host rats. Pinealocytes were found to survive and maintain functional activity. Following grafting into the $I V^{\text {th }}$ cerebral ventricle urinary 6-hydroxymelatonin (6-HM), the major metabolite of melatonin, was detectable. However, the 6-HM levels were still much lower than that which could be detected in an intact rat (Brightman et al., 1985).

Morphological observations of pineal grafts in the third cerebral ventricle have been reported by a few investigators (Welsh and Rollag, 1986; $\mathrm{Li}$ and Welsh, 1989). However, 
functional parameters of pineal grafts in the third cerebral ventricle have not been studied. The present investigation has, for the first time, provided detailed morphological and functional data about pineal grafts in the third cerebral ventricle. Pinealocytes in these grafts not only survived and exhibited ultrastructural features indicative of active secretory processes, but also significantly increased nighttime melatonin synthesis and release. Most pineal grafts in the third cerebral ventricle in the present investigation were found to contact CSF directly. To reiterate, CSF may play important roles both as a trophic mediator for the graft and as a secretion pathway for melatonin synthesized by the pinealocytes of the graft.

In a previous study, TH-immunopositive fibers in the host hypothalamus were found distributed around the pineal grafts (Li and Welsh, 1989). In that study, only a few fibers were observed to enter the peripheral area but not the core of the grafts. In the present investigation, however, TH-positive fibers were frequently observed in the central area of the pineal grafts (Fig. 24). Large numbers of TH-positive fibers were found to enter into the pineal graft from the host hypothalamus. In some cases, TH-positive fibers entered the grafts from the underlying host median eminence. This THpositive innervation of the grafts may be responsible for the increases in nighttime melatonin concentration following pineal transplantation into the third cerebral ventricle. 
Innervation of pineal grafts in the third cerebral ventricle was highly selective. TH-positive nerve fibers were often present only in some areas of the parenchyma of the graft and totally lacking in other areas of the same graft. This might explain why the restored levels in serum melatonin concentration in ventricular pineal grafts were significantly lower than that of normal controls. In the normal controls, TH-positive fibers were observed throughout the entire pineal gland.

The origin of TH-positive fibers which innervate pineal grafts stereotaxically placed into the third cerebral ventricle is most likely from the host hypothalamus based on the pattern of selective distribution and entry within the graft i.e., TH fibers enter the parenchyma of pineal grafts from the A12 and A14 tier of catecholeaminergic neurons in the adjacent endocrine hypothalamus.

Day-night differences in serum melatonin concentration was not observed in pinealectomized hosts with pineal grafts in the third cerebral ventricle. However, nighttime serum melatonin concentrations increase significantly in these animals as compared to non-transplanted animals. In the present investigation, although some grafts in the third cerebral ventricle receive large numbers of $\mathrm{TH}$-positive fibers from the adjacent host hypothalamus, which is regarded as part 
of the innervating pathway for the normal pineal gland, daynight differences in serum melatonin concentration was not evident in these animals. This might be explained by an inability of neurons in the hypothalamus which reinnervate the pineal grafts to conduct the appropriate light-dark signal to pinealocytes of the graft, although they do stimulate the pinealocytes to synthesize and release melatonin. Despite the evidence of reinnervation it is apparent that grafted pinealocytes in the cerebral ventricle of host rats did not receive sufficient stimulus reflecting the light-dark cycle from the external environment.

Transplantation of pineal gland into the pineal region in situ transplantation)

Pineal transplantation in situ (i.e. into the pineal region) has not been reported in mammals. It was presumed that the pineal graft might be able to reestablish its function more easily than other locations because the graft might be reinnervated by the host sympathetic neurites which normally innervate the pineal gland. However, results of the present investigation have demonstrated that serum melatonin concentration in pinealectomized animals which received pineal transplants into the pineal region (in situ) was statistically no different when compared to pinealectomized animals without grafts. A possible explanation may be that sympathetic nerves in pineal regions may have undergone axotomy during pinealec- 
tomy. Reinnervation from regenerating axons may not possess the necessary trophic influence required to stimulate recovery of function of the pineal gland transplanted in situ.

\section{Transplantation of pineal gland beneath the renal capsule}

The preservation of histological structure of pineal glands grafted beneath the renal capsule has been verified (Reiter, 1967). Pinealocytes were found to maintain a high protein secretory activity 40 days following grafting under the renal capsule. This was suggested by the increased number of nuclear membrane infoldings, the presence of numerous cisternae of rough endoplasmic reticulum polyribosomes, and the well developed nucleoli (Aguado et al., 1977). Nerve fibers and endings were present in the pineal graft. The positive reaction of the vesicles of these endings with a zinc iodideosmium tetroxide mixture following aldehyde treatment suggested that these nerve endings were cholinergic in nature (Augado et al., 1977). Some TH-positive nerve fibers were also observed in the renal pineal grafts (Li et al., 1991). Pineal grafts beneath the renal capsule, however, were incapable of causing gonadal atrophy (Reiter, 1967).

In the present investigation, ultrastructural characteristics of pinealocytes in subcapsular grafts appear similar to those of third cerebral ventricular grafts. The grafts were well vascularized by fenestrated capillaries. However, 
no functional activity of pinealocytes was observed. Nighttime serum melatonin concentration in animals with renal capsular pineal grafts remained the same as that of pinealectomized animals which remained untreated (no-transplantation) . Lack of functional recovery of subcapsular grafts may relate to the failure of graft reinnervation. This failure may be due to the lack of extensive sympathetic innervation in the kidney and the possibility that pineal tissue may selectively receive sympathetic innervation only from specific neuronal pools, such as SCG. Although nighttime melatonin concentration in the present study did not show a significant increase, day-time melatonin showed a significant increase compared to nighttime levels both in the same group of animals (i.e. pineal grafting to renal capsule) and in pinealectomized animals that remained untreated (non-transplantation). This reversed day-night difference in melatonin concentration with higher levels during the day has never been reported. The mechanism and functional significance of this enigmatic phenomenon still require further investigation.

Transplantation of pineal gland into the anterior chamber of the eye

The present study has demonstrated that the anterior chamber of the eye is an ideal location for the transplantation of pineal glands. All grafts in the anterior chamber of the eye in this investigation survived and exhibited signifi- 
cant recovery of function. The aqueous humor of the anterior chamber may serve as a nutrient medium for pineal grafts. simple surgery and a quick transplantation procedure may also contribute to better survival of pineal grafts. However, the appropriate reinnervation of the grafts may play the most important role in functional recovery.

Earlier studies have demonstrated that pinealocytes exhibited a normal microscopic appearance following grafting into the anterior chamber of the eye (Moore, 1975; Bäckström et al., 1976). The pineal grafts became reinnervated by the collateral sprouts of post-ganglionic sympathetic neurons from the ScG that innervate the host iris as determined by catecholamine fluorescence histochemistry (Moore, 1975; Bäckström et al., 1976). Pineal enzymes, N-acetyltransferase (NAT) and hydroxy-indole-o-methyl-transferase (HIOMT), activity was restored in the grafts following transplantation into the anterior chamber of the eye. Moreover, the nighttime NAT activity of the grafts was significantly higher than the daytime NAT activity (Moore, 1975; Bäckström et al., 1976; Lingappa and zigmond, 1987). A higher HIOMT activity in dark than in light $(2.7: 1)$ was also documented in the pineal grafts of the anterior chamber of the eye (Bāckstrom et al., 1976). The findings of a day-night rhythr in NAT and HIOMT activity in the pineal grafts may indicate that collateral sprouting of the sympathetic neurons that innervate the iris establish 
patterns of normal neural control over the grafted pineal glands.

Results from the present investigation are similar to that of previous studies. Nighttime serum melatonin concentration was completely restored in pinealectomized animals with two pineal glands grafted into the anterior chamber of the eye. No difference was observed in serum melatonin concentration between these animals and the normal control animals. This seems to indicate that if the right conditions prevail, two transplanted pineal glands are capable of replacing one intact in situ pineal gland in terms of melatonin synthesis.

Similar to the previous studies discussed above, daynight difference in serum melatonin concentration was restored in pinealectomized animals after receiving pineal transplantation into the anterior chamber of the eye. In the previous studies, NAT activity was used to evaluate the functional recovery of the pineal gland, while in this study serum melatonin concentration has been used to examine the functional recovery. It is clear that serum melatonin concentration is a more precise index for evaluate the day-night differences of pineal function. This is because day and night serum melatonin concentration can be measured and compared in the same animal, while day and night pineal NAT activity can only be compared between animals. 
Recovery of day-night difference in serum melatonin concentration in pinealectomized rats which received pineal transplantation in the anterior chamber of the eye may be linked directly to appropriate reinnervation. Lafge numbers of unmyelinated adrenergic nerve fibers from the iris were observed to enter the grafts. The iris receives sympathetic input from the superior cervical ganglion (Wurtman and Axelrod, 1966). Thus, innervation of pineal grafts in the anterior chamber of the eye from the host SCG may be responsible for the restoration of day-night difference in serum melatonin concentration.

\section{BIGNIFICANCE OP REINAERVATION OF THE PINEAL GRAFT ON THE RESTORATION OF FUNCTION}

Results of the present investigation have demonstrated that reinnervation of the pineal grafts is critical for functional recovery. Although pinealocytes survive and appear to maintain functional activity following transplantation into the selected locations, increases in serum melatonin concentration can only occur in certain locations in which the grafts receive appropriate reinnervation. Both grafts in the third cerebral ventricle and the anterior chamber of the eye received reinnervation from the host. Serum melatonin concentration was found to increase in both cases. By contrast, no nerve fibers were detected by light and electron microscopy in the pineal grafts placed beneath the renal 
capsule. Correspondingly, serum melatonin concentration in those animal remained at a very low level.

It is interesting that although patterns of neural innervation in the grafts transplanted into the pineal region (in situ transplantation) were similar to those of third cerebral ventricular grafts, no increase in serum melatonin concentration was observed. It is not clear why this reinnervation did not restore the function of the pineal graft, while reinnervation of the grafts in the third cerebral ventricle did. Possible explanations may include the following: the pineal region of pinealectomized rats had undergone pinealectomy 1-2 weeks before transplantation. Hence, pinealectomy might already have damaged the innervating fibers of this area. After transplantation, pineal grafts may receive reinnervation from regenerating nerve fibers. Reinnervation of the grafts by these regenerating nerve fibers might be not appropriate for stimulating the secretory function of pinealocytes in the grafts. Grafts in the third cerebral ventricle were apparently reinnervated by the sprouting from the adjacent host hypothalamus. Why reinnervation from sprouting and regenerating neurites have different effects on the pineal graft needs further elucidation. 
Effects of reinnervating patterns on functional restoration of the pineal grafts

Reinnervation, coupled with an increase in serum melatonin was observed in this investigation in animals with pineal grafts in the third cerebral ventricle as well as those with grafts in the anterior chamber of the eye. Patterns of reinnervation in these two locations were significantly different. Reinnervation of the pineal grafts in the third cerebral ventricle appeared more regional, i.e. nerve fibers were only found in some areas of the grafts and totally lacking in others. It is apparent that only selective regions in these ventricular grafts received reinnervation by the host hypothalamus and, hence, were responsible for the synthesis and release of melatonin. This might explain why the increased level of nighttime melatonin concentration in these animals was significantly lower than that of normal controls.

By contrast, pineal grafts in the anterior chamber of the eye received a widespread uniform network of reinnervation. Correspondingly, nighttime melatonin concentration was restored completely. No difference was observed in nighttime serum melatonin concentration between the animals receiving pineal grafts to the anterior eye chamber and normal controls.

Findings of the present study indicate that reinnervation of the pineal grafts is responsible for the increase of serum 
melatonin concentration. The increasing levels of serum melatonin concentration may be related to the amount and pattern of the reinnervation, regardless of the origin of the reinnervation. Both reinnervation from the host hypothalamus and SCG appear capable of stimulating pinealocytes in the grafts and may serve to increase serum melatonin concentration. Apparently the more reinnervating neurites pineal grafts receive, the higher the level of serum melatonin concentration observed. Hence, there may be a direct correlation between the number of reinnervating neurites and the degree of recovery as observed by heightened melatonin synthesis and release.

Effects of different origins of reinnervation on functional restoration in pineal arafts

An important characteristic of normal pineal function is the circadian control of melatonin synthesis and release. Although pineal grafts in the third cerebral ventricle as well as the anterior chamber of the eye demonstrated a significant increase in nighttime serum melatonin concentrations, significant day-night differences in serum melatonin concentration with higher nighttime levels was observed only in the latter. It is apparent that restoration of day-night rhythm in serum melatonin concentration in animals with pineal transplants is related to the appropriateness of reinnervation. Reinnervation from the host SCG appears to be necessary. Results of 
the present investigation are consistent with those of previous studies. Earlier investigations have demonstrated that NAT and HIOMT activity in the graft were significantly higher during the dark phase than during the light phase following transplantation into the anterior chamber of the eye (Moore, 1975; Bäckström et al., 1976). By contrast, no daynight difference in NAT and HIOKT activity was observed following superior cervical ganglionectomy in grafted animals (Bäckström et al., 1976).

In the present study, similar findings were obtained. No day-night difference was observed in serum melatonin concentrations following pineal gland transplantation into the anterior chamber of the eye in ganglionectomized host animals. Moreover, nighttime serum melatonin concentrations were similar to those of pinealectomized rats without grafts. This seems to indicate further that the secretory function of pinealocytes in the graft is directly related to adrenergic innervation. Adrenergic innervation of the iris is from the SCG (Matsuyama et al., 1985) and, therefore, pineal grafts in the anterior chamber of the eye receive no adrenergic innervation after ganglionectomy. It is assumed that no other sources of adrenergic innervation are available in this graft site. In support of this, the morphological findings of the present study showed no nerve fibers within the pineal grafts in the anterior chamber of the eye following ganglionectomy. 
Pineal grafts in the anterior chamber of the eye have been observed to be relnnervated by the collateral sprouting from sympathetic neurons that are located in SCG which normally innervate the iris (Bäckström et al., 1976; Moore, 1975). Further studies have indicated that the transplanted pineal gland in the anterior chamber of the eye is reinnervated by neurons in SCG which are not functionally equivalent to those which innervate the in sity pineal gland (Lingappa and Zigmond, 1987).

In the present investigation, although day-night differences in serum melatonin concentration are apparent in animals with pineal grafts in the anterior chamber of the eye, these differences were not as large as those observed in normal control animals. The day/night ratio of serum melatonin concentration was $1: 2$ in the former and $1: 3.6$ in the latter. The explanation for this phenomenon may be that differences exist between populations of sympathetic neurons that innervate the pineal gland and those that normally innervate the iris. A recent investigation by Lingappa and zigmond (1987) demonstrated that an hour after a brief light exposure (animals were exposed to 1 minute of light in the late dark period and then returned immediately to the dark for 1 hour), peak nighttime NAT activity in the pineal grafts of the anterior chamber of the eye was unchanged, while peak nighttime NAT activity in intact pineal glands in situ is dramatically decreased. It would appear that neurons innervating the 
intact pineal gland may mediate a light-induced inhibition of NAT activity, while neurons innervating the iris do not. This suggests that the neurons innervating the iris and pineal gland mediate functionally different signals even though both populations of sympathetic neurons induce a circadian rhythm in pineal NAT activity (Lingappa and zigmond, 1987). 


\section{CONCLUSIONB}

1. Pinealocytes survive and exhibit ultrastructural features indicative of active secretory processes following transplantation into four selected sites: the third cerebral ventricle, in situ, under the renal capsule, and into the anterior chamber of the eye.

2. Capillaries in the pineal grafts of the selected implantation sites are uniformly fenestrated and are confluent with the host circulation.

3. Nighttime serum melatonin concentration increases in pinealectomized animals following pineal transplantation into the third cerebral ventricle or the anterior chamber of the eye. This increase in nighttime serum melatonin concentration may be directly related to adrenergic reinnervation of the grafts.

4. Day-night differences in serum melatonin concentration are restored in pinealectomized rats with pineal transplants in the anterior chamber of the eye. Reinnervation of the grafts by the host superior cervical sympathetic ganglion appears necessary for the restoration of the day-night rhythm in serum melatonin concentration. 
5. Results of this research indicate that functional recovery of pineal grafts only occur in certain selective locations and only when such grafts receive appropriate reinnervation from the host brain. Transplantation of the mammalian pineal gland is an efficatious model for investigating the basic concepts and mechanisms of neural reorganization, plasticity, and recovery of function in the field of basic cellular neurobiology. 


\section{Bibliography}

Aguado, L.I., Benelbas, G.A., Gutierrez, L.S. and Rodriguez, E.M. Ultrastructure of the rat pineal gland grafted under the kidney capsule. Cell Tiss. Res. 176:131-142, 1977.

Anderson, E. The anatomy of bovine and ovine pineal. Light and electron microscopic studies. J. Ultrastruct. Res. Suppl. $8: 1-80,1965$.

Bäckström, M., Olson, L. and Seiger, A. N-Acetyltransferase and hydroxy-indole-o-methyltransferase activity in intraocular pineal transplants: diurnal rhythm as evidence for a functional sympathetic adrenergic innervation. Acta Physiol. Scand. $96: 64-71,1976$.

Björklund, A., Katzman, R., Stenevi, U. and West, K.A. Development and growth of axonal sprouts from noradrenaline and 5-hydroxytryptamine neurons in the rat spinal cord. Brain Res. 31:21-33, 1971 .

Björklund, A. and Stenevi, U. Growth of central catecholamine neurons into smooth muscle grafts in the rat mesencephalon. Brain Res. 31:1-20, 1971.

Björklund, A. and Stenevi, U. Intracerebral neural implants: Neuronal replacement and reconstruction of damaged circuits. Ann. Rev. Neurosci. 7:279-308, 1984.

Bostelmann, w. Das ultrastrukturelle und enzymhistochemische Verhalten der Rattenzirbeldrüse nach Funktionphasewechsel durch Dauerbeleuchtung und standige Dunkelheit.. Endokrinologie, 53:365-383, 1968 .

Brightman, M.W., Markey, S.P., and Klein, D.C. Cotransplants of pineal gland and superior cervical ganglion to the IVth ventricle. In: Neural Grafting in the Mammalian CNS (A. Bjorklund and U. Stenevi, eds.) Elsevier, Amsterdam, NY, pp. 235-241.

Broadwell, R.D., Charlton, H.M., Balin, B.J. and Salcman, M. Angioarchitecture of the CNS, pituitary gland and intracerebral grafts revealed with peroxidase cytochemistry. $J$. Comp. Neurol. 160:47-62, 1987.

Broadwell, R.D. The blood-brain barriex in normal and transplanted brain and graft rejection. In: Peripheral Signaling of the Brain: Neural Immune and Cognitive Function. Proc. 6th Int. Neural Control Bodily Function. Basic and Clinical Function (R.C.A. Frederickson, J.L.McGaugh, and D.L. Felten, Eds.). Hogrefe and Huber, Toronto, pp. 1-32. 
Calvo, J., and Boya, J. Ultrastructure of the pineal gland in the adult rat. J. Anat. 138:405-409, 1984

Cantor, E.H., Greenberg, I.H. and Weiss, B. Effect of longterm changes in sympathetic nervous activity on the betaadrenergic receptor-adenylate cyclase complex of the rat pineal gland. Mol. Pharmacol., 19:21-26, 1981.

Clabough, J.W. Ultrastructural features of the pineal gland in normal and light deprived hamsters. $z$. Zellforsch., $114: 151-164,1971$.

Collin, J.P. Recent advances in pineal cytochemistry. Evidence of the production of indoleamines and proteinaceous substances by rudimentary photoreceptor cells and pinealocytes of Amniota. Prog. Brain Res, 52:271-296, 1979.

Dafny, N. Evidence that the rat pineal has neuronal connections via the pineal stalk. Exp. Neurol. 79:858-861, 1983 .

Das, G.D. and Altman J. Transplanted precursors of nerve cells: their fate in the cerebelium of young rats. Science, $173: 637-638$, 1971 .

Das, G.D. and Altman J. Studies on the transplantation of developing neural tissue in the mammalian brain. I. Transplantation of cerebellar slabs into the cerebellum of neonate rats. Brain Res. 38:233-249, 1972.

Delconte, G. Einpflanzungen von embryonalem Gewebe ins Gehirn. Beiträge zur Patolog. Anatomie, 42:193-202, 1907.

DeMartino, C., Deluca, F., Minio-Paluello, F., Tonietti, G and orci L. The osmiophilic granules of the pineal body in rats. Experimentia, 19:639-640, 1963 .

Duncan, D. and Micheletti, G. Notes on the fine structures of the pineal organ of cats. Texas Rep. Biol. Med., 24:576$587,1966$.

Dunn, E.H. Primary and secondary findings in a series of attempts to transplant cerebral cortex in the albino rat. $J$. Comp. Neurol., 27:565-582, 1917.

Einhorn, N. and Rowntree, I. Experimental phases of the pineal problem. Endocrinology 24:221-229, 1939.

Erlich, S.S. and Apuzzo, M.L.J. The pineal gland: Anatomy, physiology, and clinical significance. J. Neurosurg. 63:321341,1985 .

Faldino, G. Sullo sviluppo dei tessuti emrionali omoplastici innestati nella camera anteriore dell'occhio del conglio. Arc. de Scienze Biol., 5:328-346, 1924. 
Flerkó, B. and Szentágothai, J. Oestrogen sensitive nervous structures in the hypothalamus. Acta endocr. 26:121-127, 1957.

Forssman, J. Ueber die Ursachen, welche die Wachsthmrichtung der peripheren Nervenfasern bei der Regeneration bestimmen, Thesis, Lund Gustav Fisher Verlag, Jena, pp 1-47, 1898.

Gash, D.M. and Sladek, J.R. Neural transplantation: problems and prospects. Where do we go from here? Mayo clin. Proc. $64: 363-367,1989$.

Gittes, R.F. and Chu E.W. Reversal of the effect of pinealectomy in female rats by multiple isogeneic pineal transplants. Endocrinology 77:1061-1067, 1965.

Guérillot, C., Pfister, A., Müller and DaLage, C. Recherche de l'origine des fibres nerveuses extraorthosympathiques innervant l'épiphyse du rat (étude du transport rétrograde de la peroxydase). Reprod. Nutr. Dev. 22:371-378, 1982 .

Gusek, W., Buss, H. and Wartenburg, H. Weitere untersuchungen zur feinstruktur der epiphysis cerebri normaler und vorbehandelter ratten. Prog. Brain Res. 10:317-331, 1965.

Hedlund, L., Lischko, M.M., Rollag, M.D. and Niswender, G.D. Melatonin: Daily cycle in plasma and cerebrospinal fluid of calves. Science 195:686-687, 1977.

Hewing, M. A liquor contacting area in the pineal recess of the golden hamster (Mesocricetus auratus). Anat Embryol $153: 295-304$, 1978 .

Hewing, M. Cerebrospinal fluid-contacting area in the pineal recess of the vole (Microtus agrestis), guinea pig (Cavia cobaya), and Rhesus monkey (Macaca mulatta). Cell Tissue Res, $209: 473-484$, 1980a.

Hewing, M. synaptic ribbons in the pineal system of normal and light deprived golden hamsters. Anat. Embryol. 159:71$80,1980 \mathrm{~b}$.

Hewing, M. Pinealocytes contacting the cerebrospinal fluid of the suprapineal recess in the Mongolian gerbil (Meriones unguiculatus). Cell Tissue Res. 222:177-185, 1982.

Hoffman, R.A. The epiphyseal complex in fish and reptiles. Amer. Z011. 10:191-199.

Holmes, R.I. Iris reactions to homo- and auto-grafts of pineal tissue in rats and rabbits. Anat. Rec. 127:173-186, 1957. 
Ito, T. and Matsushima, S. Electron microscopic observations on the mouse pineal, with particular emphasis on its secretory nature. Arch. Histol. Jap., 30:1-15, 1968.

Johnson, G.E. and Lahr, E.L. Pineal implants in rats. Anat. Rec. (Suppl. 3):28, 1932 .

Kappers, J.A. The development, topographical relations and innervation of the epiphysis cerebri in the albino rat. $z$. Zellforsch. 52:163-215, 1960 .

Kappers, J.A. The pineal gland: An introduction. In: The Pineal Gland. (Wolstenholme, G.E.W. and Knight, J., eds.) Churchill Livingstone, London, pp. 3-25, 1971.

Karasek, M. Some functional aspects of the ultrastructure of rat pinealocytes. Endocrinol. Exp. 15:17-34, 1981.

Karesek, M., Hurlbut, E.C., Hansen, J.T. and Reiter, R.J. Ultrastructure of pinealocytes of the kangaroo rat (Dipodomys ordi). Cell Tissue Res. 226:167-175, 1982a.

Karasek, M., King, T.S., Petterborg, L.J., Hansen, J.T., Bartke, A. and Reiter, R.J. Dense-core vesicles in the mammalian pinealocytes and their relation to secretory processes. TSEM Journal 13:13-19, 1982b.

Karasek, M. Ultrastructure of the mammalian pineal gland: Its comparative and functional aspects. In: pineal Research Reviews, 1. (Reiter, R.J., ed.). Alan R.. Liss, New York, pp. $2-48,1983$.

Karasek, M., King, T.S., Hansen, J.T. and Reiter, R.J. Quantitative changes in the numbers of dense-core vesicles and 'synaptic' ribbons in pinealocytes of the Djungarian hamster (Phodopus sungorus) following sympathectomy. Cytobios 25:157$162,1982$.

Kelly, P.J., Ahskog, J.E., vanHeerden, J.A., Carmichael, S.W., Stoddard, S.I. and Bell, G.N. Adrenal medullary autograft transplantation into the striatum of patients with Parkinson's disease. Mayo clin. Proc. 64:282-290, 1989.

Kennaway, D.J., Firth, R.G., Philipou, G., Matthews, C.D. and Seamark, R.F. A specific radioimmunoassay for melatonin in biological tissue and fluid and its validation by gas chromatography-mass spectrometry. Endocrinology 101:119-127, 1977.

King, T.S. and Dougherty, W.J. Effect of denervation on 'synaptic' ribbon population in the rat pineal gland. $J$. Neurocytol. 11:19-28, 1982a. 
King, T.S. and Dougherty, w.J. Age-related changes in pineal 'synaptic' ribbon populations in rat exposed to continuous light or darkness. Am. J. Anat. 163:169-179, 1982b.

Klassen, H. and Lund, R.D. Retinal transplants can drive a pupillary reflex in host rat brain. Proc. Natn. Acad. Sci. U.S.A. $84: 6958-6960,1987$.

Klein, D.C. and Weller, J.L. Indole metabolism in the pineal gland: A circadian rhythm in N-acetyl-transferase. Science 169:1093-1095, 1970.

Klein, D.C., Weller, J.L. and Moore, R.Y. Melatonin metabolism: neural regulation of pineal serotonin: acetyl coenzyme A N-acetyl-transferase activity. Proc. Nat. Acad. Sci. (U.S.A.) 68:3107-3110, 1971.

Klein, D.C. and Moore, R.Y. Pineal N-acetyltransferase and hydroxy-indole-o-methyltransferase: control by retinohypothalamic tract and suprachiasmatic nucleus. Brain. Res. 174:245$250,1979$.

Klein, D.C., Smoot, R., Weller, J.L., Higga, S., Markey, S.P., Creed, G.J. and Jacobowitz, D.M. Lesions of the paraventricular nucleus area of the hypothalamus disrupt the suprachiasmatic-spinal cord circuit in the melatonin rhythm generating system. Brain Res. Bull 10:647-652.

Korf, H.W. and Wagner, U. Evidence for a nervous connection between the brain and the pineal organ in the guinea-pig. Cell Tissue Res. 109:505-510, 1980.

Kozelka, A.W. Implantation of pineal glands in the leghorn fowl. Proc. Soc. Exp. Biol. and Med. 30:842-844, 1933.

Kurumado, K. and Mori, w. Pineal synaptic ribbons in blinded rats. Cell Tiss. Res. 208:229-235, 1980.

LeBeux, Y.J. An ultrastructural study of the neurosecretory cells of the medial vascular prechiasmatic gland, the preoptic recess and anterior part of the suprachiasmatic area. I. Cytoplasmic inclusions resembling nucleoli. z. zellforsch. $114: 404-440$, 1970 .

LeBeux, Y.J., Langelier, P. and Poirier, L.J. Further ultrastructural data on the cytoplasmic nucleolus resembling bodies or nematosomes. Their relationship with the subsynaptic web and a cytoplasmic filamentous network. $\mathrm{Z}$. zellforsch. 118:147-155, 1971 .

LeGros clark, W.E. Neuronal differentiation in implanted foetal cortical tissue. J. Neurol. Psychiat. 3:263-284, 1940. 
Li, L. and Turner, J.E. Inherited retinal dystrophy in the RCS rat: Prevention of photoreceptor degeneration by pigment epithelial cell transplantation. Exp. Eye Res. 47:911-917.

Li, K. and Welsh, M.G. Ultrastructure of superficial pineal gland grafts in the third ventricle. Am. Assoc. of Anat. 102nd Annual Meeting, April 8-12, 1989, 126A.

Lingappa, J.R. and Zigmond, R.E. Pineal transplants in oculo: Limitations on the ability of collateral sprouts of foreign neurons to establish normal function. J. Neurosci. $7(11): 3525-3528,1987$.

Lues, G. Die Feinstruktur der zirbeldruse normaler. Trachtiger und experimentall beeinfluesster Meerschweinchem. $Z$. Zellforsch. $114: 38-60,1971$.

Matsushima, S. and Reiter, R.J. Ultrastructural observations of the pineal gland capillaries in four rodent species. Am. J. Anat. 143:265-282, 1975.

Matsushima, S. and Reiter, R.J. Fine structural features of adrenergic nerve fibers and endings in the pineal gland of the rat, ground squirrel, and chinchilla. Am. J. Anat. 148:463$478,1977$.

Matsushima, S. Morisawa, Y., Petterborg, L.J., Zeagler, J.W. and Reiter, R.J. Ultrastructure of pinealocytes of the cotton rat (Sigmondon hispidus). Cell Tiss. Res. 204:407-416, 1979.

Matsuyama, T., Shiosaka, S., Wanaka, A. Yoneda S., Kimura, K., Hayakawa, T., Emson, P.C. and Tohyama, M. Fine structure of peptidergic and catecholaminergic nerve fibers in the anterior cerebral artery and their interrelationship: An immunoelectron microscopic study. J. Comp. Neurol. 235:268-276, 1985.

McNulty, J.A., Prechel, M.M., Van de Kar, L.D. and Fox, I.M. Effects of isoproterenol on synaptic ribbons in pinealocytes of the rat and C57BL/6J mouse. J. Pin. Res. 7:305-311, 1989.

McNulty, J.A., Fox, L.M., Shaw, P.L., Alones, V.A., Klausen, B., Swenson, R. and Castro, A.J. Pineal gland transplants into the cerebral hemisphere of neonatal rats: a study of the blood brain barrier and innervation. J. Neural Transplant. Plast. (in press).

Milofsky, A.H. The fine structure of the pineal in the rat with specific reference to parenchyma. Anat. Rec., 127:435$436,1957$.

Moller, M. Non-sympathetic synaptic innervation of the pinealocyte of the Mongolian gerbil (Meriones unguiculatus): an electron microscopic study. J. of Neurocytol. 14:541-550, 1985. 
Moller, M. and Korf, H.W. Central innervation of the pineal organ of the Mongolian gerbil: a histochemical and lesion study. Cell Tiss. Res. 230:259-272, 1983a.

Moller, M. and Korf, H.W. The origin of central pinealopetal nerve fiber in the Mongolian gerbil as demonstrated by the retrograde transport of horseradish peroxidase. Cell Tiss. Res. 230:273-287, 1983b.

Moller, $M$. and Korf, H.W. Neural connections between the brain and the pineal gland of the golden hamster (Mesocricetus auratus): Tracer studies by use of horseradish peroxidase in vivo and in vitro. Cell Tiss. Res. 247:145-153, 1987.

Moore, R.Y. and Klein, D.C. Visual pathways and the central neural control of a circadian rhythm in pineal serotonin $\mathrm{N}-$ acetyl-transferase activity. Brain Res. 71:17-33, 1974 .

Moore, R.Y. Pineal transplants to the anterior chamber of the eye: evidence for functional reinnervation. Exp. Neurol. 49:617-621, 1975.

Moore, R.Y. The innervation of the mammalian pineal gland. In: The pineal and Reproduction. (Reiter, R.J. ed.). Karger, Basel, pp. 1-29, 1978.

Moore, R.Y. The retinohypothalamic tract, suprachiasmatic hypothalamic nucleus and central neural mechanisms of circadian rhythm regulation. In: Biological Rhythms and Their Central Mechanism. (Suda, M., Hayaishi, O. and Nakagawa, H., eds.). Elsevier/North Holland, Ansterdam, pp. 343-354, 1979 .

Nonaka, T., Araki, M., Kimura, H., Nagatsu, I., Satoh, F., and Masuzawa, T. Transplantation of the rat pineal organ to the brain: pinealocyte differentiation and innervation. Cell Tiss. Res. 260:273-278, 1990.

Olson, L. and Malfors, T. Growth characteristics of adrenergic nerves $i$ the adult rat. Fluorescence histochemical and ${ }^{3} \mathrm{H}-$ noradrenaline uptake studies using tissue transplantation to the anterior chamber of the eye. Acta physiol. scand., suppl. $348: 1-112,1970$.

Olson, I. and Seiger, A. Brain tissue transplanted to the anterior chamber of the eye. I. Fluorescence histochemistry of immature catecholamine and 5-hydroxytryptamine neurons innervating the rat iris. Z. Zellforsch., 195:175-194, 1972.

Olson, L., Björklund, H. and Hoffer, B.J. Camera bulbi anterior: New vistas on a classical locus for neural tissue transplantation. In: Neural Transplants (Sladek, J.R., Jr. and Gash, D.M., eds). Plenum Press, N.Y. pp. 125-165, 1984 
Pang, S.F. Persistence of pineal and serum melatonin rhythms in the pineal-autotransplanted chickens. Am. Zool. 17:901, 1977 .

Pévet, P. On the presence of different populations of pinealocytes in the mammalian pineal gland. J. Neural Transm. 40:289-304, 1977.

Pévet, P. and Karasek, M. Are the pineal active compounds of mammals proteinaceous in nature? An ultrastructural contribution. Acta Med. Pol. 18:351-353, 1977.

Pévet P. Secretory processes in the mammalian pinealocytes under natural and experimental conditions. Prog. Brain Res. 52:149-194, 1979 .

Quay, W.B. Endocrine effects of the mammalian pineal. Am. Zool. 10:237-246, 1970 .

Quay, W.B. Pineal Chemistry. Springfield, IL: Charles C. Thomas, pp. 38-45 1974 .

Quay, W.B. Survival and characteristics of autoplastic, heterotopic transplants of pineal and dorsal sas tissues. Anat. Rec. 184:506, 1976.

Quay, W.B. Heterotopic pineal transplants in mammals: Fates, functions an factors. Advances in Pie. Res. 2:97-107, 1987.

Ranson, , S.W. Transplantation of the spinal ganglion into the brain. Quart. Bull Northwest Univ. Med. School. 11:176-178, 1909.

Reiter, JR..J. The effect of pineal grafts, pinealectomy and denervation of the pineal gland on the reproductive organs of male hamsters. Neuroendocrinology 2:138-146, 1967.

Reiter, R.J., The pineal and its hormones in the control of reproduction. Endocr. Rev. 1:109-131, 1980.

Reiter, R.J. The mammalian pineal gland: structure and function. An J. Anat. 162:217-313, 1986 .

Reiter, R.J. Neuroendocrine effects of the pineal gland and of melatonin. In: Frontiers in Neuroendocrinology vol $7: 287-$ 325 (Ganong, W.F. and Matin, L. eds.) Raven Press:New York, 1982 .

Reiter, R.J. The pineal gland: An important link to the environment. NIPS Vol 1:202-205, 1986

Reiter, R.J. Normal patterns of melatonin levels in the pineal gland and body fluids of humans and experimental animals. J. Neural Transm. Suppl. 21:35-44, 1986b. 
Reiter, R.J., Hester, R.J. Interrelationships of the pienal gland, the superior cervical ganglia, and the photoperiod in the regulation of the endocrine systems of hamster. Endocrinology 79:1168-1170, 1966.

Reiter, R.J., Vaughan, M.K., and Blask, D.E. Possible role of the cerebrospinal fluid in the transport of pineal hormones in mammals. Brain-Endocrine Interaction II. In: The Ventricular System, (Kniggge, Scott, Koboyoshi, Eds), 2nd Int. Symp., Shizouka, pp. 337-354, 1974 .

Reppert, S.M., Perlow, M.J., Tamarkin, L. and Klein, D.C. A diurnal melatonin rhythm in primate cerebrospinal fluid. Endocrinology 104:295-301, 1979 .

Rodriguez, E.M. The cerebrospinal fluid as a pathway for neuroendocrine integration. J. Endocrinol. 71:407-443, 1976 .

Rollag, M.D., Morgan, R.J. and Niswender, G.D. Route of melatonin secretion in sheep. Biomed. Sci. Instrument 13:111$117,1977$.

Rollag, M.D., Morgan, R.J. and Niswender, G.D. Route of melatonin in sheep. Endocrinology 102:1-8, 1978.

Romijn, J.J. Structure and innervation of the pineal gland of the rabbit, oryctolagus cuniculus (L.). II. An electron microscopic investigation of pinealocytes. 2. Zellforsch. $141: 545-560,1973$.

Romijn, H.J. The ultrastructure of the rabbit pineal gland after sympathectomy, parasympathectomy, continuous illumination and continuous darkness. J. Neural Transm. 36:183-194, 1975.

Romijn, H.J. Influence of some sympatholytic, parasympatholytic, and serotonin-synthesis-inhibiting agent on the ultrastructure of the rabbit pineal organ. Cell Tiss. Res. $167: 167-177,1976$.

Samarasinghe, D.D., Petterborg, L.J., Zeagler, J.W., Tiang, K.M. and Reiter, R.J. On the occurrence of a myeloid body in pinealocytes of the white-footed mouse, peromyscus leucopus. Cell Tiss. Res. 228:649-659, 1983 .

Scott, D.E. and Sherman, D.M. Neuronal and neurovascular integration following transplantation of the fetal hypothalamus into the third cerebral ventricle of adult Brattleboro rats: Neurological transplants, I. Brain Res. Bull. 12:453467,1984 . 
Scott, D.E. Fetal hypothalamic transplants in diabetic rats analyzed by scanning electron microscopy. Neurosci. Lett. $61: 149-164$, 1985.

Scott, D.E., Wu, W. and Gilman, A. Neural transplantation in the cerebral ventricular system. Virginia Med. November:536$542,1988$.

Sheridan, M.N. and Reiter, R.J. The fine structure of the pineal gland in the pocket gopher, Geomys bursarius. Am. J. Anat. $136: 363-382,1973$.

Shirai, Y. Transplantation of rat sarcoma in adult heterogeneous animals. Jap. med. World 1:14-15, 1921.

Simons, D.J. and Iund, R.D. Fetal retinae transplanted over tecta of neonatal rats respond to light and evoke patterned neuronal discharges in the host superior colliculus. Devel. Brain Res. 21:156-159, 1985.

Sladek, J.R.Jr. and Shoulson, I. Neural transplantation: A call for patience rather than patients. Science (June 10) $240: 1386-1388,1988$.

Smith, I., Mullen, P.E., Snedden, W. and Wilson, B.W. Absolute identification of melatonin in human plasma and cerebrospinal fluid. Nature (Lond) 260:718-719.

Tello, F. La influencia del neurotropismo en la regeneracion de los centros nervisosos. Trab. Lab. Invest. Biol. Univ.. Madr. 9:123-159, 1911.

Theron, J.J. Biagio, R. and Meyer, A.C. Circadian changes in microtubules, synaptic ribbons and synaptic ribbon fields in the pinealocytes of the baboon (Papio ursinus). Cell Tiss. Res. 217:405-413, 1981 .

Thompson, W.J. Successful brain grafting, N.Y. med. J. 51:701-702, 1890 .

Tilney, F. and Warren, L.F. The morphology and evolutionary significance of the pineal body. Am. J. Anat. Membr. 9:1-257, 1919 .

Vollrath, L. The pineal organ. In: Handbuch der Mikrokopischen Anatomie des Menschen. (Oksche, A. and Vollrath, L. eds). Springer-Verlag, Heidelberg, pp. 146-158, 1981.

Vollrath, L. and Huss, H. The synaptic ribbons of the guinea pigs pineal gland under normal and experimental conditions. 2. Zellforsch. 139:417-429, 1973 . 
Vollrath, I. and Howe, $C$. Iight and drug induced changes of epiphysial synaptic ribbons. Cell Tiss. Res., 165:383-390, 1976.

Vries, R.A.C. Abolition of the effect of pinealectomy on hypothalamic magnocellular neurosecretory activity in male rats by hypothalamic pineal implants. Neuroendocrinology $9: 358-364$, 1972 .

Wartenburg, H. The mammalian pineal organ: Electron microscopic studies on fine structure of pinealocytes, glial cells and on the perivascular compartment. $z$. Zellforsch. 86:7497,1968 .

Welsh, M.G. and Reiter, R.J. The pineal gland of the gerbil, Meriones unguiculatus. I. An ultrastructural study. Celi Tiss. Res. 193:323-336, 1978.

Welsh, M.G. and Rollag, M.D. Superficial pineal gland transplants into the third ventricle of the gerbil. Anat. Rec. . 214:142A-143A, 1986.

Welsh, M.G., Cameron, I.I.. and Reiter, R.J. The pineal gland of the gerbil, Meriones unguiculatus. II. Morphometric analysis over a 24-hour period. Cell Tiss. Res., 204:95-109, 1979.

Wilkinson, M., Arendt, J., Bradtke, J. and dezieger, D. Determination of a dark-induced increase pineal $\mathrm{N}$-acetyltransferase activity and simultaneous radioimmunoassay of melatonin in pineal, serum and pituitary tissue of the male cat. J. Endocrinol. 72:243-244, 1977 .

Wolfe, D.E. The epiphyseal cell: An electron microscopic study of its intercellular relationships and intracellular morphology in the pineal body of the albino rat. Prog. Brain Res. 10:332-386.

Wragg, I.E., Snyder, S, and Axelrod, J. Response of anterior chamber pineal grafts to light stimulus. Anat. Rec. 154:444, 1966.

Wragg, I.E., Machado, C.R.S., Snyder, S. and Axelrod, J. Anterior chamber pineal transplants: their metabolic activity and independence of environmental lighting. Life sci. 6:31$38,1967$.

Wurtman, R.J., Axelrod, J. and Fischer, J.E. Melatonin synthesis in the pineal gland: Effect of light mediated by the sympathetic nervous system. Endocrinology 75:226-272, 1965.

wurtman, R.J. and Axelrod, J. A 24-hour rhythm in the content of norepinephrine in the pineal and salivary gland of the rat. Life Sci. 5:665-669, 1966. 
Zimmerman, N.H. and Menaker, M. Pineal function within the circadian system of the House sparrow. The physiologist $18: 464,1975 a$.

2 immerman, N.H. and Menaker, M. Neural connections of sparrow pineal: role in circadian control of activity. Science 190:477-479, $1975 b$. 


\section{ADTOBIOGRAPHICAL BTATEKENT}

Wutian Wu was born on January 1, 1954 in Guangdong, the People's Republic of China. The author received a M.D. degree from Zhongshau Medical College in February 1976 and a Master of Science degree in Anatomy from the same Medical College in February 1982. the title of the thesis, submitted in partial fulfillment of the requirements for the Master of science degree, was "The origins of the afferent fiber of the parafascicular nucleus in the rat--A study with the retrograde method of HRP. This was published under the same title in Acta Anatomical Sinica 15:14, 1984.

The author received a scholarship stipend and a tuition waiver from January 1988 until December 1991 from Eastern Virginia Medical school and old Dominion University.

The author was admitted to membership in the American Association of Anatomists and to the Society for Neuroscience in 1989 .

The following is a list of publications from a total of 18 publications:

Wu, W., Reiter, R.J., Troiana, M.E., and Vaughan, G.M.: Elevated daytime rat pineal and serum melatonin levels induced by isoproterenol are depressed by swiming. Life Science, Vol 41, No. 12, pp 1473, 1987.

Wu, W., Chen, Y., and Reiter, R.J.: Evidence that the deep pineal gland of the rat respond to isoproterenol and to swimning stress. Neuroendocrinology Letters, 10(1):19, 1988.

Wu, W., Chen, Y., and Reiter, R.J.: Increased responsiveness of rat pineal melatonin to swimming stress at night. Proceedings of the Society of Experimental biology and Medicine, 187:315, 1988.

Scott, D.E., Wu, W., and Gilman, A.M.: Neural transplantation in the cerebral ventricular system. Virginia Med., 536546 , Nov., 1988.

Wu, W., Scott; D.E., and Gilman, A.M.: Correlative scanningimmunoelectron microscopic analysis of neuropeptide localization and neuronal plasticity in the endocrine hypothalamus. Brain Research Bull. $22(2): 399-410,1989$.

Wu, W., Scott, D.E., and Miller, E.: Transplantation of the pineal gland in the mammalian third cerebral ventricle. Exp. Neurol. 108:23, 1990.

Wu, W., Scott, D.E., and Reiter, R. J.: No difference in daynight melatonin concentration after pineal grafting into the third cerebral ventricle of pinealectomized rats. (In press $\mathrm{J}$. of Pineal Research). 